\title{
EFEITO DA REAÇÃO DO SOLO NA DISPONIBILIDADE DE FÓSFORO EM LATOSSOLO ROXO, AVALIADA POR EXTRATORES QUÍMICOS E POR PLANTAS DE ARROZ E MILHO
}

ANTONIO SARAIVA MUNIZ

Engenheiro Agrônomo

Orientador: Prof. Dr. JORGE DE CASTRO KIEHL

Tese apresentada à Escola Superior de Agricultura "Luiz de Queiroz", da Universidade de Săo Paulo, para obtenção do título de Doutor em Agronomin, Área de Concentração: Solos e Nutrição de Plantas.

PIRACICABA

Estado de São Paulo - Brasil

Novembro - 1995 


\section{Dados Internacionais de Catalogação na Publicação (CIP) DIVISÃO DE BIBLIOTECA E DOCUMENTAÇÃO - Campus "Luiz} de Queiroz"/USP

\section{Muniz, Antonio Saraiva}

Efeito da reação do solo na disponibilidade de fósforo em latossolo roxo, avaliado por extratores químicos e por plantas de arroz e milho / Antonio Saraiva Muniz, Piracicaba, 1995

$$
\text { 146p. : Il. }
$$

Tese (doutorado) - Escola Superior de Agricultura Luiz de Queiroz, 1996. Bibliografia

I - Fósforo no solo - Disponibilidade 2. Latossolo roxo 3. Solo Fertilidade 1.

Título

CDD 631.42 


\section{EFEITO DA REAÇÃO DO SOLO NA DISPONIBILIDADE DE FÓSFORO EM LATOSSOLO ROXO, AVALIADA POR EXTRATORES QUÍMICOS E POR PLANTAS DE ARROZ E MILHO}

ANTONIO SARAIVA MUNIZ

Aprovada em: 01.02.96.

Comissão julgadora:

Prof. Dr. Jorge de Castro Kiehl

ESALQ/USP

Prof. Dr. Antonio Enedi Boaretto

CENA/USP

Prof. Dr. Takashi Muraoka

CENA/USP

Prof. Dr. Leonardo Theodoro Büll

UNESP/BOTUCATU

Dra. Raffaella Rosseto

IAC/CAMPINAS

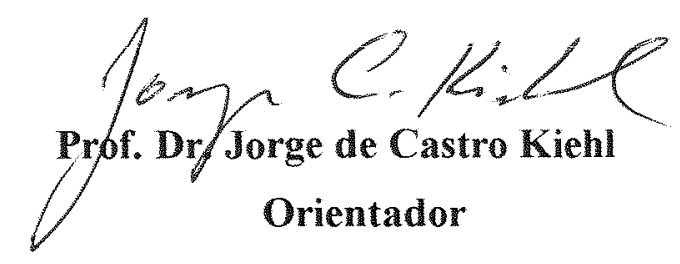


A DEUS

Dedico.

Aos meus filhos

Bruno

Tiago

Antonio Junior

Ofereço. 


\section{AGRADECIMENTOS}

À Universidade Estadual de Maringá, pela oportunidade de realização deste curso de pós-graduação.

À Escola Superior de Agricultura "Luiz de Queiroz" (ESALQ/USP), pela oportunidade oferecida.

Ao Dr. Bernardo van Raij, pela orientação, apoio e incentivo no planejamento e execução desta pesquisa.

Ao Prof. Dr. Jorge de Castro Kiehl, pela confiança, apoio e orientação na fase final deste trabalho.

À CAPES, pela concessão da bolsa de estudos.

Ao Professor Luiz Ignácio Prochnow pelo apoio na utilização do Laboratório de Fertilidade do Solo, do Departamento de Ciência do Solo da ESALQ/USP.

Aos Funcionários do Departamento de Ciência do Solo, Luiz Antonio Silva Junior, José Luiz Vicente, Antonio Carlos Ferreira, Anderson Luiz Scarazate, Vanda Maria Zancheta, Eleusa Cecília Bassi Brancalion, João Alvaro Granja, Miriam Volpato, Mário Benedito Lodovico, pelo apoio e convivência agradável no período de análises laboratoriais. 
Ao Amigo e Colega de curso Ivanildo Evódio Marriel, pelo apoio, amizade e incentivo.

Ao Engenheiro Agrônomo e Pesquisador Edson Lima de Oliveira, do Instituto Agronômico do Paraná (IAPAR) em Londrina-PR, pelo apoio na fase de coleta de terra.

Ao Prof. Dr. Ronaldo Ivan da Silveira pelo empréstimo dos vasos durante todo o período do experimento.

Aos Funcignários da Biblioteca Central da ESALQ, em especial os do setor de empréstimos, pelo bom atendimento.

Ao Amigo Jan Loman, pela hospitalidade demonstrada durante alguns períodos de permanência em Piracicaba.

A Marlene Yukie Saraiva Muniz, pela ajuda valiosa na digitação deste trabalho.

A todos aqueles que direta ou indiretamente contribuíram para a realização deste trabalho. 


\section{SUMÁRIO}

Página

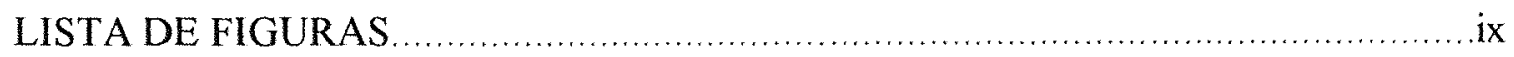

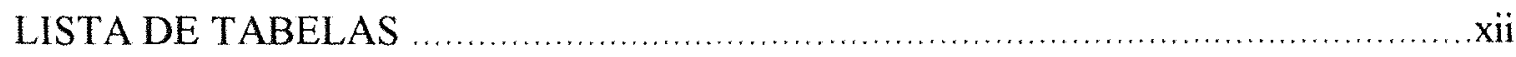

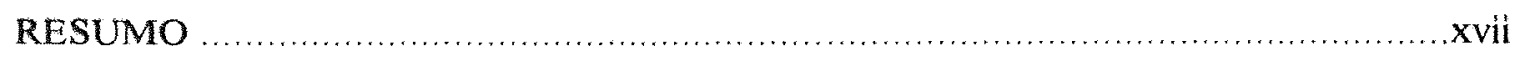

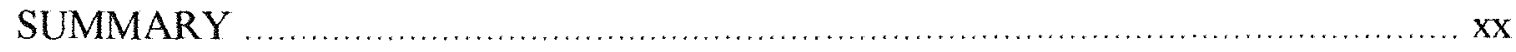

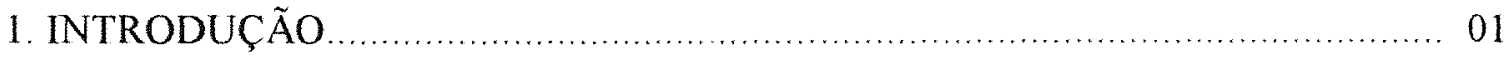

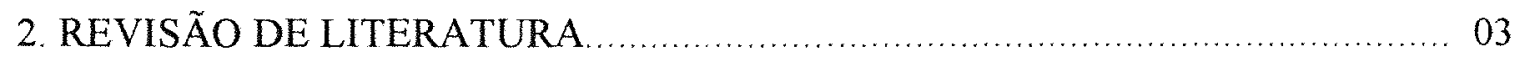

2.1. Características gerais dos Latossolos Roxos ............................................ 03

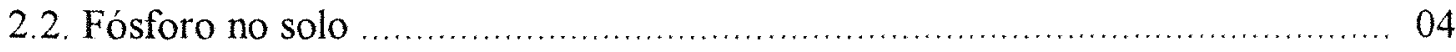

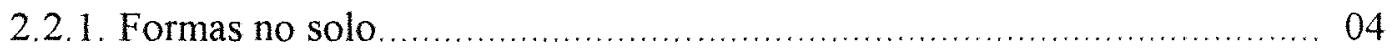

2.2.2. Retenção de fósforo pelo solo .................................................. 06

2.2.3. Avaliação da disponibilidade de fósforo para plantas ...................... 14

2.2.4. Reação do solo e a disponibilidade de fósforo................................. 23

3.MATERIAL E MÉTODOS _........................................................... 37

3.1. Solos utilizados nos experimentos ................................................... 37

3.2. Experimentos em casa de vegetação …................................................ 40

3.2.1. Experimento com arroz …..................................................... 40

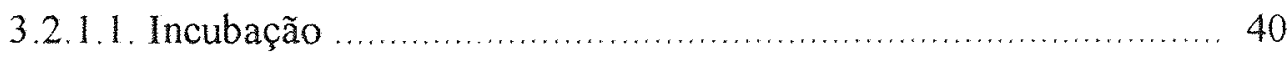


3.2.1.2. Cultivo do Arroz

3.2.2. Experimento com milho

3.3. Análises de solos e plantas

3.3.1. Análise química de plantas

3.3.2. Análise de solos

3.3.3. Verificação do efeito do corretivo aplicado na acidez dos extratores e Bray-1 Mehlich-1 44

3.3.4. Análises estatísticas 45

4. RESULTADOS E DISCUSSÃO 46

4. $1 \mathrm{pH}$ em $\mathrm{CaCl} 20,01 \mathrm{~mol} \cdot \mathrm{L}^{-1}$ e Alumínio trocável 46

4.2. Fósforo extraído 53

4.2.1. Extrator Bray-1 53

4.2.2. Extrator Mehlich-1 61

4.2.3. Extrator Mehlich-3 65

4.2.4. Extrator Olsen 69

4.2.5. Extrator Resina 73

4.2.6. Os extratores 77

4.3. Parâmetros da planta 90

4.3.1. Matéria seca da parte aérea 90

4.3.2. Teor de fósforo na parte aérea 96

4.3.3. Quantidade de fósforo na parte aérea 103 
4.3.4. A disponibilidade de fósforo e as respostas das plantas

4.4. Relação entre parâmetro da planta e fósforo extraido pelos diferentes extratores

4.4.1. Arroz 112

4.4.2. Milho 115

4.4.3. Sensibilidade dos extratores 117

4.5. Calagem e efeito residual do fósforo 121

5. CONCLUSÕES 123

REFERÊNCIAS BIBLIOGRÁFICAS 125 


\section{LISTA DE TIUTRS}

Figura

Página

$01 \mathrm{pH}$ em $\mathrm{CaCl}_{2}$ 0,01 mol.t. em função de doses de corretivo, em $\mathrm{g} \cdot \mathrm{kg}^{-1}$ $\mathrm{CaCO}_{3}$, antes do cultivo de arroz milho

02 Fósforo extraído por Bray-1, em função de doses de corretivo, nas amostras de solos (LDI ...RP13), antes do cultivo de arroz e milho.

03 Fósforo extraido por Mehlich-1, em função de doses de corretivo, nas amostras de solos (LDI ..RP13), antes do cultivo de arroz e milho.

04 Fósforo extraído por Mehlich-3, em função de doses de corretivo, nas amostras de solos (LD1 ...RP13), antes do cultivo de arroz e milho.

05 Fósforo extraído por Olsen, em função de doses de corretivo, nas amostras de solos (LD1 ...RP13), antes do cultivo de arroz e milho

06 Fósforo extraido por resina, em função de doses de corretivo, nas amostras de solos (LD1 ...RP13), antes do cultivo de arroz e milho

07 Fósforo extraido nas amostras de solo (LD1 ... RP13) por diferentes extratores, em função de doses de corretivo, antes do cultivo de arroz...

08 Fósforo extraído nas amostras de solo (LDl ... RP13) por diferentes extratores, em função do $\mathrm{pH}$ do solo, antes do cultivo de arroz...............

09 Fósforo extraido nas amostras de solo (LD1 ... RP13) por diferentes extratores, em função de doses de corretivo, antes do cultivo de milho. 
10 Fósforo extraido nas amostras de solo (LD1 ... RP13) por diferentes extratores, em função do $\mathrm{pH}$ do solo, antes do cultivo de milho

11 Fósforo extraído por resina, nas amostras de solo (LD1 ... RP13), em função de doses de corretivo, antes do cultivo de arroz e milho.

12 Fósforo extraido por Bray-1, nas amostras de solo (LD1 ... RP13), em função de doses de corretivo, antes do cultivo de arroz e milho.

13 Fósforo extraído por Mehlich-3, nas diferentes amostras de solo (LD1 ... RP13), em função de doses de corretivo, antes do cultivo de arroz e milho.

14 Fósforo extraido por Olsen, nas diferentes amostras de solo (LD1 ... RP13), em função de doses de corretivo, antes do cultivo de arroz e milho

15 Fósforo extraido por Mehlich-1, nas diferentes amostras de solo (LD1 ... RP13), em função de doses de corretivo, antes do cultivo de arroz e milho

16 Materia seca acumulada na parte aérea de plantas de arroz, cultivadas nas diferentes amostras de solo (LDI ... RP13), em função de doses de corretivo

17 Matéria seca acumulada na parte aérea de plantas de milho, cultivadas nas diferentes amostras de solo (LD1 ... RP13) em função de doses de corretivo 
18 Matéria seca da parte aérea de arroz e milho, cultivadas nas amostras de solo (LD1 ... RP13), em função de doses de corretivo.

19 Teores de fósforo na parte aérea de plantas de arroz e milho, nas amostras de solo (LD1 ... RP13), submetidas a doses de corretivos

20 Concentração de fósforo na parte aérea de plantas de arroz cultivadas nas diferentes amostras de solo (LD1 ... RP13), submetidas a doses de corretivo

21 Concentração de fósforo na parte aérea de plantas de milho, cultivadas nas amostras de solo (LD1 ... RP13), em função de doses de corretivo....

22 Fósforo acumulado na parte aérea de plantas de arroz cultivadas nas amostras de solo (LD1 ... RP13), em função de doses de corretivo

23 Fósforo acumulado na parte aérea de plantas de milho cultivadas nas amostras de solo (LD1 ... RP13) em função de doses de corretivo.

24 Fósforo acumulado na parte aérea de plantas de arroz e milho cultivadas nas amostras de solo (LD1 ... RP13), em função de doses de corretivo.... 


\section{LISTA DE TABELAS}

Tabela

Página

1 Características físicas e químicas das amostras de solo utilizadas no experimento, na época da coleta

2 Resumo das análises de variância dos dados relativos a pH em $\mathrm{CaCl}_{2}$,, $01 \mathrm{~mol} \cdot \mathrm{L}^{-1}$, teores de fósforo extraídos por diferentes extratores e a parâmetros das plantas de arroz e milho, cultivadas nas diferentes amostras de solos submetidas a doses de corretivo. ...

3 Valores de $\mathrm{pH}$ em $\mathrm{CaCl}_{2}$ 0,01 mol. $\mathrm{L}^{-1}$ nas amostras de solo, em função de doses de corretivo, em $\mathrm{g} \cdot \mathrm{kg}^{-1} \mathrm{CaCO}_{3}$, no $1^{\circ}$ cultivo (arroz) e $2^{\circ}$ cultivo (milho). Média de três repetições.

4 Equações de regressão entre valores de $\mathrm{pH}$ em $\mathrm{CaCl}_{2} \quad 0,01 \mathrm{~mol}^{-}$ l(y), das amostras de solo coletadas antes dos cultivos de arroz e milho (y) e doses de corretivo aplicadas (x), em g. kg ${ }^{-1} \mathrm{CaCO}_{3}$

5 Teores de alumínio trocável, em $\mathrm{cmol}_{\mathrm{c}} \cdot \mathrm{dm}^{-3}$, em amostras de solo tratadas com diferentes doses do corretivo, antes dos cultivos do arroz e do milho. Média de 3 repetições

6 Teores de fósforo extraídos por Bray-1, em mg.dm ${ }^{-3}$, de amostras de solos submetidas a doses de corretivo, em $\mathrm{g} \cdot \mathrm{kg}^{-1} \mathrm{CaCO}_{3}$, antes dos cultivos de arroz e milho. Média de três repetições 
7 Coeficientes de correlação linear simples entre $0 \mathrm{pH} \mathrm{CaCl}_{2}$ 0,01mol. $L^{-1}$ e os teores de P Bray-1, P Mehlich-1, P Mehlich-3, P Olsen, $\mathrm{P}$ resina antes dos cultivos de arroz e milho.

8 Volume de $\mathrm{NaOH} 0,025 \mathrm{~mol} \mathrm{~L}^{-1}$ gasto para titular $5 \mathrm{ml}$ de extrato (solo + extrator) de amostras de solo tratadas com diferentes doses de corretivo antes do cultivo de arroz e quantidade de hidrogênio do extrator consumida. Média de três repetições.

9 Valores de $\mathrm{pH}$ dos extratos obtidos com os diferentes extratores, antes do cultivo do arroz de amostras de solo tratadas com doses de corretivo. 60

10 Teores de fósforo extraídos por Mehlich-1, em $\mathrm{mg} \cdot \mathrm{dm}^{-3}$, de amostras de solo submetidas a doses de corretivo, em g. $\mathrm{kg}^{-1} \mathrm{CaCO}_{3}$, antes dos cultivos de arroz e milho. Média de três 62 repetições.

11 Teores de fósforo extraidos por Mehlich-3, em $\mathrm{mg} \cdot \mathrm{dm}^{-3}$, de amostras de solo submetidas a doses de corretivo, em $\mathrm{g} . \mathrm{kg}^{-1} \mathrm{CaCO}_{3 .}$, antes dos cultivos de arroz e milho. Média de três repetições.

12 Teores de fósforo extraídos por Olsen, em mg.dm ${ }^{-3}$, de amostras de solo submetidas a doses de corretivo, em g. $\mathrm{kg}^{-1} \mathrm{CaCO}_{3}$, antes dos cultivos de arroz e milho. Média de três repetições. 
13 Teores de fósforo extraídos por resina, em mg. $\mathrm{dm}^{-3}$, de amostras de solos submetidas a doses de corretivo, em $\mathrm{g} \cdot \mathrm{kg}^{-1} \mathrm{CaCO}_{3}$, antes dos cultivos de arroz e milho. Média de três repetições

14 Coeficientes de correlação linear simples para os teores de P Bray1, $\mathrm{P}$ Mehlich-1, $\mathrm{P}$ Mehlich-3, $\mathrm{P}$ Olsen, $\mathrm{P}$ resina, comparados entre si.

15 Matéria seca acumulada da parte aérea de plantas de arroz e milho, em g/vaso, cultivadas nas amostras de solo submetidas a doses de corretivo, em g. $\mathrm{kg}^{-1} \mathrm{CaCO}_{3}$. Média de três repetições

16 Dose de corretivo, em g. $\mathrm{kg}^{-1} \mathrm{CaCO}_{3}$, estimada para se obter a produção máxima de matéria seca de plantas de milho e valores de matéria seca e $\mathrm{pH} \mathrm{CaCl} 20,01 \mathrm{~mol} \cdot \mathrm{L}^{-1}$ na dose 0 e dose para máxima produção de matéria seca

17 Teores de fósforo na parte aérea de plantas de arroz e milho, em $\mathrm{g} \cdot \mathrm{kg}^{-1}$, cultivadas nas diferentes amostras de solos submetidas a doses de corretivo, em $\mathrm{gkg}^{-1} \mathrm{CaCO}_{3}$. Média de três repetições.

18 Dose de corretivo, em g. $\mathrm{kg}^{-1} \mathrm{CaCO}_{3}$, estimada para se obter o teor máximo de $\mathrm{P}$, em $\mathrm{g} \cdot \mathrm{kg}^{-1}$, na parte aérea de plantas milho e valores de $\mathrm{pH} \mathrm{CaCl} 20,01$ mol. $\mathrm{L}^{-1}$ e teor de $\mathrm{P}$ na dose 0 e dose para máxima concentração de $\mathrm{P}$ nas plantas 
19 Fósforo acumulado na parte aérea de arroz e milho, em mg/vaso, cultivados nas diferentes amostras de solo submetidas a doses de corretivo, em g. $\mathrm{kg}^{-1} \mathrm{CaCO}_{3}$. Média de três repetições.

20 Dose de corretivo, em g.kg ${ }^{-1} \mathrm{CaCO}_{3}$, estimada para se obter o máximo $\mathrm{P}$ acumulado, em $\mathrm{mg} / \mathrm{vaso}$, na parte aérea de plantas milho e valores de $\mathrm{pH} \mathrm{CaCl}_{2}$ 0,01 mol. $\mathrm{L}^{-1}$ e quantidade de $\mathrm{P}$ acumulado, na dose 0 e dose para máximo acúmulo

21 Coeficientes de correlação linear simples (r) entre os teores de fósforo extraídos pelos diferentes extratores e parâmetros das plantas de arroz, considerando-se os solos em conjunto

22 Coeficiente de correlação linear simples $(r)$ entre os teores de fósforo extraídos pelos diferentes extratores e parâmetros das plantas de arroz, cultivados em diferentes solos, considerando-se as doses de corretivo em conjunto

23 Coeficientes de correlação linear simples (r) entre os teores de fósforo extraídos pelos diferentes extratores e parâmetros das plantas de milho, considerando-se os solos em conjunto

24 Coeficiente de correlação linear simples entre os teores de P extraídos pelos diferentes extratores e parâmetros de plantas de milho cultivadas em diferentes amostras de solo, considerando-se as doses de corretivo em conjunto. 
doses de corretivo em conjunto.

25 Valores de $\mathrm{pH}$ em $\mathrm{CaCl} 2$ 0,01 mol.L-1 e teores de fósforo extraídos por Bray-1, Mehlich-3, Olsen, resina, em mg.dm ${ }^{-3}$, na dose 0 de corretivo, em g. $\mathrm{kg}^{-1} \mathrm{CaCO}_{3}$, e estimados na dose para produção máxima de matéria seca. 


\title{
EFEITO DA REAÇ̃̃O DO SOLO NA DISPONIBILIDADE DE FÓSFORO EM LATOSSOLO ROXO, AVALIADA POR EXTRATORES QUÍMICOS E POR PLANTAS DE ARROZ E MILHO
}

\author{
Autor: ANTONIO SARAIVA MUNIZ \\ Orientador: Prof. Dr. JORGE DE CASTRO KIEHL
}

\section{RESUMO}

Para avaliar o efeito do $\mathrm{pH}$ na disponibilidade do fósforo acumulado no solo pela aplicação de fertilizantes, nove amostras com diferentes teores de fósforo foram coletadas da camada $0-15 \mathrm{~cm}$ de latossolos roxos ácidos. As amostras foram tratadas com uma mistura de $\mathrm{CaCO}_{3}$ e $\mathrm{MgCO}_{3}$ na proporção de $4: 1$ (carbonatos) nas doses correspondentes a $0,1,2,4$ e $8 \mathrm{~g} \mathrm{~kg}^{-1} \mathrm{CaCO}_{3}$, colocadas em vasos de $3 \mathrm{~kg}$ e submetidas a ciclo de umedecimento e secamento por 180 dias, em casa-de-vegetação. A seguir, plantas de arroz (Oriza sativa L.) foram cultivadas por 45 dias e, posteriormente, plantas de milho (Zea mays L.) por 30 dias. Amostras de solo coletadas dos vasos antes do plantio do arroz e, antes do plantio do milho, foram submetidas à determinação do pH em $\mathrm{CaCl}_{2}$,, 01 mol. $\mathrm{L}^{-1}$ e do teor de fósforo empregando-se os extratores Bray-1, Mehlich-1, Mehlich-3, Olsen e resina. A produção de matéria seca, o teor de fósforo e a quantidade total de fósforo na parte aérea das plantas também foram determinados. 
A aplicação das doses de corretivo resultou aumentos de $\mathrm{pH}$ em $\mathrm{CaCl}_{2}$ das amostras de valores mínimos entre 3,7 e 4,5 até valores máximos entre 6,6 e 6,9. A influência do aumento do $\mathrm{pH}$ do solo com carbonatos na quantidade de fósforo extraída variou acentuadamente com a natureza do extrator. Quando foi utilizado o Bray-1, a quantidade de fósforo extraída diminuiu linearmente com o aumento das doses de carbonatos, enquanto para o Mehlich-3 e resina a quantidade extraída aumentou com a dose de calcário (para a resina o aumento foi bem mais evidente e linear). Na maioria dos casos, a quantidade de fósforo extraída pelo extrator Olsen diminuiu com a dose de carbonatos entre a faixa de $\mathrm{pH}$ em $\mathrm{CaCl}_{2}$ de 4,2 a 5,5 e aumentou acima dessa faixa, de acordo com uma equação de segundo grau; em outros casos, o fósforo extraído por Olsen aumentou linearmente com a dose do neutralizante. O efeito da dose de carbonatos na quantidade de fósforo extraída pelo Mehlich-1 não foi significativa para todos os solos, mas mostrou-se dependente do tempo decorrido entre a calagem e a amostragem nos casos em que o efeito foi significativo, a quantidade diminuiu linearmente com a dose aplicada nas amostras coletadas antes do cultivo do arroz, mas aumentou linearmente naquelas coletadas antes do cultivo do milho. Quanto à sensibilidade para detectar variações na disponibilidade do fósforo do solo, os extratores classificaram-se na seguinte ordem: resina $>$ Mehlich-3 $>$ Olsen $>$ Bray-1 $>$ Mehlich-1.

A produção de matéria seca e a quantidade total de fósforo na parte aérea do arroz diminuiu acentuadamente com a dose de carbonatos, principalmente quando a maior dose foi utilizada; como consequeencia, o efeito do teor inicial de fósforo do solo foi mascarado pelo efeito da calagem. Aparentemente, esse efeito negativo da calagem 
deveu-se à diminuição da disponibilidade de algum nutriente (provavelmente micronutriente), causada pelo aumento do $\mathrm{pH}$.

A produção de matéria seca e o acúmulo de fósforo na parte aérea das plantas de milho foram muito menos influenciados pelos efeitos indiretos do aumento do pH do que o foram no arroz. Ambos esses parâmetros aumentaram até a dose de 2 ou 4 g. $\mathrm{kg}^{-1}$ de carbonatos e diminuíram quando doses mais elevadas foram aplicadas. Como consequência desse comportamento, as plantas de milho responderam melhor que as de arroz às variações do teor de fósforo provocados pela calagem dos latossolos roxos estudados. 
EFFECT OF SOIL REACTION ON THE AVAILABILITY OF RESIDUAL PHOSPHORUS IN OXISSOL (DUSK-RED LATOSOLS), AS EVALUATED BY CHEMICAL EXTRACTION AND ABSORPTION BY RICE AND CORN PLANTS

\author{
Author: ANTONIO SARAIVA MUNIZ \\ Adviser: Prof. Dr. JORGE DE CASTRO KIEHL
}

\title{
SUMMARY
}

To evaluate the effect of $\mathrm{pH}$ on the availability of phosphorus accumulated in the soil after fertilizers applications, nine samples with varying phosphorus content were collected from the $0-15 \mathrm{~cm}$ layer of acid oxissol (dusk-red latossol). Samples were treated with a $4: 1$ mixture of $\mathrm{CaCO}_{3}$ and $\mathrm{MgCO}_{3}$ (carbonates) at rates of $0,1,2,4$ and 8 $\mathrm{g} \cdot \mathrm{kg}^{-1}$, placed in pots of $3 \mathrm{~kg}$ and were subjected to cycles of moistening and drying for 180 days, in the greenhouse. After rice (Oriza sativa L.) plants were cultivated for 45 days and, later, corn (Zea mays L.) plants for 30 days. Soil samples collected from the pots before seeding the rice and before seeding the corn, were subjected to determination of $\mathrm{pH}$ in $\mathrm{CaCl}_{2} 0.01 \mathrm{~mol} \mathrm{L^{-1 }}$ and phosphorus by extraction with Bray-1, Mehlich-1, Mehlich-3, Olsen and resin. The amount of dry matter, $P$ content and total amount of $P$ in the plant tops were also determined. 
The aplication of carbonates increased the $\mathrm{pH} \mathrm{CaCl}_{2}$ of the soil samples from values within 3.7 and 4.5 to values within 6.6 and 6.9 . The influence of increasing soil $\mathrm{pH}$ with carbonates on the amount of phosphorus extracted from the soil varied greatly with the extractant. When Bray-1 was utilized, the amount of phosphorus extracted decreased linearly with the increasing rates of carbonates, while for both Mehlich-3 and resin the amount extracted increased with the lime rate (for resin the increase was far evident and linear). In most cases the amount of $\mathrm{P}$ extracted by Olsen decreased with the rate of carbonates within the $\mathrm{pH}$ in $\mathrm{CaCl}_{2}$ range of 4.2 to 5.5 and increased above this band, accordingly to a second order equation; in other cases, Olsen extracted $\mathrm{P}$ increased linearly with the neutralizer rate. The effect of carbonates rates on the amount of P extracted by Mehlich-1 was not significant for all soils, but it showed to be dependent on the time elapsed from liming to sampling: for the cases where the effect was significant the amount decreased linearly with the application rate in the samples collected before rice was cultivated, but increased linearly in those collected before corn cultivation. In terms of sensibility to detect variations in the availability of soil phosphorus, the extractants followed the order: resin $>$ Mehlich- $3>$ Olsen $>$ Bray $-1>$ Mehlich-1.

The amount of dry matter and the total amount of phosphorus in rice tops decreased substantially with the rate of applied carbonates, specially when the higher dose was employed; as a result, the effect of the initial phosphorus content of the soil was obscured by the effect of the lime application. Apparently this negative effect of liming 
was due to a reduction in nutrient (probably a micronutrient) availability as a result of $\mathrm{pH}$ increase

Dry matter and phosphorus accumulation in corn tops were much less influenced by the indirect effects of the $\mathrm{pH}$ raise than it was in rice. Both of this parameters increased up to the rate of 2 ou $4 \mathrm{~g} \cdot \mathrm{kg}^{-1}$ of carbonates and decreased when higher doses were applied. As a consequence of this behavior, corn plants responded better than rice to the variations in phosphorus content of the studied latosols. 


\section{INTRODUÇÃO}

A análise de solo é ferramenta primordial para a avaliação e a correção da fertilidade do solo visando adequar as condições do solo para o bom desenvolvimento das plantas. Constitui-se em instrumento de apoio no processo de decisão acerca do manejo de uma cultura. Neste sentido, é fundamental que a análise de solo reflita, da melhor maneira possível, as condições de fertilidade do solo, de modo a se ter informações prévias que possibilitem interpretações seguras.

A condição de deficiência natural do nutriente fósforo, na quase totalidade dos solos tropicais, e a diversidade e complexidade dos fatores que influenciam sua disponibilidade e aproveitamento pelas plantas, constituem aspectos que conferem à avaliação do $\mathbf{P}$ disponível às plantas, por meio de extratores, um interesse especial, uma estimulante linha de pesquisa e, em certos aspectos, inesgotável

Questões como a influência de características do solo na ação e eficiência dos extratores em estimar a fração lábil do fósforo no solo, ainda suscitam discussões e estimulam pesquisas. Neste contexto estão a dificuldade de avaliação da disponibilidade do fósforo em solos argilosos, bem como a sensibilidade dos extratores químicos em 
refletir as variações nos teores do nutriente no solo em decorrência de variações no $\mathrm{pH}$ do solo.

No Brasil, essas questões assumem relevância para os solos argilosos altamente intemperizados, originados de rochas eruptivas básicas, dentre eles destacando-se o Latossolo Roxo e a Terra Roxa Estruturada. Esses solos, em decorrência do manejo agrícola adotado em áreas de agricultura intensiva, têm recebido com freqüência adubação fosfatada e, periodicamente, calagem. A compreensão do efeito desta última prática na adubação e, em especial, na disponibilidade de fósforo é fundamental para um manejo adequado dos solos ácidos, objetivando a economia da adubação fosfatada e a maximização da produção agrícola.

$\mathrm{Na}$ realidade, em relação ao efeito do $\mathrm{pH}$ do solo sobre a disponibilidade de fósforo para as plantas, tem-se observado: 1) resultados inconclusivos mostrando ora aumento, ora diminuição, ora não alteração do conteúdo de fósforo na planta após calagem e, 2) comportamento diferenciado de extratores químicos em relação à estimativa do status do fósforo no solo para as plantas.

Nesta pesquisa pretendeu-se: (1) estudar a influencia do $\mathrm{pH}$ na disponibilidade de fósforo em amostras de latossolos roxos provenientes de Ribeirão Preto (SP) e Londrina (PR), e (2) verificar a sensibilidade dos extratores químicos Bray-1, Mehlich-1, Mehlich-3, Olsen e resina em refletir variações nos teores de fósforo no solo decorrentes das variações no $\mathrm{pH}$, e avaliar teores de $\mathrm{P}$ disponível às plantas de arroz e milho, (3) avaliar as respostas diferenciadas do cultivo de arroz e milho à calagem e seus efeitos na disponibilidade de fósforo. 


\section{REVISÃO DE LITERATURA}

\subsection{Características gerais dos Latossolos Roxos}

Os latossolos têm suas características determinadas pelo intenso intemperismo. São de ocorrência em regiões quentes e úmidas, cujas condições favorecem a elevação inicial do pH e a criação de condições para solubilização e remoção da sílica, e das bases cálcio, magnésio, potássio e sódio. Com a intensa remoção de bases e de sílica, o solo adquire acidez e sua matriz passa a constituir-se predominantemente por um residuo de sesquióxidos de ferro e alumínio (RESENDE, 1981).

São solos profundos apresentando perfil bem desenvolvido e seqüência de horizontes A, B, C. O horizonte B é latossólico, precedido de qualquer horizonte A diagnóstico, exceto turfoso (CAMARGO et al., 1987).

Os solos da classe Latossolo Roxo, no estado do Paraná, ocupam área em torno de $28.203 \mathrm{~km}^{2}$, sendo aproximadamente $12.573 \mathrm{~km}^{2}$ de solos distróficos e $6.734 \mathrm{~km}^{2}$ de solos álicos e $8.896 \mathrm{~km}^{2}$ de solos eutróficos (LARACH et al., 1984). São solos formados a partir de rochas eruptivas básicas, muito profundos, normalmente com mais de três metros de espessura, sendo observada ocorrência de solos com mais de cinco metros ou 
até mesmo dez metros de profundidade, com textura muito argilosa, tanto no horizonte $\mathrm{A}$ como no B, coloração arroxeada, porosos, muito friáveis e acentuadamente drenados, que associados ao fato de ocorrerem em áreas de relevo suave, conferem a esses solos, no seu estado natural, boa resistência à erosão.

Apresentam argila com baixa capacidade de troca cátions, com predominância de caulinita e gibsita, seguidos de vermiculita cloritizada, hematita e elevados teores de sesquióxidos de ferro e alumínio e óxidos de titânio e manganês.

A localização desse solos em relevo plano, facilitando a mecanização, a boa resistência à erosão e as altas produtividades de culturas de cereais nele cultivados, quando tem sua acidez corrigida e são adubados, têm conferido às regiões onde ocorrem, grande importância econômica.

\subsection{Fósforo no solo.}

\subsubsection{Formas no solo.}

O fósforo no solo representado pelo equilibrio P-fase sólida $\rightarrow$ P-solução, ocorre nas mais diversas formas químicas, com compostos de diferentes natureza e solubilidade.

$\mathrm{Na}$ fase sólida o fósforo encontra-se sob a forma de grupos orgânicos e inorgânicos (FASSBENDER, 1975). Como fósforo inorgânico, está adsorvido ou precipitado, ligado aos sítios de adsorção aniônica dos colóides do solo ou sob a forma 
de compostos de ferro, alumínio e cálcio (compostos inorgânicos de P-Fe, P-Al, P-Ca, Pocluso) e ainda sob a forma de compostos orgânicos (P-orgânico), que por mineralização acrescentam fosfatos inorgânicos ao sistema.

Em solução, o fósforo pode ser encontrado nas diferentes formas do ácido ortofosfórico: $\mathrm{H}_{3} \mathrm{PO}_{4}, \mathrm{H}_{2} \mathrm{PO}_{4}{ }^{-}, \mathrm{HPO}_{4}{ }^{2-}, \mathrm{PO}_{4}{ }^{3-}$, cuja concentração relativa dessas formas depende do pH. Nas condições de solos ácidos, predomina na solução do solo (Psolução) a forma $\mathrm{H}_{2} \mathrm{PO}_{4}{ }^{*}$, com tendência ao equilibrio nas concentrações de $\mathrm{H}_{2} \mathrm{PO}^{*}$ e HPO4 ${ }^{2-}$, em torno de pH 7 (THOMAS, 1974). Os níveis de P-solução são muito baixos, apresentando-se deficientes na maioria dos solos e, para um suprimento satisfatório das necessidades de uma cultura, há constante reposição do fósforo em solução proveniente do P-fase sólida.

As designações P-Al, P-Fe e P-Ca (CHANG \& JACKSON, 1957) englobam, com exceção dos compostos deste elemento solúveis em água $\left(\mathrm{P}-\mathrm{H}_{2} \mathrm{O}\right)$ uma diversidade de compostos de constituição complexa, muitas vezes não bem definidos, com grau variável de solubilidade. A importância de uma forma em relação à outra para a nutrição da planta depende da natureza do solo (FASSBENDER et al., 1968; BAHIA FILHO \& BRAGA, 1975a,b e NOVAIS, 1977).

As quantidades e proporções das formas de fósforo variam com o solo, tendo o grau de intemperismo grande influência, bem como a natureza do adubo adicionado e o seu tempo de reação no solo (FASSBENDER, 1975; NOVOA \& NUNES, 1975).

GONÇALVEZ (1988) ao incubar amostras de latossolos com fósforo $\left(\mathrm{KH}_{2} \mathrm{PO} 4\right.$, $\mathrm{NH}_{4} \mathrm{H}_{2} \mathrm{PO}_{4}$ e $\mathrm{NaH}_{2} \mathrm{PO}_{4}$ ) e avaliar as formas de $\mathrm{P}$ no período de 0 a 300 dias, verificou 
que o fósforo aplicado ao solo foi imediatamente convertido para P-Al e, com o tempo, a quantidade dessa forma diminuía em favor do aumento de P-Fe. Atribuiu esse fato à solubilização do $\mathrm{P}-\mathrm{Al}$ e refixação do fósforo na forma de $\mathrm{P}-\mathrm{Fe}$, mais estável.

Comportamento semelhante foi observado por MOREIRA (1988). Empregando fontes solúveis $\left(\mathrm{KH}_{2} \mathrm{PO}_{4}\right.$, e $\left.\mathrm{NaH}_{2} \mathrm{PO}_{4}\right)$, observou redução nos teores de $\mathrm{P}-\mathrm{Al}$, e respectivos acréscimos da forma P-Fe, com o tempo. De modo geral, o aumento do tempo de contato do $\mathrm{P}$ com o solo causou decréscimo na produção de matéria seca e no acúmulo de $\mathrm{P}$ na parte aérea das plantas, atribuindo-se esses fatos ao decréscimo verificado na quantidade da forma inorgânica P-Al e/ou ao aumento da forma P-Fe.

Maior contribuição à nutrição das plantas nos solos tropicais tem sido atribuída às formas P-Al e P-Fe (BRAGA \& DEFELIPO, 1972b; BAHIA FILHO \& BRAGA, 1975a,b; MENDEZ, 1986). Segundo CHANG \& JACKSON (1957), a contribuição do P-Ca à nutrição das plantas em condições de solos tropicais é pequena, uma vez que envolve formas bastante insolúveis. A diversidade das formas de $\mathrm{P}$ no solo e o seu grau variável de solubilidade, segundo FITTS \& NELSON (1956), seria uma das razões da complexidade da avaliação da disponibilidade desse nutriente no solo.

\subsubsection{Retenção de fósforo pelo solo.}

Quando um grânulo de fertilizante contendo fosfato monocálcico (PMC) é colocado no solo, ele dissolve-se rapidamente. Sua dissolução é limitada somente pela velocidade com que a água pode atingir o grânulo de fertilizante (LINDSAY \& 
STEPHENSON, 1959 a,b). Devido à maior tensão de água, exercida pela presença de sais no grânulo, esta passa do solo para o grânulo, formando uma região de alta concentração do nutriente ao seu redor.

A solução formada pelo PMC dissolvido move por capilaridade do grânulo para o solo circundante. Essa solução é altamente concentrada em ácido $(\mathrm{pH} \cong 1,5)$ e a sua pressão de vapor representa uma umidade relativa próxima a $90 \%$, menor que a umidade relativa do ar do solo que está entre 98 e 100\%. Este gradiente de pressão de vapor contribui para o movimento do vapor d'água do solo para o grânulo e simultaneamente da solução concentrada em fósforo para fora do grânulo (LINDSAY, 1979). Contudo, nem todo o fósforo do grânulo migra para o solo. Com a dissolução do PMC no grânulo forma-se uma solução supersaturada de CaHPO4 (PDC) e $\mathrm{CaHPO}_{4} 2 \mathrm{H}_{2} \mathrm{O}(\mathrm{PCDD})$ que em parte precipita-se no sítio do grânulo durante a dissolução. A sobra de $\mathrm{P}$ no sítio do grânulo como fosfato dicálcico anidro ou dihidratado que precipitou, pode atingir niveis de 15 a 40\% do fósforo original (LEHR et al, 1959; LINDSAY \& STEPHENSON, 1959 a,b, BROWN \& LEHR, 1959).

Com a dissolução do fertilizante pela água do solo, diversas reações ocorrem entre os fosfatos, os constituintes do solo e outros compostos não fosfáticos do solo. Com o tempo, o fósforo é removido da solução, transferido para a fase sólida. A adição de uma fonte de fósforo solúvel ao solo resulta sempre na retenção do fósforo em formas menos solúveis (FASSBENDER, 1966)

No processo de retenção do fósforo no solo, pelo menos dois mecanismos estão envolvidos: a adsorção e a precipitação (HSU, 1965 e FASSBENDER, 1966). BOHN et 
al. (1978) registram que vários pesquisadores tem mostrado que reações de interação mineral de argila-fósforo consiste de dois estágios. O estágio rápido inicial (completado em cerca de um dia) é seguido por uma reação mais lenta a qual pode continuar por várias semanas ou mais. A reação rápida inicial pode ser vista como uma combinação de adsorção não específica e troca de ligantes sobre as faces minerais. A mais lenta reação provavelmente consista de uma complexa combinação de dissolução mineral ou precipitação do fósforo adicionado com cátion da estrutura do mineral ou com cátions trocáveis.

SAMPLE et al. (1980) registram vários mecanismos para tentar explicar a retenção de fósforo no solo os quais incluem: adsorção fisica, quimiossorção, troca de ânion, precipitação superficial e separação da fase sólida. No entanto eles consideram estes mecanismos como casos especiais de precipitação e adsorção. Assim a retenção de fósforo envolveria os mecanismos de adsorção e precipitação. Nas baixas concentrações de fósforo, óxidos e hidróxidos retém $\mathrm{P}$ através de reações tipo sorção. Em altas concentrações, a precipitação foi sugerida como o mecanismo de retenção de fósforo baseando-se na descontinuidade observada nas isotermas de adsorção convencionais. Consideraram que pouca evidência direta é oferecida para caracterizar a existência de uma fase precipitada separada. Ponderaram que, no caso da reação dos fertilizantes no solo, muitos pesquisadores envolvidos em identificar produtos de precipitação inicial tem tendido a ignorar alguma contribuição das reações de adsorção. Consideram essa hipótese compreensível em vista da grande mudança química no ambiente circundando o sítio de aplicação do fertilizante. Todavia, quando uma solução fertilizante move através 
do solo, tornando mais e mais diluída por causa da precipitação e contato com o solo úmido, um ponto seria atingido onde, além dele, a adsorção domina e a fase precipitada seria negligenciável.

Alguns autores, contudo, demonstraram a formação de precipitados quando da adição de fosfatos de cálcio ao solo (TAYLOR \& GURNEY, 1965a; DAVEY \& SHAYAN, 1980). Utilizando diversas técnicas de identificação de minerais, MARTIN et al. (1988) verificaram a ocorrência de isolados cristalitos de mineral grifita $\left[\mathrm{Fe}_{3} \mathrm{Mn}_{2}(\mathrm{PO} 4)_{2,5}(\mathrm{OH})_{2}\right]$ quando colocaram uma solução de $\mathrm{KH}_{2} \mathrm{PO}_{4} 10^{-3} \mathrm{~mol} . \mathrm{L}^{-1}$ em contato com goetita. Segundo esses autores, os resultados sugerem que retenção nos sistemas óxido de ferro pode ser primariamente devido à precipitação antes que à adsorção. Verificaram que: a) o equilíbrio goetita com solução de fosfato $10^{-3} \mathrm{~mol} \cdot \mathrm{L}^{-1}$ conduziu à formação de fase fosfato de ferro como cristalitos sobre a superficie da goetita. b) o mecanismo de formação da fase fosfato precipitado parece envolver dissolução parcial da goetita e reprecipitação porque os cristalitos ocorrem sobre a superficie e nenhuma alteração apreciável da fase goetita foi observada.

PIERZYNSKI et al. (1990) usando a técnica da óptica eletrônica, encontraram que alumínio e silício foram os elementos dominantes associados com fósforo, como partículas discretas bem como sobre partículas. SLOAN et al. (1995) observaram que aplicações de fertilizantes decresceram $\mathrm{Al}, \mathrm{Ca}, \mathrm{Mg}$ e $\mathrm{Mn}$ em um Argiustoll com pH 4,0, proporcionalmente às doses de $\mathrm{P}$ aplicadas e aumentou sulfatos.

Para BARROW (1980), três zonas podem ser reconhecidas próximas ao grânulo de fertilizante. Uma zona central contendo resíduo de $P$, que no caso dos fosfatos 
monocálcicos seria o fosfato dicálcico. Ao redor desta zona central há a zona concentrada dentro da qual ocorrem os fenômenos de dissolução dos constituintes do solo pela solução ácida rica em fósforo e sua reação com os cátions $\mathrm{Ca}, \mathrm{Fe}$ e $\mathrm{Al}$, formando precipitados. A partir dessa zona haveria formação de zonas com concentrações mais baixas e a reação do P ocorre inicialmente com íons da solução do solo e, posteriormente, com os da superficie das partículas.

Van RIEMSDIJK et al. (1984) propuseram um modelo de difusão-precipitação para descrever o mecanismo de retenção de fósforo em solos argilosos ácidos e contendo óxidos ou hidróxidos de ferro e alumínio. Este modelo pressupõe a formação de cobertura de um fosfato do cátion metálico sobre a superficie das partículas dos óxidos.

Van der ZEE (1988) admite que o fosfato difunde-se para dentro da partícula sesquioxídica, formando uma fase interna de precipitado de fósforo. A reação contrária é controlada por cinética de dissolução ou algum tipo de processo de difusão, muito lento, considerado como irreversível numa escala de tempo de experimento. Denominam este modelo USC (Unreacted Shrinking Core).

A retenção do fósforo no solo ocorre em velocidades diferentes, sendo registrada uma etapa rápida e uma etapa lenta (HSU, 1964). VEITH \& SPOSITO (1977) observaram ser a primeira etapa uma reação mais rápida, caracterizada pela adsorção propriamente dita e a segunda etapa mais lenta, uma precipitação.

A reação de adsorção é influenciada pelo $\mathrm{pH}$ e pela concentração. A reação lenta tem sido descrita por alguns pesquisadores como um processo de difusão controlada. Diferentes mecanismos tem sido propostos para explicar a reação lenta, mas 
todos consideram a ocorrência de uma reação do fósforo com a fase sólida reativa, ocorrendo concomitantemente com rápida adsorção (VAN der ZEE et al., 1987).

Modelos cinéticos são propostos para compreensão dos mecanismos de adsorção de íons à superfície dos minerais, tendo-se observado que a reação não se processa em apenas uma etapa, e que a velocidade da primeira etapa é maior do que a da segunda (BITTENCOURT e ZAMBELLO, 1974; GRIFFIN e JURINAK, 1974).

REIS (1992) constatou que o processo de adsorção de fósforo pela fração argila de onze solos deu-se em mais de uma etapa e, para a maioria dos solos, mais da metade do fósforo adicionado foi consumido na reação mais rápida, que se deu entre 30 e 90 minutos; assim, é possível explicar o processo de adsorção pelo mecanismo cinético múltiplo de primeira ordem reversivel.

FIXEN \& GROVE (1990) consideraram que a remoção de fósforo da solução do solo, após adição de fertilizante solúvel, deve-se caracterizar por processos contínuos de adsorção-precipitação e que resultam em uma série contínua de compostos químicos de fósforo.

Admite-se que a adsorção de fósforo ocorre em sítios de diferentes naturezas. BACHE (1964) sugeriu que a superficie de adsorção da gibsita era composta de três regiões, com diferentes graus de energia, os quais são função da concentração. Em baixas concentrações ocorreria a primeira regiấo, com elevada energia de adsorção; a segunda região caracterizar-se-ia por precipitação, e a terceira pela adsorção de baixa energia no precipitado. 
MULJADI et al. (1966 a,b,c) propuseram mecanismo semelhante: admitiram três regiões de adsorção, para caulinita, gibsita e pseudoboemita, sendo a adsorção nessas regiões influenciadas pelo pH e concentração. A região I seria caracterizada pela troca entre o grupamento $\mathrm{OH}^{-}$do óxido hidratado ou da caulinita e o ânion $\mathrm{H}_{2} \mathrm{PO}_{4}{ }^{\circ}$, possuindo maior energia de adsorção. A região II, com as mesmas características de troca da região 1, apresenta menor energia de adsorção, correspondendo a concentrações maiores de fósforo. Na região III, admitiam a penetração de fósforo em alguma parte amorfa da superficie dos cristais.

RYDEN et al. $(1977 \mathrm{a}, \mathrm{b})$ registraram ocorrência de três regiões de adsorção. Na primeira região ocorreria adsorção de fósforo na superfície protonada do adsorvente, com a troca do ligante $\mathrm{OH}_{2}^{+}$a qual denominaram de quimiossorção $\mathrm{Na}$ segunda região, similarmente à primeira, ocorreria adsorção com a participação do ligante $\mathrm{OH}$. A terceira região seria caracterizada por uma adsorção de caráter mais físico que químico, apresentando o fósforo adsorvido uma baixa energia de ligação. Em relação à estabilidade dessas regiões, estes autores registraram passagem do fósforo adsorvido na região III para as formas quimiossorvidas das regiões 1 e II.

Segundo KILE et al. (1975), a maioria dos sítios de adsorção na gibsita é constituida pelos átomos situados na superficie do cristal. Postularam que a adsorção de fosfato sobre a gibsita envolve dois átomos de aluminio, formando uma estrutura hexagonal estável onde o fosfato age como um ligante bidentado. Usando a técnica de expectros de infravermelho, PARFIT'T et al. (1975) propôs a existência de uma 
coordenação binuclear dos íons fosfatos a dois íons $\mathrm{Fe}^{3+}$ sobre a superficie da goetita; envolvendo a troca ou a substituição de outro ligante (hidroxila ou água) do $\mathrm{Fe}^{3+}$

PARFITT (1978) discordou da proposição de que a III região fosse caracterizada por um processo de adsorção física predominantemente. Admitiu que esta adsorção fraca poderia ser resultante da troca de ligantes sobre a superficie proximamente saturada, onde a carga superficial é muito reduzida.

As reações da etapa lenta no solo, após a adição de fertilizante resultam em decréscimo de disponibilidade de fósforo para as plantas, diminuindo a eficiência dos adubos fosfatados adicionados ao solo (BARROW, 1980). BAHIA FILHO, (1982) registrou pronunciada histerese entre as quantidades de fósforo adicionado e de fósforo adsorvido, em solos com diferentes capacidade tampão máxima e submetidos a cultivos sucessivos. A velocidade deste fenômeno é afetada por vários fatores destacando-se tipo de solo, dose e fonte de fósforo, manejo e pH do solo (GOEDERT \& SOUZA, 1984). A maioria das pesquisas concentram-se em estudar os mecanismos que retardam ou diminuem esse processo.

Efeitos de $\mathrm{pH}$ e concentração na reversibilidade do fósforo adsorvido nas três regiões têm sido registrados (MULJADI et al., 1966 a; LEAL e VELOSO, 1972, 1973 e VASCONCELOS et al., 1974) 


\subsection{3. - Avaliação da disponibilidade de fósforo para as plantas.}

Quando adubos fosfatados solúveis (superfosfato triplo, por exemplo) são adicionados ao solo, há um aumento do P-solução e, devido ao fenômeno de adsorção e precipitação dos íons fosfato no solo, o P da solução passa para a fase sólida. Parte desse fósforo irá constituir o P-lábil, mas a maior parte formará o P-não lábil, cuja proporção aumenta com o tempo pela passagem das formas lábeis para não lábeis (RAIJ, 1981). As formas P-lábil e P-não lábil são constituídas pelos compostos de P-inorgânico, representados genericamente por $\mathrm{P}-\mathrm{Al}, \mathrm{P}-\mathrm{Fe}, \mathrm{P}-\mathrm{Ca}$; as proporções delas dependem do tempo de formação destes compostos e das condições de solo capazes de favorecer seu envelhecimento ou transformação a formas não-lábeis.

A forma P-lábil no solo foi considerada, inicialmente, como aquela determinada através de troca isotópica com fósforo radioativo (LARSEN, 1967). McAULIFFE et al. (1948) utilizaram o princípio da troca isotópica para determinar o fósforo da superficie dos minerais, denominado por RUSSEL et al. (1954) de fósforo isotopicamente trocável ou valor "E", O valor "E" é a medida da quantidade de um nutriente existente na superficie das partículas e, que é trocável com o íon quimicamente idêntico, o qual é possivel determinar com o uso de traçadores radioativos, ou seja é a quantidade de fósforo da superfície do solo que é trocável com os íns fosfatos radioativos adicionados em solução, segundo a reação: 


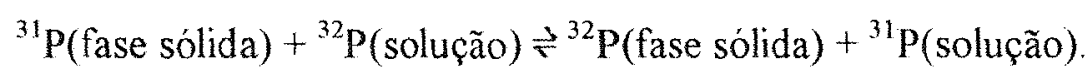

A troca isotópica constitui um dos métodos para se estudar a forma de $\mathrm{P}$ aproveitável pelas plantas (CARMELLO, 1980). MURAOKA et al. (1991) citam outras denominações utilizadas para o $\mathrm{P}$ isotopicamente trocável: "fósforo adsorvido na superficie das partículas do solo", e "quantidade total de fósforo disponível do solo".

A dinămica do fósforo no solo proveniente de um fertilizante fosfatado solúvel pode, então, ser representada esquematicamente como a seguir:

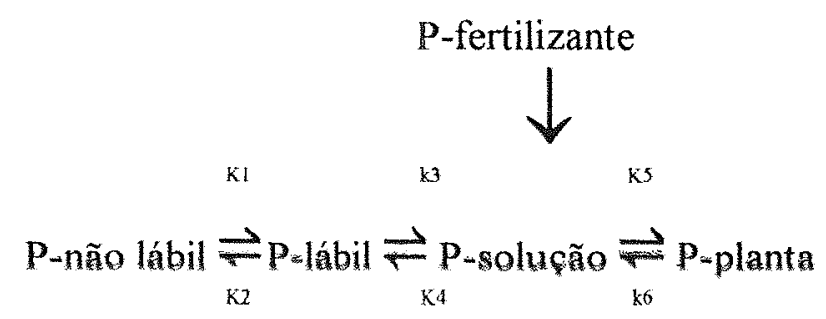

O P-lábil é constituído de compostos de fósforo meta-estáveis e outros compostos mal formados. Um dos mecanismos de reposição do P-solução dar-se-ia através da dissolução dos compostos de fosfato lábil que se encontram em diversas formas químicas (RAIJ, 1991).

A disponibilidade de fósforo para as plantas dependeria do P-lábil, representando o "fator quantidade" ou a reserva de fósforo no solo do P-solução ou "fator intensidade", representado pelo elemento na solução do solo e do "fator capacidade", definido pela relação entre as constantes $\mathrm{K} 3 / \mathrm{K} 4$, e também denominado "poder tampão de fosfato" do solo, que é referida como a capacidade do solo em manter determinado nível de $\mathrm{P}$ na 
solução; pelas constantes K5 (influxo) e K6 (efluxo), sendo esta desprezível para plantas em crescimento.

$\mathrm{Na}$ avaliação da disponibilidade de qualquer nutriente, uma das premissas fundamentais para se verificar se um extrator é adequado para a análise deste nutriente é a de que as quantidades extraídas por ele correlacionem com a absorção pela planta. A uma variação na quantidade extraída deverá corresponder a variações no crescimento vegetal (BRAY, 1947), e consequentemente existir correlação entre teor no solo e parâmetros de crescimento vegetal. Com base neste princípio, vários extratores podem ser empregados para se estimar a quantidade disponível de um elemento, da mesma forma que com um extrator pode-se medir a disponibilidade de mais de um elemento (THOMAS \& PEASLEE, 1973). Contudo, a eficiência dos extratores é bastante variável em função de sua composição e das características do solo.

Para a avaliação do P no solo existem vários extratores (BINGHAM, 1962; THOMAS \& PEASLE, 1973; FIXEN \& GROVE, 1990). Com eles procura-se estimar a fração de P-fase sólida que estaria disponivel para as plantas e obter uma estimativa do Plábil ou fator quantidade (BAHIA FILHO \& BRAGA, 1975a; RAIJ, 1978; BAHIA FILHO, 1982).

Segundo KAMPRATH \& WATSON (1980), os extratores podem ser agrupados em:

a) Soluções diluídas de ácidos fortes, como Mehlich-1 $\left(\mathrm{HCl} 0,05 \mathrm{~mol} \cdot \mathrm{L}^{-1}+\right.$ $\mathrm{H}_{2} \mathrm{SO}_{4} 0,0125 \mathrm{~mol}^{-1} \mathrm{~L}^{-1}$ e $\mathrm{H}_{2} \mathrm{SO}_{4} 0,025$ mol. L ${ }^{-1}$. 
b) Soluções diluidas de ácido forte mais um íon complexante, como Bray-1 ( $\mathrm{HCl}$ $\left.0,025 \mathrm{~mol} . \mathrm{L}^{-1}+\mathrm{NH}_{4} \mathrm{~F} 0,03 \mathrm{~mol} \cdot \mathrm{L}^{-1}\right)$.

c) Soluções diluídas de sais originados de ácidos fracos, como por exemplo, lactato de cálcio $0,01 \mathrm{~mol} \mathrm{~L}^{-1}$.

d) Soluções alcalinas tamponadas, como o extrator de Olsen $\left(\mathrm{NaHCO}_{3} \quad 0,5\right.$ mol. $\left.\mathrm{L}^{-1} \mathrm{pH} 8,5\right)$.

O método baseado na extração com resina trocadora de ânions (RAIJ et al 1986) proposto originalmente por AMER et al. (1955), vem sendo utilizado em análise de rotina em inúmeros laboratórios do Brasil, podendo ser enquadrado num grupo especial de resinas-extratoras, por não se tratar de solução extratora.

A natureza química do $\mathrm{P}$ extraído do solo pelo extrator varia entre solos e depende do mecanismo de extração: por ácidos diluídos, através da solução solubilizadora dos íons $\mathrm{H}^{+}$; pela complexação de cátions $\mathrm{Al}^{+3}$ e $\mathrm{Fe}^{+3}$ ligados a fósforo pela ação dos ânions citrato, lactato, tartarato, ou F; por troca de ligantes; ou por hidrólise pelos íons $\mathrm{OH}^{-}$ou $\mathrm{HCO}_{3}^{-}$(OLSEN \& $\mathrm{KHASAWNEH}^{-1980)}$.

Para KAMPRATH \& WATSON (1980) os mecanismos de remoção do fósforo da fase sólida através de extratores dá-se por quatro reações:

a) Ação solvente de ácidos. As soluções empregadas têm, em geral, $\mathrm{pH}$ de 2 a 3 , ocasionando a dissolução de fosfatos de cálcio e, em menor intensidade, de fosfatos de ferro e aluminio;

b) Substituição de ânions. Os fosfatos adsorvidos na superficie do solo podem ser substituídos por outros ânions como sulfato e bicarbonato; 
c) Complexação de cátions combinados com o fósforo, liberando o nutriente ligado ao metal. São complexantes os ions fluoreto, citrato, lactato e tartarato. O íon mais utilizado é o fluoreto $\left(F^{-}\right)$, muito eficiente na complexação de alumínio, liberando assim o nutriente ligado a esse metal;

d) Hidrólise de cátions combinados com o P. Em soluções extratoras de pH mais elevado, o fósforo ligado ao ferro e alumínio é liberado por hidrólise dos metais, fenômeno característico da ação do extrator $\mathrm{NaHCO}_{3} 0,5$ mol. $\mathrm{L}^{-1}$, pH 8,5.

Os extratores ácidos, como Mehlich-1 $\left(\mathrm{H}_{2} \mathrm{SO}_{4} 0,0125 \mathrm{~mol} \cdot \mathrm{L}^{-1}+\mathrm{HCl} 0,05\right.$ mol. $\mathrm{L}^{-1}$ ), são mais indicados para solos com baixa CTC, altamente intemperizados e com teores baixos de fósforo ligado a cálcio (P-Ca). Os extratores constituídos de íons

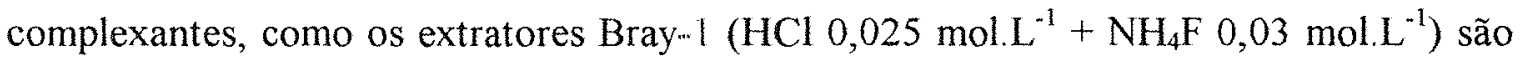
mais indicados para solos com CTC variando de média a baixa, grau de intemperização de moderado a alto e apresentando baixos conteúdos de fósforo ligado a cálcio (THOMAS \& PEASLE, 1973).

FIXEN \& GROVE (1990) registram que os extratores ácidos são mais apropriados para solos ácidos e extratores contendo bicarbonatos são mais apropriados para solos calcários. No entanto, são também registradas observações de que o extrator Olsen tem bom desempenho em solos ácidos, como observado por HOLFORD (1980b) e SMITH \& SANCHEZ (1982), assim como o extrator resina (RAIJ et al., 1986), de natureza alcalina, é utilizado com sucesso em solos ácidos.

Os extratores ácidos (Mehlich-1 e $\mathrm{H}_{2} \mathrm{SO}_{4}$ 0,025 mol. $\mathrm{L}^{-1}$ ), em solos com altos teores de P-Ca ou que receberam fosfato natural, podem superestimar a disponibilidade 
de $\mathrm{P}$ devido à ação solubilizadora dos íons hidrogênio sobre os compostos de P-Ca que são de baixo aproveitamento pelas plantas. Esse efeito foi observado por FEITOSA \& RAIJ (1976), SFREDO et al. (1979), BRAGA et al. (1980) e VASCONCELLOS et al. (1986), entre outros.

A subestimativa de $\mathrm{P}$ disponível em solos argilosos por extratores ácidos, relatada desde há muito tempo (PRATT \& GARBER, 1964), tem sido apontada como fator limitante do uso desses extratores nesses solos (RAIJ, 1978; KAMPRATH \& WATSON, 1980).

A ineficiência para extrair $\mathrm{P}$ de alguns solos ricos em óxidos de ferro e alumínio e que não respondem ao fertilizante fosfatado aplicado às culturas, e a indicação de teores altos em solos que receberam fosfato natural, mas onde pode ocorrer deficiência aguda do elemento, constituem-se nos principais problemas dos extratores ácidos em uso no Brasil (RAIJ et al., 1982; RAIJ et al., 1986).

Pesquisas realizadas com diferentes solos mostram que o nível crítico de fósforo para as plantas, estimado por extratores ácidos, diminui com o aumento da capacidade tampão de fosfato e parâmetros a ela relacionados. São registradas relações inversas com teor de argila (VIDOR \& FREIRE, 1971; NOVAIS, 1977; FREIRE et al., 1979), teor de goetita (BAHIA FILHO, 1982) e fósforo remanescente na solução após agitação do solo com uma solução contendo concentração de P conhecida (BAHIA FILHO, 1982; MUNIZ et al. 1987; NEVES, 1983).

BAHIA FILHO (1982), ao explicar a sensibilidade dos extratores Mehlich-1 e Bray-1 à capacidade tampão de fosfato do solo, sugeriu que ela seria devida à exaustão 
dos extratores químicos pela goetita, o principal componente responsável pelas variações observadas na capacidade tampão dos solos por eles estudados. Essa sensibilidade seria consequêencia do desgaste ou consumo dos extratores, em razão da redução da concentração ácida dos mesmos, pela protonação na superficie de óxidos hidratados de ferro e alumínio, que pode adsorver os ànions $\mathrm{SO}_{4}{ }^{2-}, \mathrm{F}^{-}$ou mesmo readsorver fósforo extraído.

HOLFORD (1980 a,b) argumenta que a relativa eficácia de um extrator pode ser afetada por sua sensibilidade, ao tamponamento: um extrator, supersensível subestimaria o fósforo disponível em um solo fortemente tamponado, enquanto um extrator subsensível o superestimaria. Em qualquer destas duas condições o nível crítico do elemento estimado por um extrator seria afetado por variações no tamponamento, enquanto que numa correta sensibilidade, não haveria diferenças.

Para KHASAWNEH (1971), uma adequada avaliação da disponibilidade de fósforo para as plantas deve abranger informações de pelo menos dois destes fatores: quantidade, intensidade e capacidade. HOLFORD (1976) considerou a existência de dois problemas fundamentais envolvidos na avaliação do $\mathrm{P}$ disponível: a dificuldade em se medir com um extrator químico todo o fósforo disponível para as plantas e a impossibilidade de se medir a capacidade do solo de manter o fósforo na solução durante o período de crescimento vegetal. Por outro lado, o conhecimento do fator capacidade não é suficiente se não se conhece o fator quantidade ou fator intensidade

NOVAIS \& KAMPRATH (1979 a,b) apontaram a necessidade de serem conhecidos aspectos relativos ao fator capacidade, além do fósforo extraido pelos 
extratores químicos, como critério auxiliar de recomendação de adubação fosfatada. Assim as características do solo que refletissem o fator capacidade seriam adequadas para estimar níveis criticos bem como para estabelecer recomendações de adubação

Como tentativa de superar este problema, têm sido proposto nos estados do Rio Grande do Sul (SIQUEIRA, 1987) e Minas Gerais (COMISSÃO DE FERTILIDADE DO SOLO DO ESTADO DE MINAS GERAIS, 1989) que a interpretação dos teores de P na análise de solo, obtidos pelos extratores com composição ácida, seja feita levando-se em conta o teor de argila do solo.

KAMPRATH \& WATSON (1980) consideram que idealmente o extrator de fósforo deveria considerar ambos os fâtores - quantidade e intensidade. Na prática, entretanto, extratores caracterizam ora o fator quantidade, ora o fator intensidade. Extratores fracos como água e $\mathrm{CaCl}_{2}$ avaliam o fator intensidade, enquanto extratores fortes como ácidos, íons complexantes e soluções alcalinas tamponadas medem o fator quantidade. A maioria dos extratores satisfatórios seriam aqueles capazes de medir a porção do $\mathrm{P}$ da fase sólida de solo controlando o P-solução do solo.

O poder de remoção de fósforo do solo de um extrator está associado ao seu modo de ação, às formas de $\mathrm{P}$ no solo e às características do solo. Maior extração pelo extrator não corresponde, necessariamente, a maior eficiência na avaliação da disponibilidade para as plantas, ou seja, de avaliar a fração de P-lábil do solo.

COOKE \& HISLOP (1963) argumentam que qualquer método de estimar o fósforo disponivel do solo, aplicável a todos os solos, deve evitar a destruição química do solo, e que os principais métodos não destrutivos estão baseados na: a) troca isotópica de 
fosfato; b) equilibrio do solo com soluçôes salinas de baixa concentração; c) remoção de fosfato por resina trocadora de ânion.

AMER et al. (1955) já registravam que o extrator resina seria o mais adequado uma vez que simularia melhor a relação planta-solo no processo de absorção de fósforo, da mesma forma que no processo de absorção pela planta: à medida que o fósforo vai sendo removido da solução pela resina vai havendo reposição por dissolução de P-lábil. OLSEN \& KHASAWNEH (1980) registram que a resina parece extrair somente formas lábeis, embora retire apenas parte do fósforo lábil.

Tem-se demonstrado que o extrator resina sofre menor influência das características do solo associadas à capacidade tampão de fosfato bem como fornece melhores correlações com parâmetros de crescimento da planta, quando se consideram solos com características fisicas e químicas diferentes.

RAIJ et al. (1984) compararam os extratores para fósforo $\mathrm{H}_{2} \mathrm{SO}_{4} 0,025$ mol. $\mathrm{L}^{-1}$, Bray-1, Olsen e resina, correlacionando teores no solo com produção relativa de milho e algodão em experimentos de campo. Verificaram melhor correlação da produção com o extrator resina.

Cultivando soja (Glycine max, L. Merril) em amostras de dez latossolos diferentes, MUNIZ (1983) verificou que os níveis críticos de $\mathrm{P}$ obtidos pelos extratores Mehlich-1, Bray-1 e Bray-2, para obtenção de $90 \%$ da produção máxima estimada, diminuiu com o aumento da capacidade tampão de fosfato do solo. Entretanto, NOVAIS et al.(1988) observaram que os níveis críticos obtidos pela resina, nestes mesmos solos, não variaram com os valores do fator capacidade 
MOURA FILHO (1990) verificou que os níveis críticos para arroz em diferentes solos correlacionaram-se com características do solo que refletem a capacidade tampão de fosfato para os extratores Mehlich-1 e Bray-1, não ocorrendo o mesmo com resina e Olsen. Em experimento conduzido em casa de vegetação, SILVA (1990) observou que a ordem crescente quanto à sensibilidade dos extratores ao fator capacidade de fósforo foi resina, Bray-1 e Mehlich-1

$\mathrm{Na}$ realidade, na interacão solo-extrator pode predominar ora o efeito do solo, ora o efeito do extrator, conduzindo a situações ora de subestimativa, ora de superestimativa da fração P-lábil ou extração de formas não lábeis como se fossem lábeis Este aspecto explica, em muitos casos, a restrição de um extrator a um grupo de solos ou a solos com determinadas características fisico-químicas, explicando também a diversidade de extratores utilizados nas diversas regiões do mundo.

KAMPRATH \& WATSON (1980) consideram como características desejáveis de um extrator para estimar a disponibilidade de fósforo para as plantas: a) mostrar boa correlação de quantidades extraídas com parâmetros de crescimento das plantas e, b) sofrer pouca influência das características do solo como $\mathrm{pH}$ e propriedades mineralógicas.

\subsection{4. - A reação do solo e a disponibilidade de fósforo}

Para AMARASIRI \& OLSEN (1973) a convicção existente de que a concentração de $\mathrm{P}$ em solo ácido geralmente aumentava após calagem, ainda carecia de 
evidência experimental e estava inconclusiva. De fato, pesquisas publicadas, antes e depois de 1973, parecem corroborar esta idéia quando se consideram solos, plantas e extratores diferentes.

O efeito da variação do $\mathrm{pH}$ do solo na disponibilidade de fósforo e absorção do nutriente pela planta, pode estar associado a várias causas, como: 1) precipitação do alumínio em solução e trocável (WHITE, 1983), resultando na formação de hidróxidos de alumímio, associada à precipitação de hidróxidos de ferro e óxidos de manganês (HAYNES, 1982, 1984; ANJOS \& ROWELL, 1987); 2) diminuição da saturação de alumínio no solo (SANCHEZ \& UEHARA, 1980); 3) composição mineralógica do solo (WHITE, 1983); 4) mineralização do $\mathrm{P}$ orgânico pela maior atividade biológica possibilitada pela elevação de pH (HAYNES, 1982) ou efeito de imobilização de P por microorganismos, como aventado por HORNECK et al. (1990); 5) alterações de pH na rizosfera (BARBER, 1980) 6) e envelhecimento de polimeros Al-OH, resultante de umedecimento e secagem, com melhor cristalização e menor adsorção de fósforo (HAYNES, 1982, 1984).

AMARASIRI \& OLSEN (1973) observaram que, para qualquer nivel de fósforo em um solo ácido (pH inicial em torno de 3,7), a elevação do pH para 6,5, decresceu os níveis de P solúvel e P-lábil (avaliado por troca isotópica). Para esses autores, a redução do $\mathrm{P}$ solúvel em $\mathrm{CaCl}_{2}$ 0,01 mol. $\mathrm{L}^{-1}$, do P-lábil e o aumento da adsorção máxima de fósforo poderiam ser devidos a hidróxidos de $\mathrm{Fe}$ e Al recém-formados, precipitados, cujo efeito seria de muito maior magnitude que aqueles devidos à precipitação de fosfatos por Al e Fe solúvel. 
Segundo MURRMANN \& PEECH (1969), a calagem decresceria a concentração de $\mathrm{P}$ pelo processo de oclusão de $\mathrm{P}$ pelos hidróxidos de $\mathrm{Fe}$ e $\mathrm{Al}$ precipitados, mas para AMARASIRI \& OLSEN (1973) a oclusão isoladamente não explicaria o decréscimo observado em P solúvel e P-lábil com a calagem, haja vista que nos solos tratados com calcário antes da adubação fosfatada, os hidróxidos de ferro e alumínio já teriam sidos precipitados por ocasião da adição do fósforo.

SIMS \& ELIS (1983a,b) estudaram o efeito da calagem (com base no teor de Al trocável e elevação do $\mathrm{pH}$ a 6,8 ) em duas condições de incubação (umidade contínua e alternada com secamento) no período de até um ano e verificaram diminuição das constantes de Langmuir $\mathrm{k}$ e b, associadas às energias de ligação e de adsorção máxima, respectivamente. Este fenômeno ocorreu com maior intensidade nas amostras que foram incubadas em regime de umedecimento e secagem alternados, no período de 30 a 240 dias. Relatam que o envelhecimento da suspensão Al-OH reduziu sua capacidade para adsorção de fósforo, enquanto o Al-OH precipitado em $\mathrm{pH} 5,5$ inicialmente adsorveu mais fósforo que aquele precipitado em $\mathrm{pH} 7,0$. Aos noventa dias a diferença entre eles tornou-se insignificante. Sugeriram que o "envelhecimento da superficie adsorvente, representada pelos polímeros $\mathrm{Al}-\mathrm{OH}$, reduziu a intensidade de ligação com o fósforo quando o pH do solo aumentou".

Por sua vez, HAYNES $(1982,1984)$, em revisão sobre o assunto, relata que quando o fósforo foi aplicado em um solo ácido $(\mathrm{pH} \mathrm{4,2)} \mathrm{com} \mathrm{alto} \mathrm{teor} \mathrm{de} \mathrm{alumínio}$ trocável $\left(12,8\right.$ mmol $\left._{\mathrm{c}} \mathrm{kg}^{-1}\right)$, a calagem aumentou a adsorção de fosfato quando o solo havia sido previamente incubado com calcário com umidade constante e, quando o solo 
havia sido seco após a incubação e antes da aplicação do fosfato, a calagem decresceu a adsorção de fósforo. Sugeriu que o secamento, aparentemente, causou a cristalização dos polímeros $\mathrm{Al}-\mathrm{OH}$ como gibsita, sendo a área anfotérica da superficie sobre $\mathrm{Al}(\mathrm{OH})_{3}$ cristalino menor em comparação à área superficial dos $\mathrm{Al}-\mathrm{OH}$ amorfos.

Experimentos conduzidos no campo, onde é natural ocorrerem condições de secamento e umedecimento alternados e haver maior tempo de contato, embora as reações sejam mais lentas, parecem corroborar esta idéia. Entre outros, têm-se registros de maior disponibilidade de fósforo com a calagem feitos por SILVA et al. (1987) em algodoeiro; por QUAGGIO et al. (1982) em cultura de soja, e por RAIJ \& QUAGGIO (1990) em culturas de feijão, girassol e soja.

Experimentos conduzidos em casa de vegetação, com amostras provenientes de áreas experimentais, mostraram maior disponibilidade de fósforo avaliada através da absorção de fósforo pelas plantas (MALAVOLTA et al., 1965; CURTIM \& SMILLIE, 1984) ou menor adsorção de fósforo pelo solo com aumento de pH (LOPEZHERNANDEZ \& BURNHAM, 1974). Em alguns experimentos em casa de vegetação nos quais se fez calagem prévia, e ocorreu umedecimento e secagem alternados, num tempo superior a pelo menos 30 dias, houve aumento de disponibilidade de fósforo (McCLEAN \& COOK, 1955; KUNISH, 1982; SIMS \& ELIS, 1983a) e em outros, onde houve incubação simultânea (NELLER, 1953; ADAMS \& ODOM, 1985) ou com antecedência menor de 28 dias (AMARASIRI \& OLSEN, 1973) houve diminuição

Existem restrições à hipótese da melhor cristalização resultante do umedecimento e secagem alternados. WHITE (1983) argumenta que há ampla evidência 
da estabilidade de espécies carregadas Al-hidróxidos, e que o processo de secamento teria que ser extremamente severo e prolongado para que a atividade da superficie ativa do solo decrescesse a um ponto onde sua capacidade de adsorção fosse menor que no solo antes da calagem. Essas informações se contrapõem com os resultados obtidos por TAYLOR \& GURNEY (1965b), AMARASIRI \& OLSEN (1973) e FRIESSEN et al (1980)

Algumas hipóteses são levantadas por WHITE (1983): a) para solos nos quais minerais de argila, com teores relativamente altos em alumínio trocável, formam a maior parte da superficie de adsorção, a sorção de fósforo aumentaria com o pH na faixa de $\mathrm{pH}$ 4,0 a 7,$0 ;$ b) se o $\mathrm{Al}$ já estiver extensivamente hidrolisado, como em turfas ácidas e em solos ricos em minerais de argila 2:1 interestratificado com polímeros Al-hidróxidos, a mudança de $\mathrm{pH}$ deve ter pouco efeito sobre a sorção de fósforo correspondendo à categoria de solos de pH 5,0 a 6,0 e com baixa saturação de $\mathrm{Al}$; c) se as superfícies de adsorção são predominantemente oxídicas, uma elevação de pH causaria decréscimo na sorção de fósforo na faixa de $\mathrm{pH} 4,0$ a 7,0 , embora o decréscimo não seria tão grande se ocorressem entre $\mathrm{pH} 7,0$ e 10,0

SANCHEZ \& UEHARA (1980) verificaram que a calagem reduziu adsorção de fósforo em solos muito ácidos ( $\mathrm{pH} 5,0$ ) com teores elevados de $\mathrm{Al}^{3+}$, mas teve pouco ou nenhum efeito sobre solos de $\mathrm{pH}$ entre 5,0 e 6,0 com niveis de saturação de $\mathrm{Al}^{3+}$ menores que $45 \%$ da capacidade de troca de cátion. ANJOS \& ROWELL (1987) registraram, em dois solos com teores elevados de aluminio trocável, decréscimo de P-solução e P- 
isotopicamente trocável quando foram incubados com calcário por três dias, e aumento quando foram incubados por 23 meses.

Em relação aos teores de Al trocável, WHITE (1983) propôs, a partir da avaliação de outras pesquisas, que: 1) quando o conteúdo de $\mathrm{Al}$ no solo for maior que $0,02 \mathrm{mmol} \cdot \mathrm{g}^{-1}$ a calagem reduziria o teor de $\mathrm{P}$ solúvel; 2) quando o teor de $\mathrm{Al}$ estivesse entre 0,002 e $0,02 \mathrm{mmol}^{-1}$ uma resposta variável seria obtida dependendo do nível de fósforo adicionado e, 3) abaixo de $0,002 \mathrm{mmol} \mathrm{Al.g}{ }^{-1}$ haveria uma tendência de aumentar a solubilidade de fósforo ou não ocorreria nenhuma mudança.

Estudos realizados em sistemas puros artificiais ou separados de componentes do solo são fundamentais para se entender os fenômenos relacionados ao $\mathrm{pH}$ e à disponibilidade de fósforo assim como ajuda a explicá-los.

HINGSTON et al. (1972), estudando adsorção de fósforo em óxidos de ferro (goetita e hematita), em meio com $\mathrm{NaCl}$, verificaram que adsorção de fósforo decresceu quando o pH aumentou na faixa de 2 a 12 . Ao estudarem adsorção de fósforo em meio contendo óxidos de alumínio diluídos em $\mathrm{NaCl}, \mathrm{CHEN}$ et al. (1973) verificaram que a sorção de fósforo atingiu um máximo entre pH 4,0 e 5,0.

Conforme afirma WHITE (1983), em pH abaixo de 3 o fósforo forma complexos solúveis com íns monômeros de $\mathrm{Al}$ dissolvidos do óxido e com a elevação do $\mathrm{pH}$, ions $\mathrm{Al}^{3+}$ hidrolizam-se e o fósforo forma complexos com íons complexos $\mathrm{Al}-\mathrm{OH}$, nos quais são fortemente adsorvidos. Quando o produto de atividade $\left(\mathrm{Al}^{3+}\right)\left(\mathrm{PO}^{3-}\right)$ em solução exceder o produto de solubilidade dos fosfatos de alumínio amorfos (PAA), estes compostos precipitam-se sobre a superficie do óxido, e com a elevação do pH acima de 
$7,0, \mathrm{Al}(\mathrm{OH})_{3}$ torna-se a fase mais estável e os fosfatos de alumínio dissolvem-se para liberar fósforo em solução. SHANG et al. (1992) verificaram que a taxa de adsorção de fosfatos orgânicos e inorgânicos por precipitados de $\mathrm{Fe}$ e $\mathrm{Al}$ (artificiais) diluídos em $\mathrm{NaCl}$ decresceu com o aumento de $\mathrm{pH}$.

Além das causas consideradas por HAYNES (1982) ou seja, de que o decréscimo na retenção de fósforo poderia ser atribuída a um efeito do umedecimento e secagem do solo após aplicar calcário e possivel efeito da mineralização do fósforo orgânico, BARROW (1984) considera que há pelo menos mais quatro fatores que necessitam ser considerados: $\mathbf{1}^{\circ}$ ) a faixa de $\mathrm{pH}$ sobre os quais os efeitos são medidos; $\mathbf{2}^{\circ}$ ) a relação entre pH e potencial eletrostático no plano de adsorção, considerando que o decréscimo do potencial eletrostático, com o aumento de $\mathrm{pH}$, torna a reação com os íons fosfatos negativamente carregados mais dificil, ocorrendo deste modo menor adsorção; $3^{0}$ ) o eletrólito diluente. Adsorção de fósforo em função do $\mathrm{pH}$ pode ser diferente, dependendo do eletrólito diluente, apontando que quando o diluente é $\mathrm{NaCl}$ o aumento de pH produz um claro e consistente decréscimo da sorção de fosfato e quando o diluente for $\mathrm{CaCl}_{2}$ pode ocorrer aumento na adsorção de fósforo com $0 \mathrm{pH} ; 4^{\circ}$ ) a quantidade de fosfato presente no solo. Considera que, para um solo sem virtualmente nenhum fosfato lábil, o único efeito de $\mathrm{pH}$ ocorreria sobre a capacidade do solo reter fosfato recentemente adicionado.

Outro aspecto interessante é a composição mineralógica e magnitude dos componentes do solo. CURI \& FRANZMEIR (1984) e SOUZA et al. (1991), trabalhando com amostras dos mesmos solos, verificaram que à medida que aumentou o 
teor de goetita nos solos aumentou a capacidade de adsorção de fosfato e diminuiu a dessorção.

BAHIA FILHO (1982) verificou que a goetita foi o principal constituinte responsável pelas variações observadas na capacidade tampão máxima e na adsorção máxima de fósforo. A redução da disponibilidade de fósforo para o vegetal esteve associada a este mineral, sendo que a natureza da ligação estabelecida pareceu ser mais importante que a extensão da superficie de adsorção. Esse autor supôs que a menor eficiência do extrator Mehlich-1 em avaliar o P disponivel em solos com alto teor de goetita deveu-se ao consumo de ions $\mathrm{H}^{+}$da solução ácida para protonação da superficie da goetita.

A natureza e estabilidade dos compostos de fósforo formados no solo, após adição do adubo fosfatado, são fatores que irão influenciar o comportamento do fósforo em função do $\mathrm{pH}$. Os fosfatos de cálcio básico normalmente apresentam composição entre o fosfato dicálcico e fosfato octocálcico, podendo se formar em pH acima de 5,56,5 ; enquanto os fosfatos de ferro e alumínio tendem a se formar em valores de menor $\mathrm{pH}$ (LINDSAY, 1979).

Estudando a solubilidade da variscita sintética $\mathrm{Al}(\mathrm{OH})_{2} \mathrm{H}_{2} \mathrm{PO} 4$ e de produtos de reações imediatas após a aplicação de fosfato ao solo, LINDSAY et al. (1959) encontraram que estes produtos foram muito mais solúveis que a variscita, mas com o envelhecimento foram lentamente transformados em variscita, os quais podem coexistir com gibsita, na fase sólida estável. 
HSU (1964), trabalhando com um solo com pH 6,4, verificou que as solubilidades da variscita, do $\mathrm{Al}(\mathrm{OH})_{2} \mathrm{H}_{2} \mathrm{PO}_{4}$ e do $\mathrm{Fe}(\mathrm{OH})_{2} \mathrm{H}_{2} \mathrm{PO}_{4}$ sintéticos foram consideravelmente aumentadas quando em contato com o solo, indicando que estes compostos não são provavelmente produtos de fixação de fósforo sob esta condição de $\mathrm{pH}$.

A solubilidade dos produtos fosfatados é influenciada pelo $\mathrm{pH}$. Considerando este aspecto, LINDSAY e MORENO (1960) apresentam um diagrama de solubilidade, representando as isotermas das atividades para $\mathrm{AlPO}_{4} \cdot 2 \mathrm{H}_{2} \mathrm{O}$ (variscita) FePO $\mathrm{O}_{4} \cdot 2 \mathrm{H}_{2} \mathrm{O}$ (estrengita), $\mathrm{Ca}_{10}\left(\mathrm{PO}_{4}\right) \mathrm{F}_{2}$ (Fluorapatita), $\mathrm{Ca}_{10}\left(\mathrm{PO}_{4}\right)_{6}(\mathrm{OH})_{2}$ (hidroxapatita), $\mathrm{CaHPO}_{4} \cdot 2 \mathrm{H}_{2} \mathrm{O}$ (fosfato dicálcico dihidratado).

Com o aumento de $\mathrm{pH}$ há tendência de aumentar a solubilidade das formas $\mathrm{P}-\mathrm{Fe}$ e P-Al (estrengita, variscita) e diminuição da solubilidade das formas de P-Ca (fluorapatita, hidroxiapatita, fosfato octocálcico e fosfato dicálcico). Assim, quando solos neutros ou ligeiramente ácidos são acidificados ocorre aumento na disponibilidade de fósforo devido à dissolução de fosfatos de cálcio (MURRMANN \& PEECH, 1969).

$\mathrm{BOHN}$, et al. (1978) consideram que um diagrama como esse descreve o equilibrio das reações de precipitação de $\mathrm{P}$ em vários valores de $\mathrm{pH}$, embora considerações cinéticas freqüentemente impeçam a precisa aplicação de dados de solubilidade ao sistema solo; consideram também que, apesar do diagrama ser desenvolvidos a partir de considerações termodinâmicas, não dá nenhuma indicação da cinética de transformação do $\mathrm{P}$. Segundo os autores, os diagramas explicam as reações de P no solo qualitativamente, sendo as previsões quantitativas menos promissoras. 
Uma das principais consequências dos processos e reações do fósforo no solo é a crescente redução na disponibilidade do nutriente às plantas, com o equilibrio das reações deslocando-se sempre para as formas não lábeis.

Para solos altamente intemperizados, deve-se esperar que com aumento de $\mathrm{pH}$ ocorra um aumento da disponibilidade de fósforo. SWENSON et al (1949) registraram que em valores de pH maiores que 6,5, o composto $\mathrm{Fe}\left(\mathrm{H}_{2} \mathrm{O}\right)_{3}(\mathrm{OH})_{2}\left(\mathrm{H}_{2} \mathrm{PO}_{4}\right)$ se tornava instável e a retenção de fosfato caia significativamente. Contudo, admitiram que a prática da calagem com o objetivo de liberar o fósforo adsorvido por estes compostos é de limitado valor, uma vez que o pH do solo deverá ser elevado a 7 ou 8 para que uma quantidade apreciável de fósforo seja liberada dos compostos de ferro, ou a valores ainda maiores para a liberação dos compostos de alumínio.

No entanto, em solos bastante intemperizados (latossolos, terras roxas) tem-se verificado aumento digno de consideração do $\mathrm{P}$ disponível para as plantas, com o aumento do pH do solo. GOEDERT \& SOUZA (1984) registram que "estudos de laboratório sugerem que a calagem deve aumentar a eficiência da adubação fosfatada. Essa alternativa tem sido comprovada em campo em várias regiões do País e com várias culturas, onde um determinado nivel de produção pode ser obtido com diferentes combinações de níveis de calagem e adição de fósforo, ilustrando o importante papel da calagem na eficiência e economia da adubação fosfatada"

Com a calagem haveria uma diminuição ou retardamento da passagem de P. lábil para P-não lábil, decorrente do aumento de cargas negativas, promovendo maior repulsão dos ânions pela superfície dos colóides; aumento na concentração dos íons $\mathrm{OH}^{-}$, que competem com os ânions de $\mathrm{P}$ pelos sítios de adsorção; e diminuição dos teores de Al trocável, reduzindo o fenômeno da precipitação. A redução da adsorção de fosfato devido ao fenômeno de repulsão é admitida por SMITH \& SANCHEZ (1980) enquanto, 
a diminuição da energia de adsorção do fósforo aos colóides do solo é aceita por BOWDEN et al. (1980).

Segundo MULJADI et al. (1966 a,b) e PARFITT et al (1977), com o aumento do $\mathrm{pH}$ do solo aumentaria a competição entre os íons hidroxila e fosfato pelo mesmos sítios de adsorção especifica na superficie dos minerais. No entanto, BARROW (1984) registra que o decréscimo do potencial eletrostático com o aumento do $\mathrm{pH}$ faz com que a reação entre o plano de adsorção e os íons fosfatos negativamente carregados seja mais dificil, ocorrendo menor adsorção.

\section{Efeitos na ação dos extratores.}

Quando se considera variação da disponibilidade de fósforo, decorrente da variação do $\mathrm{pH}$ do solo, avaliada por extratores verificam-se grandes diferenças entre eles, as quais estão associadas à natureza química, modo de ação do extrator e a sua interação com o solo.

BRAGA \& DEFELIPO (1972 a,b), estudando a disponibilidade de fósforo em latossolo que recebeu corretivo, avaliada por diferentes extratores, observaram aumento nos teores extraidos de fósforo, com aumento do $\mathrm{pH}$ do solo pelos, extratores Mehlich-1 e $\mathrm{H}_{2} \mathrm{SO}_{4}$ 0,025 mol. $\mathrm{L}^{-1}$ e Olsen e diminuição pelo extrator Bray. Ao correlacionarem $\mathrm{P}$ disponivel com crescimento vegetal de painço, verificaram que os valores de crescimento relativo correlacionaram com os teores de fósforo extraídos pelo extrator Mehlich-1 e o fósforo absorvido correlacionaram com os teores de P extraído pelos extratores Bray- 1 e Olsen. 
MENDEZ (1986), estudou a eficiência da aplicação prévia de fosfato parcialmente acidulado (FAPS) e superfosfato triplo (ST), em relação a diferentes épocas de calagem, em dois solos sob cerrado (LVd e LEd), sobre o rendimento da matéria seca, fósforo absorvido por plantas de arroz de sequeiro e a disponibilidade de fósforo avaliada pelos extratores Mehlich-1, Olsen + EDTA, Bray-1 e resina. Verificou que com o emprego do ST, os teores de fósforo disponível estimados pelos extratores Mehlich-1, Bray-1 e resina, não variaram significativamente com os tempos de reação do calcário e adubo, em ambos solos. No caso do extrator Olsen-EDTA os teores de P disponivel aumentaram com o tempo de reação de calcário no solo LVd e tenderam a diminuir com o tempo de reação do calcário no LEd. Ao correlacionar os teores extraídos com parâmetros de crescimento vegetal constatou correlação entre teores obtidos pelo Bray-1 e matéria seca e fósfore acumulado e entre os teores obtidos pelo Olsen - EDTA e matéria seca. Não verificou correlação significativa entre os teores obtidos por Mehlich-1 e resina com estes parâmetros de crescimento das plantas.

VIEGAS (1990) conduziu um estudo com o objetivo de avaliar o efeito de diferentes níveis de acidez do solo - pH em $\mathrm{H}_{2} \mathrm{O}$ 4,5; 5,0; 5,5; 6,0 e 6,5 - sobre a dinâmica do nutriente fósforo e sua disponibilidade para as plantas em nove solos do Estado de Minas Gerais. Observou tendência de decréscimo de fósforo para o $\mathrm{P}$ extraído pela resina

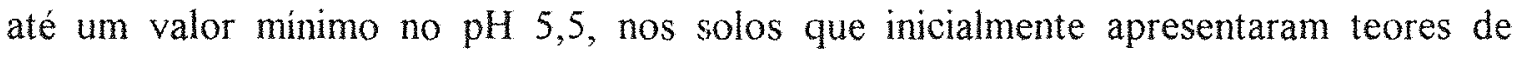
aluminio trocável maior que $10 \mathrm{mmol}_{c} \mathrm{~L}^{-1}$ de terra. Observou correlação significativa entre os teores recuperados pelos extratores Mehlich-1 e Bray-1 e matéria seca e P acumulado pelo sorgo granífero, não observando correlação com o extrator resina. Os 
coeficientes de correlação obtidos entre os teores de $\mathrm{P}$ recuperados pelos extratores Mehlich-1 e Bray-1 aumentaram com a elevação do pH e, de forma contrária, apresentaram menores valores, quando consideradas as correlações entre estes extratores e a resina. Ao se elevarem os diferentes valores de $\mathrm{pH}$ para 6,5 verificou-se uma tendência de decréscimos de P extraído pelos extratores Mehlich-1 e Bray-1 quando se utilizou o superfosfato triplo e um aumento de $\mathrm{P}$ disponivel avaliado pela resina.

RAIJ \& QUAGGIO (1990) estudaram o efeito da calagem na disponibilidade de fósforo avaliada por quatro extratores (Mehlich-1, Bray-1, resina e Olsen),com amostras de solo de quatro experimentos no Estado de São Paulo: dois com soja, um com girassol e outro com feijão. Verificaram aumento no conteúdo foliar de $\mathrm{P}$ com o aumento do $\mathrm{pH}$ $\mathrm{CaCl}_{2}$ 0,01 mol. $\mathrm{L}^{-1}$. Entretanto, ao correlacionarem teor de fósforo no solo com $\mathrm{pH}$ do solo constataram que os extratores apresentaram comportamentos diferentes. O extrator Olsen extraiu teores decrescentes de fósforo com o aumento do $\mathrm{pH}$ dos solos; os teores extraídos por Mehlich-1 correlacionaram-se positivamente com o pH dos solos em três solos, mas apresentou menor sensibilidade; o extrator resina extraiu teores crescentes de fósforo com aumento de $\mathrm{pH}$ em todos os solos, apresentando maior sensibilidade em indicar as variações de disponibilidade de fósforo ocasionados pelas variações de $\mathrm{pH}$. Com o aumento do $\mathrm{pH}$ houve maior disponibilidade de $\mathrm{P}$ para as plantas, conforme se verificou com a maior concentração de $\mathrm{P}$ nas folhas. No caso do extrator Bray-1 foi observada correlação entre teores extraidos e aumento de $\mathrm{pH}$ em apenas um solo não sendo observada nos outros solos. 
No que diz respeito ao efeito do $\mathrm{pH}$ do solo em diminuir a eficiência de extratores ácidos diluídos, este é atribuído à exaustão do ácido em solos com alta capacidade de troca de cátions, ricos em $\mathrm{Ca}$ e $\mathrm{Mg}$ ou, à reação do $\mathrm{CaCO}_{3} \mathrm{com}$ o ácido; e por extração de P-Ca nãc disponíveis à planta (KAMPRATH \& WATSON, 1980) 


\section{MATERIAL E MÉTODOS}

Para a avaliação da influência da reação do solo na disponibilidade do fósforo, medida através de extratores químicos e da absorção por plantas, foram conduzidos experimentos em casa-de-vegetação, utilizando amostras de solos ácidos, com teores de fósforo diferentes, submetidos a doses de corretivo.

\subsection{Solos utilizados nos experimentos.}

Foram coletadas nove amostras da camada superficial $(0-15 \mathrm{~cm})$ de latossolos roxos distróficos apresentando valores de $\mathrm{pH}$ em $\mathrm{CaCl}_{2} \quad 0,01 \mathrm{~mol} \mathrm{~L}^{-1}$ menor que 4,5 e com diferentes teores de fósforo, localizadas na Estação Experimental do Instituto Agronòmico do Paraná(IAPAR), em Londrina (PR) e na Estação Experimental de Ribeirão Preto do Instituto Agronômico de Campinas, em Ribeirão Preto (SP).

As amostras provenientes da Estação Experimental do IAPAR, doravante denominadas LD1, LD2, LD3, LD4, LD5, foram coletadas em abril de 1992 de parcelas 
de experimento, que tinham recebido doses diferentes de calcário e superfosfato simples ${ }^{1}$, e de área adjacente sob pousio. Foram utilizadas neste experimento as amostras provenientes de quatro parcelas que receberam somente fósforo. Estas parcelas tinham sido adubadas com superfosfato simples em pó, a lanço, em 1986. Foram aplicadas quantidades de adubo para se possibilitar teores de P Mehlich-1, em mg dm $\mathrm{dm}^{-3}$, nas faixas de teores $<5$ (LD2); entre 5-15 (LD3); 15-45 (LD4) e > 45 (LD5). Posteriormente foi cultivado com milho, efetuando-se anualmente, até 1990, adubação em sulco de 60 $\mathrm{kg} \cdot \mathrm{ha}^{-1}$ de $\mathrm{P}_{2} \mathrm{O}_{5}$, quando foi concluído o experimento. No espaço de tempo compreendido entre 1990 e a coleta das amostras de solo, a área experimental permaneceu sem ser cultivada. A amostra LD1 foi coletada em área de pousio, ao lado da área experimental.

As amostras provenientes da Estação Experimental do IAC, Ribeirão Preto (SP), doravante denominadas RP1, RP3, RP7, e RP13, foram coletadas em setembro de 1992, em quatro locais diferentes, na área de cultivo de lavouras da estação. As coletas foram efetuadas próximas a pontos de trincheiras do levantamento detalhado da Estação Experimental de Ribeirão Preto - SP. (OLIVEIRA \& MONIZ, 1975).

As principais características físicas e químicas de rotina das amostras utilizadas estão resumidas na Tabela 1 .

\footnotetext{
1 Olivcira, Edson Lima de. (Instituto Agronômico do Paraná lAPAR Londrina PR) Comunicação Pessoal, 1992.
} 


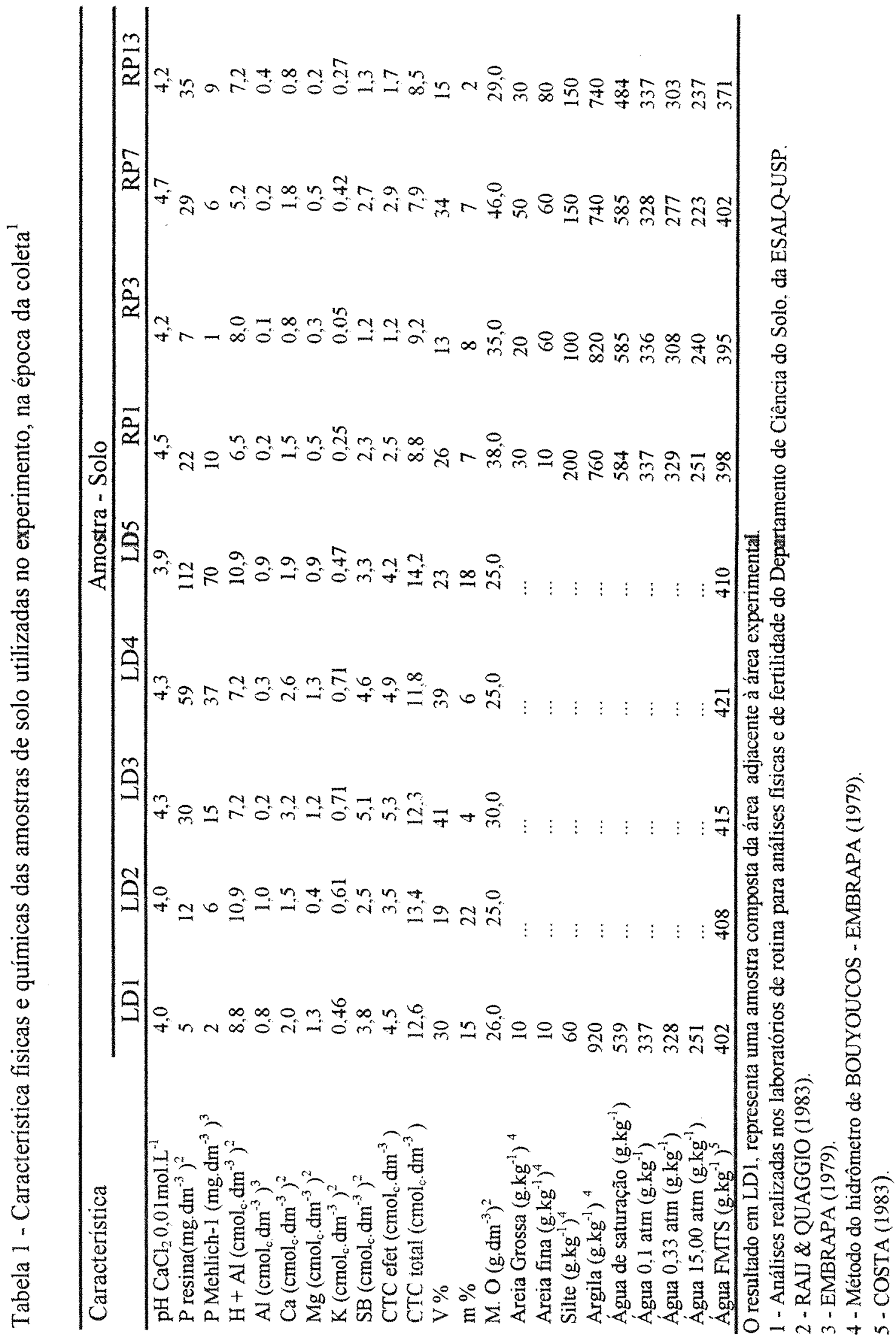




\subsection{Experimentos em casa-de-vegetação}

Foi realizado um experimento com arroz (Oriza sativa,L.) em blocos ao acaso, com três repetições, com tratamentos em arranjo fatorial $(9 \times 5)$, envolvendo nove amostras de solos e cinco doses de corretivo, totalizando 135 vasos. O experimento com milho (Zea mays, L.) constituiu-se de um cultivo subsequente ao arroz, utilizando-se as mesmas amostras de terra e delineamento experimental empregados no primeiro experimento.

\subsubsection{Experimento com arroz.}

\subsubsection{Incubação}

Para determinar as doses de corretivos que possibilitassem a elevação do $\mathrm{pH}$ em $\mathrm{H}_{2} \mathrm{O}$ até a faixa da alcalinidade, amostras com 100 gramas de terra provenientes de

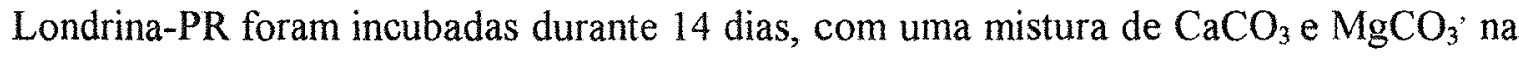
proporção de $4: 1$, nas doses correspondentes a $0,2,5 ; 5 ; 7,5$ e $10 \mathrm{~g} \mathrm{~kg}^{-1} \mathrm{de} \mathrm{CaCO}_{3}$, em duplicata (Apêndice 1).

Com base nos resultados obtidos com essa incubação prévia, foi feita a instalação do experimento em vasos. As amostras de solo foram submetidas a 5 doses de corretivo, correspondentes a $0,2,4,8{\mathrm{~g} . \mathrm{kg}^{-1}}^{\text {de }} \mathrm{CaCO}_{3}$, composto de uma mistura de 4 
partes de $\mathrm{CaCO}_{3}$ e 1 parte de $\mathrm{MgCO}_{3}$ e incubadas durante 180 dias, com teor de umidade correspondendo a $80 \%$ da umidade estimada pelo método da frente de molhamento em terra seca (COSTA, 1983)

Inicialmente as amostras de solos foram passadas em peneira de $4 \mathrm{~mm}$ e porções de 4 quilos de terra, correspondendo a cada parcela, foram misturadas com o corretivo e colocadas em saco plástico, umedecidas e deixadas incubar por 180 dias. Nos primeiros 28 dias de incubação os sacos permaneceram fechados, e a seguir ficaram abertos de modo a se permitir o secamento da terra com reposição da água aos $60,90,120$ e 150 dias.

\subsubsection{Cultivo do arroz.}

Após a incubação, a terra de cada vaso foi novamente peneirada $\mathrm{e}$ homogeneizada. Aproximadamente $500 \mathrm{~g}$ de terra de cada tratamento, das três repetições, foram coletados para análises posteriores. Depois de peneirada, porções de três quilos de terra, correspondentes a cada vaso, receberam adubação pré-semeadura conforme doses e fontes indicadas no apêndice 2. A seguir, umedeceu-se o solo com água destilada, para que contivesse $80 \%$ da umidade estimada pelo método da frente de molhamento em terra seca (COSTA, 1983). Após vinte e quatro horas, vinte sementes de arroz, da cultivar IAC-165, foram semeadas em cada vaso, realizando-se o desbaste para quatro plantas, seis dias após a emergência. Foi, também, realizada uma adubação nitrogenada de cobertura, na dosagem de $100 \mathrm{mg} \cdot \mathrm{kg}^{-1}$ de $\mathrm{N}$, na forma de nitrato de amônio p.a, 
divididos em cinco aplicações de $20 \mathrm{mg} \mathrm{kg}^{-1}$, com intervalo entre aplicações de uma semana e iniciando-se a cobertura logo após o desbaste.

Aos 39 dias após o desbaste foi efetuada a colheita da parte aérea das plantas de arroz, cortando-se as plantas a mais ou menos $1 \mathrm{~cm}$ acima da superficie da terra. Em seguida, o material foi submetido a quatro lavagens (água + detergente, água, água + ácido, água), enxugadas sobre papel e colocadas para secar, até peso constante, em estufa com circulação forçada de ar, à temperatura de $65^{\circ} \mathrm{C}\left( \pm 5^{\circ} \mathrm{C}\right)$, obtendo-se massa seca da parte aérea.

\subsubsection{Experimento com milho}

Após a colheita do experimento anterior, procedeu-se, vaso por vaso, à separação das raízes da terra. A terra foi novamente passada em peneira com abertura de malha de $4 \mathrm{~mm}$, homogeneizada e recolocada nos mesmos vasos na quantidade de $2,6 \mathrm{~kg}$ por vaso e o restante de terra de cada vaso foi separada para análises posteriores. Após aplicados os adubos nas doses e fontes indicadas no apêndice $2 \mathrm{e}$ feito umedecimento das terras, oito sementes de milho (Zea mays L.), híbrido C 901 da Cargill, foram semeadas em cada vaso desbastando-se para três plantas por vaso. Foi efetuada adubação nitrogenada em cobertura, na dosagem de $140 \mathrm{mg} \cdot \mathrm{kg}^{-1}$, na forma de nitrato de amônio (adubo), dividida em quatro aplicações de $35 \mathrm{mg} \cdot \mathrm{kg}^{-1}$, com intervalo de uma semana entre aplicações, iniciando-se a cobertura logo após o desbaste. 
As plantas foram cultivadas por trinta dias, após o que a parte aérea foi colhida e preparada conforme descrito no experimento de arroz.

O tempo decorrido entre o início da incubação com corretivo e a semeadura do milho foi de 17 meses.

\subsection{Análises de solos e plantas}

\subsubsection{Análises químicas de plantas}

Após secagem, as plantas foram moídas em moinho tipo Wiley e submetidas à digestão nitroperclórica para análise de fósforo, segundo metodologia de análise de rotina utilizada no laboratório de análise de plantas do Departamento de Ciência do Solo da ESALQ/USP (MALAVOLTA et al., 1989).

\subsubsection{Análise de solos}

Em todas as amostras de solos provenientes do campo foram realizadas análise de rotina para fins de fertilidade, segundo RAIJ \& QUAGGIO (1983); análise granulométrica segundo EMBRAPA (1979); e retenção de água pelo método da frente de molhamento em terra seca, segundo COSTA (1983).

A terra separada no momento do preparo dos vasos foi passada em peneira com abertura de malha de $2 \mathrm{~mm}$ e submetida à determinação do $\mathrm{pH}$ em $\mathrm{CaCl}_{2} 0,01 \mathrm{~mol} . \mathrm{L}^{-1}$ e $\mathrm{P}$ 
resina segundo metodologia proposta por RAIJ \& QUAGGIO (1983); e fósforo pelo extrator Bray-1 (HCL 0,025mol. $\mathrm{L}^{-1}+\mathrm{NH}_{4} \mathrm{~F}$ 0,030mol. $\mathrm{L}^{-1}$ ), segundo BRAY \& KURTZ (1945); pelo extrator Olsen $\left(\mathrm{NaHCO}_{3} 0,5 \mathrm{~mol} \mathrm{~L}^{-1}\right)$ segundo metodologia descrita em THE COUNCIL ON SOIL TESTING AND PLANT ANALYSIS (1980); e fósforo pelo extrator Mehlich-1 $\left(\mathrm{H}_{2} \mathrm{SO}_{4}\right.$ 0,0125mol. $\mathrm{L}^{-1}+\mathrm{HCL}$ 0,05mol. $\left.\mathrm{L}^{-1}\right)$; alumínio trocável, segundo metodologia da EMBRAPA (1979); Mehlich-3 ( $\mathrm{CH}_{3} \mathrm{COOH} 0,2 \mathrm{~mol} . \mathrm{L}^{-1}+$

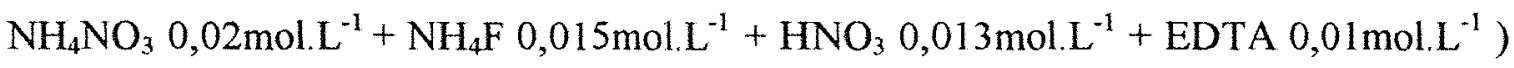
segundo MEHLICH (1984). Em todos os casos ,após a agitação, os extratos foram filtrados em papel de filtro rápido e submetidos à determinação do fósforo pelo método colorimétrico, baseado na formação do complexo fosfomolíbdico utilizando ácido ascórbico como agente redutor

Os extratos de Bray-1 e Olsen foram retornados ao funil e refiltrados, para obtenção de extratos claros. Os teores de fósforo extraídos por Bray-1, Mehlich-1, Mehlich-3, Olsen e resina doravante serão referidos como P Bray-1, P Mehlich-1, P Mehlich-3, $\mathrm{P}$ Olsen e $\mathrm{P}$ resina, respectivamente.

\subsection{3. - Verificação do efeito do corretivo aplicado na acidez dos extratores}

\section{Bray-1 e Mehlich-1.}

Para verificar o efeito do corretivo aplicado sobre a acidez dos extratores Bray-1 e Mehlich-1, uma alíquota de $5 \mathrm{~mL}$ do extrato das amostras LD5 e RP7 tratadas com as diferentes doses de carbonatos, bem como do extrator puro (branco) foi titulada com 
$\mathrm{NaOH} 0,025 \mathrm{~mol} . \mathrm{L}^{-1}$, na presença de fenolftaleína e os teores de hidrogênio determinados. Previamente procedeu-se à leitura de $\mathrm{pH}$ da suspensão solo-extrator.

\subsection{Análises estatísticas.}

Procedeu-se a análise de variância dos dados, com desdobramento dos efeitos onde houve interação. Nestes casos procedeu-se ao ajuste dos dados de massa seca da parte aérea das plantas, em g/vaso, e teores de fósforo extraídos pelos diferentes extratores, em mg.dm ${ }^{-3}$, como variável dependente $(\mathrm{y})$ de doses de corretivo (x) à função polinomial até o segundo grau e à análise de correlação, utilizando o programa Sanest. A escolha do modelo de $1^{\circ}$ ou $2^{\circ}$ grau foi efetuada considerando-se a significância dos parâmetros, com base no teste $\mathrm{F}$.

No caso em que os dados de massa seca da parte aérea das plantas ( $\mathrm{g} / \mathrm{vaso}$ ) como função de doses de corretivo $\left(\mathrm{g} \cdot \mathrm{kg}^{-1}\right)$ ajustam-se à função polinoninal de $2^{\circ} \mathrm{grau}$, foi determinado a dose para produção máxima da parte aérea das plantas igualando-se d'y/dx a zero.

Os teores de fósforo no solo que corresponderam à produção máxima de matéria seca foram estimados substituindo-se as doses para produção máxima na equação de regressão que ajustou doses de corretivo e teores de fósforo extraídos.

Do mesmo modo procedeu-se à determinação de $\mathrm{pH}$ para a produção máxima de matéria seca substituindo-se o valor de doses na equação de que relacionou doses $\mathrm{x}$ $\mathrm{pH}$. 


\section{RESULTADOS E DISCUSSÃO}

As análises de variância revelaram efeitos altamente significativos dos fatores estudados para todas as variáveis, assim como efeitos significativos das interações para quase todas variáveis (Tabela 2).

\section{1. - pH em $\mathrm{CaCl}_{2} 0,01 \mathrm{~mol} . \mathrm{L}^{-1}$ e alumínio trocável.}

A aplicação do corretivo possibilitou acentuada elevação do $\mathrm{pH}$ em $\mathrm{CaCl}_{2}$ das amostras de solo (Figura 1). No início do experimento, ou seja, antes do cultivo do arroz, os valores de $\mathrm{pH}$ chegaram próximos da neutralidade em algumas amostras tratadas com a maior dose de corretivo $\left(8 \mathrm{~g} \mathrm{~kg}^{-1} \mathrm{CaCO}_{3}\right)$.

Os valores de $\mathrm{pH}$ em $\mathrm{CaCl}_{2}$ variaram significativamente entre as amostras em todas as doses de corretivo no início do cultivo do arroz, e até a dose $4 \mathrm{~g} \cdot \mathrm{kg}^{-1} \mathrm{CaCO}_{3}$, no início do experimento com milho. Na dose $8 \mathrm{~g} \cdot \mathrm{kg}^{-1} \mathrm{CaCO}_{3}$ houve diminuição na discriminação entre solos, com ocorrência de diferenças apenas entre os solos LD4 e RP13 no experimento com arroz e não havendo diferenças significativas entre as médias de solos no experimento com milho (Tabela 3). 


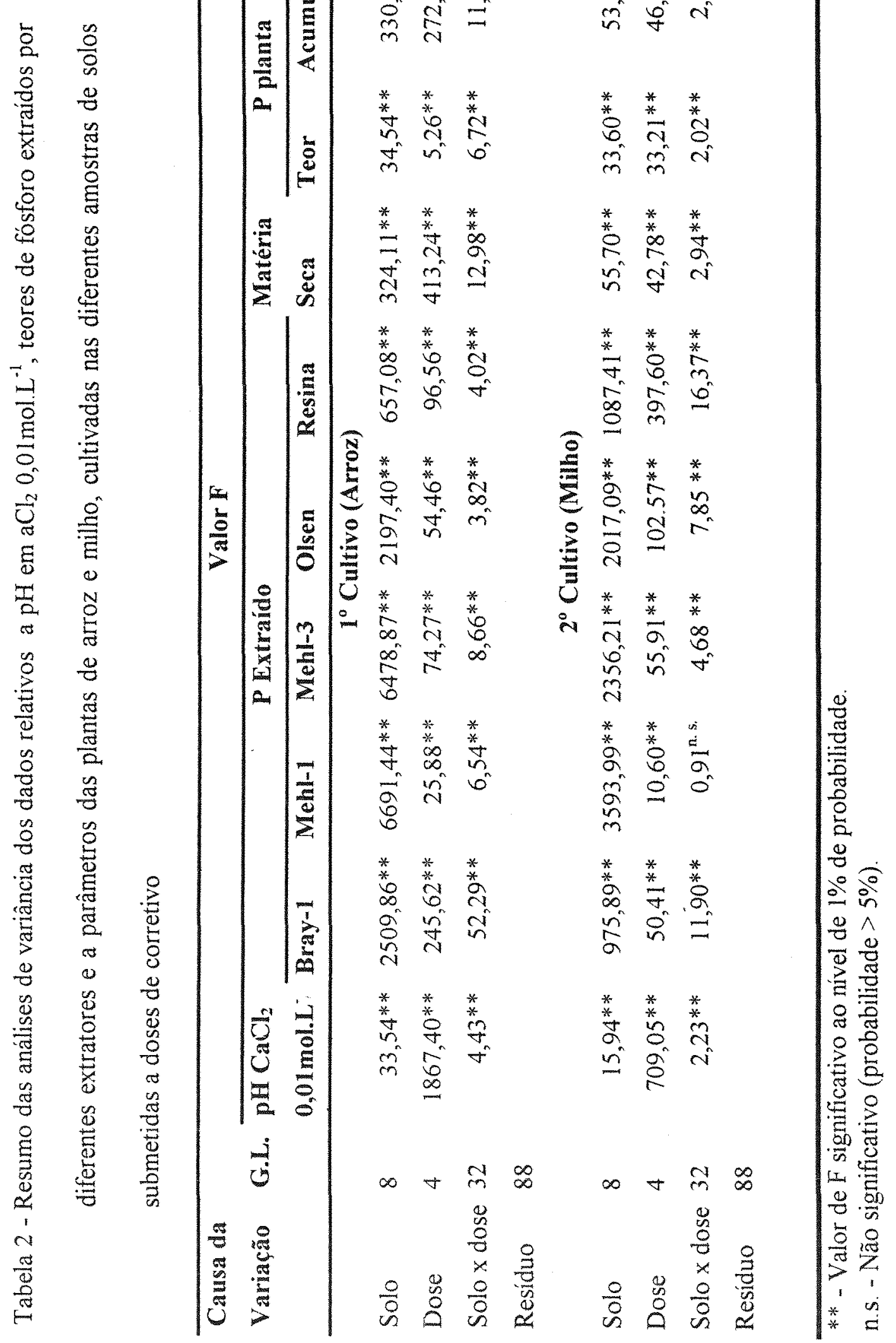




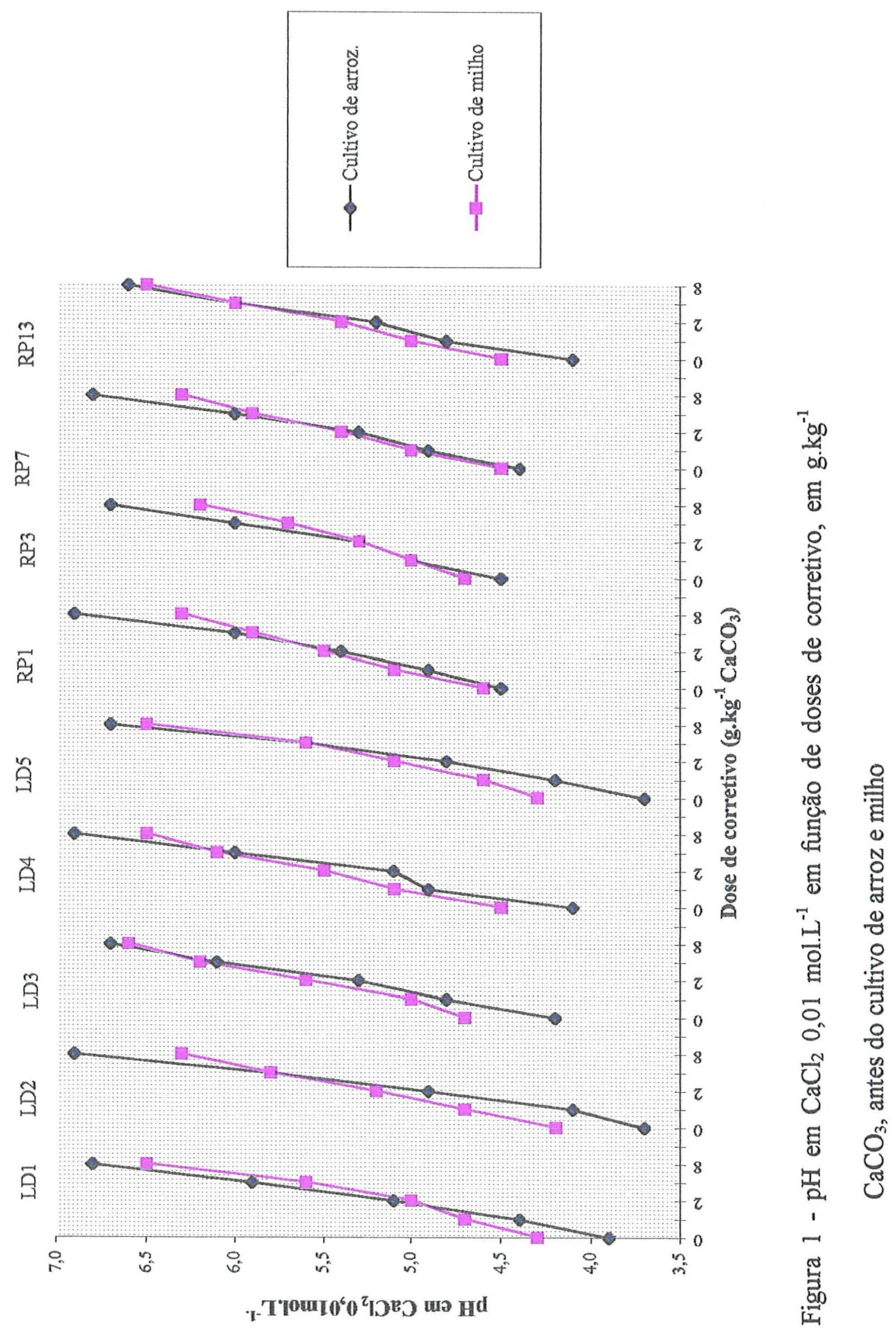


Tabela 3 - Valores de $\mathrm{pH}$ em $\mathrm{CaCl}_{2} 0,01 \mathrm{~mol} \cdot \mathrm{L}^{-1}$ nas amostras de solo, em função de doses de corretivo, em $\mathrm{g} . \mathrm{kg}^{-1} \mathrm{CaCO}_{3}$, no $1^{\circ}$ cultivo (arroz) e $2^{\circ}$ cultivo (milho). Média de três repetições ${ }^{1}$.

\begin{tabular}{|c|c|c|c|c|c|}
\hline \multirow[t]{2}{*}{ Amostra - solo } & \multicolumn{5}{|c|}{ Dose de corretivo $\left(\mathrm{g} \mathrm{kg}^{-1} \mathrm{CaCO}_{3}\right)$} \\
\hline & 0 & 1 & 2 & 4 & 8 \\
\hline \multicolumn{6}{|c|}{$1^{\circ}$ Cultivo (Arroz) } \\
\hline LD1 & $3,9 \mathrm{~cd}$ & $4,4 \mathrm{~b}$ & $5,1 \mathrm{abc}$ & $5,9 a b$ & $6,8 \mathrm{ab}$ \\
\hline LD2 & $3,7 \mathrm{~d}$ & $4,1 \mathrm{~b}$ & $4,9 \mathrm{bc}$ & $5,8 \mathrm{bc}$ & $6,9 a b$ \\
\hline LD3 & $4,2 a b c$ & 4,8 a & 5,3 a & 6,1 a & $6,7 \mathrm{ab}$ \\
\hline LD4 & $4,1 \mathrm{bc}$ & 4,8 a & $5,2 \mathrm{ab}$ & $6,0 \mathrm{ab}$ & 6,9 a \\
\hline LD5 & $3,7 \mathrm{~d}$ & $4,2 b$ & $4,8 \mathrm{c}$ & $5,6 \mathrm{c}$ & $6,7 \mathrm{ab}$ \\
\hline RP1 & 4,5 a & 4,9 a & 5,4 a & $6,0 \mathrm{ab}$ & $6,9 a b$ \\
\hline RP3 & 4,5 a & $5,0 \mathrm{a}$ & 5,3 a & $6,0 \mathrm{ab}$ & $6,7 \mathrm{ab}$ \\
\hline RP7 & $4,4 \mathrm{ab}$ & 4,9 a & 5,3 a & $6,0 \mathrm{ab}$ & $6,8 \mathrm{ab}$ \\
\hline RP13 & $4,1 \mathrm{bc}$ & 5,0 a & 5,2 a & $6,0 \mathrm{ab}$ & $6,6 \mathrm{~b}$ \\
\hline \multicolumn{6}{|c|}{$2^{\circ}$ Cultivo ( milho) } \\
\hline LD1 & $4,3 \mathrm{bc}$ & $4,7 \mathrm{bc}$ & $5,0 \mathrm{c}$ & $5,6 \mathrm{~d}$ & 6,5 a \\
\hline LD2 & $4,2 \mathrm{c}$ & $4,7 \mathrm{bc}$ & $5,2 \mathrm{bc}$ & $5,8 \mathrm{bcd}$ & $6,3 \mathrm{a}$ \\
\hline LD3 & $4,7 \mathrm{a}$ & $5,0 a b$ & 5,6 a & $6,2 \mathrm{a}$ & 6,6 a \\
\hline LD4 & $4,5 a b c$ & 5,1 a & $5,5 \mathrm{ab}$ & $6,1 a b$ & $6,5 \mathrm{a}$ \\
\hline LD5 & $4,3 \mathrm{bc}$ & $4,6 \mathrm{c}$ & $5,1 \mathrm{c}$ & $5,6 \mathrm{~cd}$ & $6,5 \mathrm{a}$ \\
\hline RP1 & $4,6 \mathrm{ab}$ & $5,1 \mathrm{a}$ & $5,5 a b$ & $5,9 \mathrm{abcd}$ & $6,3 \mathrm{a}$ \\
\hline RP3 & $4,7 \mathrm{a}$ & $5,0 a b$ & $5,3 a b c$ & $5,7 \mathrm{~cd}$ & $6,2 \mathrm{a}$ \\
\hline RP7 & $4,5 a b c$ & $5,0 a b$ & $5,4 a b c$ & $5,9 \mathrm{abcd}$ & 6,3 a \\
\hline RP13 & $4,5 \mathrm{abc}$ & $5,0 \mathrm{ab}$ & $5,4 \mathrm{abc}$ & $6,0 a b c$ & 6,5 a \\
\hline
\end{tabular}

1 Médias seguidas pela mesma letra na coluna, dentro de cada cultivo, não diferem entre si, ao nivel de $5 \%$ pelo teste Tukey. CV arroz $=2,38 \%$ e CV milho $=2,76 \%$. 
As equações de regressão da Tabela 4 e seus respectivos coeficientes de determinação mostram que os aumentos de $\mathrm{pH}$ em função das doses de corretivos foram significativos e fortemente lineares em todas as amostras e para ambos os cultivos; sendo os coeficientes angulares das equações maiores na primeira amostragem (arroz) do que na segunda (milho). Esses fatos indicam que os efeitos da calagem ainda estavam presentes no segundo cultivo, embora com intensidade menor que a constatada no primeiro. A pequena variação observada nos coeficientes angulares numa mesma época de amostragem revela que os latossolos roxos apresentaram tamponamentos semelhantes, variando de 0,273 a $0,398 \mathrm{~g} \cdot \mathrm{kg}^{-1} \mathrm{CaCO}_{3}$ por unidade de $\mathrm{pH}$, na primeira época e de 0,184 a $0,280 \mathrm{~g} \cdot \mathrm{kg}^{-1} \mathrm{CaCO}_{3}$ por unidade de $\mathrm{pH}$, na segunda época.

Como era esperado, os teores de alumínio trocável diminuíram com a calagem (Tabela 5). Mesmo nas amostras LD1, LD2 e LD5, as que continham inicialmente mais alumínio (de 0,7 a $1,1 \mathrm{cmol}_{\mathrm{c}} \cdot \mathrm{dm}^{-3}$ ), os teores diminuíram para menos de $0,5 \mathrm{cmol}_{\mathrm{c}} \cdot \mathrm{dm}^{-3} \mathrm{já}$ na aplicação da dose mais baixa de $1 \mathrm{~g} \cdot \mathrm{kg}^{-1}$ de corretivo. A partir da dose $2 \mathrm{~g} \cdot \mathrm{kg}^{-1} \mathrm{CaCO}_{3}$, o alumínio já havia sido praticamente neutralizado em todas as amostras. 
Tabela 4 - Equações de regressão entre valores de $\mathrm{pH}$ em $\mathrm{CaCl}_{2} \quad 0,01 \mathrm{~mol} \mathrm{~L}^{-1}(\mathrm{y})$, das amostras de solo coletadas antes dos cultivos de arroz e milho e doses de corretivo aplicadas (x), em $\mathrm{g} \cdot \mathrm{kg}^{-1} \mathrm{CaCO}_{3}$.

\begin{tabular}{|c|c|c|c|c|}
\hline Amostra-solo & Cultivo & Equações & $\mathrm{R}^{2}$ & $\mathrm{PROB}>\mathrm{F}$ \\
\hline LDI & $\begin{array}{l}\text { Arroz } \\
\text { Milho }\end{array}$ & $\begin{array}{l}Y=4,1+0,358 x \\
Y=4,4+0,272 x\end{array}$ & $\begin{array}{l}0,951 \\
0,987\end{array}$ & $\begin{array}{l}0,00001 \\
0,00001\end{array}$ \\
\hline LD2 & $\begin{array}{l}\text { Arroz } \\
\text { Milho }\end{array}$ & $\begin{array}{l}Y=3,9+0,398 x \\
Y=4,5+0,250 x\end{array}$ & $\begin{array}{l}0,965 \\
0,911\end{array}$ & $\begin{array}{l}0,00001 \\
0,00001\end{array}$ \\
\hline LD3 & $\begin{array}{l}\text { Arroz } \\
\text { Milho }\end{array}$ & $\begin{array}{l}Y=4,5+0,303 x \\
Y=4,9+0,232 x\end{array}$ & $\begin{array}{l}0,914 \\
0,872\end{array}$ & $\begin{array}{l}0,00001 \\
0,00001\end{array}$ \\
\hline LD4 & $\begin{array}{l}\text { Arroz } \\
\text { Milho }\end{array}$ & $\begin{array}{l}Y=4,4+0,338 x \\
Y=4,8+0,235 x\end{array}$ & $\begin{array}{l}0,995 \\
0,879\end{array}$ & $\begin{array}{l}0,00001 \\
0,00001\end{array}$ \\
\hline LD5 & $\begin{array}{l}\text { Arroz } \\
\text { Milho }\end{array}$ & $\begin{array}{l}Y=3,9+0,373 x \\
Y=4,4+0,280 x\end{array}$ & $\begin{array}{l}0,971 \\
0,984\end{array}$ & $\begin{array}{l}0,00001 \\
0,00001\end{array}$ \\
\hline RP1 & $\begin{array}{l}\text { Arroz } \\
\text { Milho }\end{array}$ & $\begin{array}{l}Y=4,6+0,293 x \\
Y=4,9+0,200 x\end{array}$ & $\begin{array}{l}0,972 \\
0,990\end{array}$ & $\begin{array}{l}0,00001 \\
0,00001\end{array}$ \\
\hline RP3 & $\begin{array}{l}\text { Arroz } \\
\text { Milho }\end{array}$ & $\begin{array}{l}Y=4,7+0,272 x \\
Y=4,8+0,186 x\end{array}$ & $\begin{array}{l}0,964 \\
0,959\end{array}$ & $\begin{array}{l}0,00001 \\
0,00001\end{array}$ \\
\hline RP7 & $\begin{array}{l}\text { Arroz } \\
\text { Milho }\end{array}$ & $\begin{array}{l}Y=4,6+0,301 x \\
Y=4,8+0,211 x\end{array}$ & $\begin{array}{l}0,965 \\
0,915\end{array}$ & $\begin{array}{l}0,00001 \\
0,00001\end{array}$ \\
\hline RP13 & $\begin{array}{l}\text { Arroz } \\
\text { Milho }\end{array}$ & $\begin{array}{l}Y=4,4+0,298 x \\
Y=4,8+0,237 x\end{array}$ & $\begin{array}{l}0,991 \\
0,915\end{array}$ & $\begin{array}{l}0,00001 \\
0,00001\end{array}$ \\
\hline
\end{tabular}


Tabela 5 - Teores de alumínio trocável, em $\mathrm{cmol}_{\mathrm{c}} \mathrm{dm}^{-3}$, em amostras de solo tratadas com diferentes doses do corretivo, antes dos cultivos do arroz e do milho. Média de três repetições.

\begin{tabular}{|c|c|c|c|c|c|c|}
\hline \multirow[t]{2}{*}{ Amostra-solo } & \multirow[t]{2}{*}{ Cultivo } & \multicolumn{5}{|c|}{ Dose de corretivo $\left(\mathrm{g} \cdot \mathrm{kg}^{-1} \mathrm{CaCO}_{3}\right)$} \\
\hline & & 0 & 1 & 2 & 4 & 8 \\
\hline \multirow[t]{2}{*}{ LDI } & Arroz & 0,7 & 0,1 & 0,0 & 0,0 & 0,0 \\
\hline & Milho & 0,7 & 0,3 & 0,0 & 0,1 & 0,0 \\
\hline \multirow[t]{2}{*}{ LD2 } & Arroz & 0,9 & 0,2 & 0,0 & 0,0 & 0,0 \\
\hline & Milho & 1,0 & 0,3 & 0,1 & 0,0 & 0,0 \\
\hline \multirow[t]{2}{*}{ LD3 } & Arroz & 0,2 & 0,0 & 0,0 & 0,0 & 0,0 \\
\hline & Milho & 0,3 & 0,1 & 0,0 & 0,0 & 0,0 \\
\hline \multirow[t]{2}{*}{ LD4 } & Arroz & 0,2 & 0,0 & 0,0 & 0,0 & 0,0 \\
\hline & Milho & 0,2 & 0,0 & 0,0 & 0,0 & 0,0 \\
\hline \multirow[t]{2}{*}{ LD5 } & Arroz & 1,0 & 0,3 & 0,1 & 0,0 & 0,0 \\
\hline & Milho & 1,1 & 0,4 & 0,1 & 0,0 & 0,0 \\
\hline \multirow[t]{2}{*}{ RPI } & Arroz & 0,1 & 0,0 & 0,0 & 0,0 & 0,0 \\
\hline & Milho & 0,2 & 0,0 & 0,0 & 0,0 & 0,0 \\
\hline \multirow[t]{2}{*}{ RP3 } & Arroz & 0,0 & 0,0 & 0,0 & 0,0 & 0,0 \\
\hline & Milho & 0,2 & 0,1 & 0,0 & 0,0 & 0,0 \\
\hline \multirow[t]{2}{*}{ RP7 } & Arroz & 0,2 & 0,0 & 0,0 & 0,0 & 0,0 \\
\hline & Milho & 0,4 & 0,1 & 0,0 & 0,0 & 0,0 \\
\hline \multirow[t]{2}{*}{ RP13 } & Arroz & 0,3 & 0,0 & 0,0 & 0,0 & 0,0 \\
\hline & Milho & 0,5 & 0,1 & 0,0 & 0,1 & 0,0 \\
\hline
\end{tabular}




\section{2 - Fósforo extraído}

\subsection{1 - Extrator Bray-1}

Os teores de fósforo extraidos por Bray-1 foram influenciados pelos fatores solos, doses e suas interações (Tabela 2).

Ocorreram diferenças de teores entre solos em todas as doses de corretivo, com maior discriminação nas maiores doses, em ambos os cultivos (Tabela 6). $\mathrm{O}$ efeito das doses foi o de diminuir os teores de P Bray-1 em todos os solos, no cultivo do arroz e na maioria dos solos, no cultivo de milho. O efeito depressivo foi observado, com maior intensidade, nas amostras com os mais altos teores de fósforo. Os teores extraídos, 26,3 e $8,3 \mathrm{mg} \cdot \mathrm{dm}^{-3,}$ com a aplicação de $8 \mathrm{~g} \cdot \mathrm{kg}^{-1} \mathrm{CaCO}_{3}$ nos solos LD5 e RP13, respectivamente, antes do cultivo de arroz, equivaleram a 42 e $46 \%$ dos teores na dose 0 g. $\mathrm{kg}^{-1} \mathrm{CaCO}_{3}$, $62,9 \mathrm{mg} \cdot \mathrm{dm}^{-3}$ e $18,0 \mathrm{mg} \cdot \mathrm{dm}^{-3}$ respectivamente, nestes solos.

A natureza do efeito de doses sobre os teores de P Bray-1, foi linear inverso, altamente significativo, na maioria dos solos (Figura 2). No desdobramento das interações, embora tenha havido diminuição dos teores de P Bray com o aumento das doses de corretivo, verifica-se que não houve correlação significativa, em nenhum dos cultivos, nos solos LD1, LD2, e RP3 e no cultivo do milho no solo LD3. Estes solos apresentam em comum teores de P Bray-1 menores que $10 \mathrm{mg} \cdot \mathrm{dm}^{-3}$ na dose zero do corretivo (Tabela 6). 
Tabela 6 - Teores de fósforo extraidos por Bray-1, em $\mathrm{mg} \cdot \mathrm{dm}^{-3}$, de amostras de solos submetidas a doses de corretivo, em $\mathrm{g} \cdot \mathrm{kg}^{-1} \mathrm{CaCO}_{3}$, antes dos cultivos de arroz e milho. Média de três repetições ${ }^{1}$.

\begin{tabular}{|c|c|c|c|c|c|}
\hline \multirow[t]{2}{*}{ Amostra-solo } & \multicolumn{5}{|c|}{ Dose de corretivo $\left(\mathrm{g} \mathrm{kg}^{-1} \mathrm{CaCO}_{3}\right)$} \\
\hline & 0 & 1 & 2 & 4 & 8 \\
\hline & \multicolumn{5}{|c|}{$1^{\circ}$ Cultivo (Arroz) } \\
\hline LD1 & $1,3 \mathrm{e}$ & $1,3 \mathrm{f}$ & $1,4 \mathrm{f}$ & $1,2 \mathrm{f}$ & $1,0 \mathrm{e}$ \\
\hline LD2 & $3,6 \mathrm{e}$ & $3,4 \mathrm{f}$ & $3,0 \mathrm{f}$ & 2,7 ef & $2,6 \mathrm{de}$ \\
\hline LD3 & $10,1 \mathrm{~d}$ & $9,9 \mathrm{e}$ & $9,3 \mathrm{de}$ & $8,1 \mathrm{~d}$ & $4,8 \mathrm{~d}$ \\
\hline LD4 & $29,4 b$ & $25,3 \mathrm{~b}$ & $24,8 \mathrm{~b}$ & $21,3 b$ & $13,4 \mathrm{~b}$ \\
\hline LD5 & $62,9 \mathrm{a}$ & $61,7 \mathrm{a}$ & $55,2 \mathrm{a}$ & $42,1 \mathrm{a}$ & $26,3 \mathrm{a}$ \\
\hline RP1 & $7,5 \mathrm{~d}$ & $6,9 \mathrm{e}$ & $6,6 \mathrm{e}$ & $5,5 \mathrm{de}$ & $5,3 \mathrm{~cd}$ \\
\hline RP3 & $1,7 \mathrm{e}$ & $1,6 \mathrm{f}$ & $1,6 \mathrm{f}$ & $1,5 \mathrm{f}$ & $1,5 \mathrm{e}$ \\
\hline RP7 & $17,6 \mathrm{c}$ & $13,4 \mathrm{~d}$ & $11,9 \mathrm{~cd}$ & $11,2 \mathrm{c}$ & $8,2 \mathrm{c}$ \\
\hline \multirow[t]{2}{*}{ RP13 } & $18,0 \mathrm{c}$ & $17,2 \mathrm{c}$ & $14,1 \mathrm{c}$ & $11,4 \mathrm{c}$ & $8,3 \mathrm{c}$ \\
\hline & \multicolumn{5}{|c|}{$2^{\circ}$ Cultivo (Milho) } \\
\hline LD1 & $1,7 \mathrm{e}$ & $1,8 \mathrm{e}$ & $1,8 \mathrm{f}$ & $1,9 \mathrm{~g}$ & $1,7 \mathrm{f}$ \\
\hline LD2 & $3,5 \mathrm{e}$ & $3,5 \mathrm{de}$ & 3,2 ef & $3,5 \mathrm{efg}$ & 3,0 ef \\
\hline LD3 & $7,8 \mathrm{~d}$ & $7,6 \mathrm{c}$ & $7,6 \mathrm{~cd}$ & $6,2 \mathrm{de}$ & $6,8 \mathrm{~cd}$ \\
\hline LD4 & $18,5 \mathrm{~b}$ & $17,1 b$ & $15,7 b$ & $14,4 \mathrm{~b}$ & $12,7 \mathrm{~b}$ \\
\hline LD5 & $41,5 \mathrm{a}$ & 36,9 a & $35,1 \mathrm{a}$ & 29,9 a & $22,4 a$ \\
\hline RP1 & $7,3 \mathrm{~d}$ & $6,1 \mathrm{~cd}$ & $5,4 \mathrm{de}$ & 5,6 def & $4,9 \mathrm{de}$ \\
\hline RP3 & $2,9 \mathrm{e}$ & $2,5 \mathrm{e}$ & $2,8 \mathrm{ef}$ & $2,6 \mathrm{fg}$ & 3,1 ef \\
\hline RP7 & $11,8 \mathrm{c}$ & $9,2 \mathrm{c}$ & $8,7 \mathrm{c}$ & $8,7 \mathrm{~cd}$ & $8,3 \mathrm{c}$ \\
\hline RP13 & $14,9 \mathrm{c}$ & $14,8 \mathrm{~b}$ & $14,5 \mathrm{~b}$ & $9,8 \mathrm{c}$ & $8,8 \mathrm{c}$ \\
\hline
\end{tabular}

1 - Médias seguidas pela mesma letra, na coluna dentro de cada cultivo, não diferem entre si ao nivel de $5 \%$ pelo teste Tukey. C. V. arroz $=8,91 \%$; C.V. milho $=11,89 \%$ 

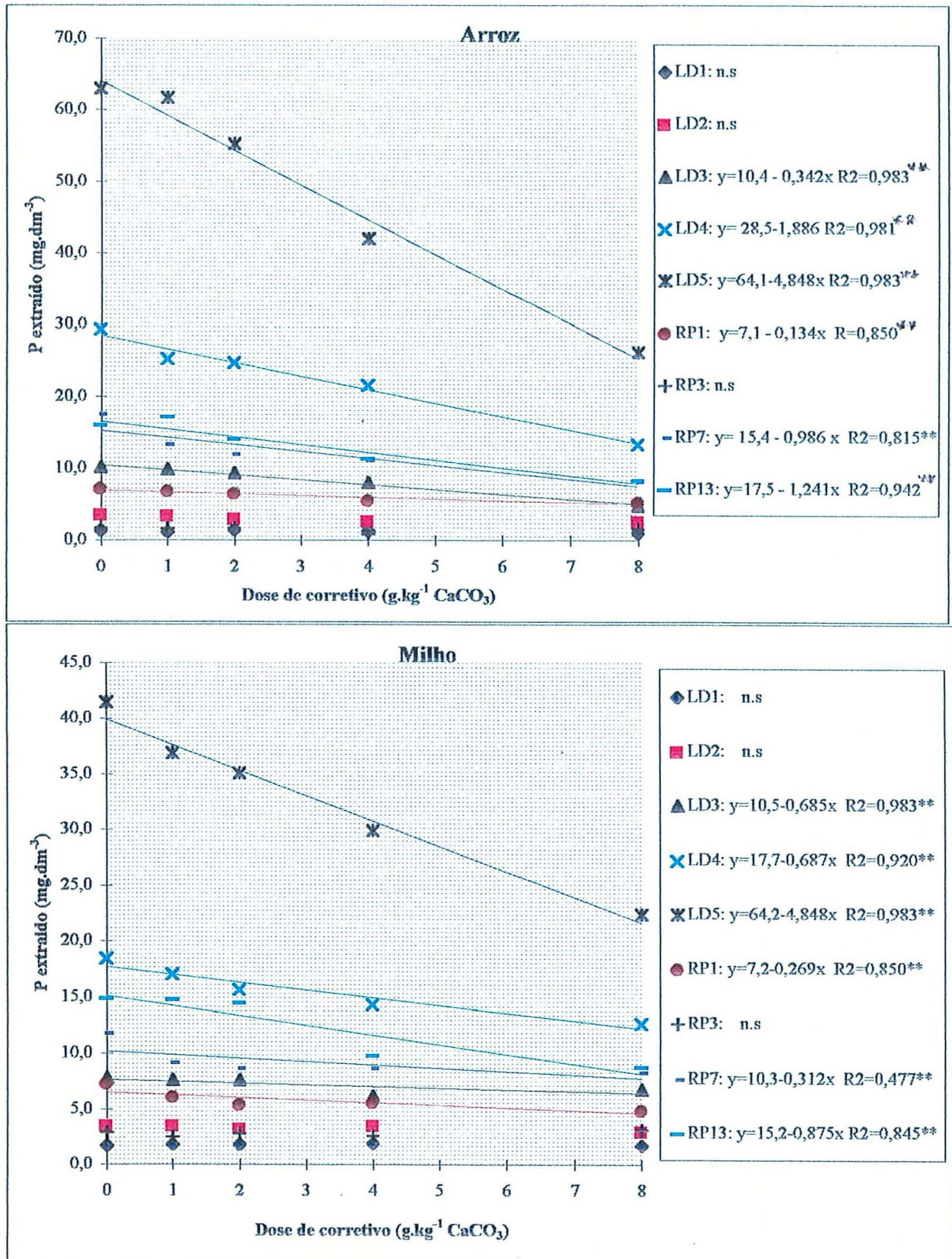

Figura 2 - Fósforo extraído por Bray-1, em função de doses de corretivo, nas amostras de solos (LD1...RP13), antes do cultivo de arroz e milho. 
Os teores de P Bray-1 correlacionaram-se inversamente com os valores de $\mathrm{pH}$ $\mathrm{CaCl}_{2}$ 0,01mol. $\mathrm{L}^{-1}$ na maioria dos solos, com exceção do solo LD1, em ambos os cultivos, e dos solos LD2 e RP3 no cultivo do milho (Tabela 7). Esses resultados são concordantes com os obtidos por BRAGA \& DEFELIPO (1972 a,b) e com as tendências verificadas por VIEGAS (1990) e RAIJ \& QUAGGIO (1990).

$\mathrm{O}$ extrator Bray-1 tem sua capacidade de extração devida à presença do $\mathrm{HCl}$ e do ânion fluoreto. $\mathrm{O} \mathrm{HCl} \mathrm{exerce} \mathrm{uma} \mathrm{ação} \mathrm{solubilizadora} \mathrm{sobre} \mathrm{os} \mathrm{minerais} \mathrm{de} \mathrm{P}$ do solo, especialmente P-Ca. O fluor exerce ação complexadora sobre $\mathrm{Fe}$ e $\mathrm{Al}$, liberando o P ligado a esses metais (THOMAS \& PEASLE, 1973), bem como sobre o Ca das formas de fosfato dicálcico (KAMPRATH \& WATSON, 1980).

Com a calagem, ocorre elevação de pH e as formas P-Al e P-Fe, abundantes em solos ácidos, tornam-se instáveis e solubilizam-se (HSU, 1964; LINDSAY \& MORENO, 1960). No presente trabalho supõe-se aumento das formas de fosfato bicálcicas, o que poderia favorecer a extração. Contudo, houve diminuição de P Bray-1 com o aumento de $\mathrm{pH}$.

Outros aspectos podem estar associados à menor capacidade de extração do Bray-1, tais como a exaustão do extrator devido ao consumo de $\mathrm{H}^{+}$pelo solo (KAMPRATH \& WATSON, 1980, BAHIA FILHO, 1982) e a diminuição da ação do ion fluoreto por sua complexação pelos íons $\mathrm{Ca}^{2+}$ no solo.

A elevação do $\mathrm{pH}$ do solo com a adição de $\mathrm{CaCO}_{3}$ e $\mathrm{MgCO}_{3}$ fornece componentes para a exaustão do extrator Bray-1: o consumo de íons hidrogênio devido à reação com ânions básicos $\mathrm{CO}_{3}{ }^{\circ}, \mathrm{HCO}_{3-}$ e $\mathrm{OH}$ e a redução na capacidade de 


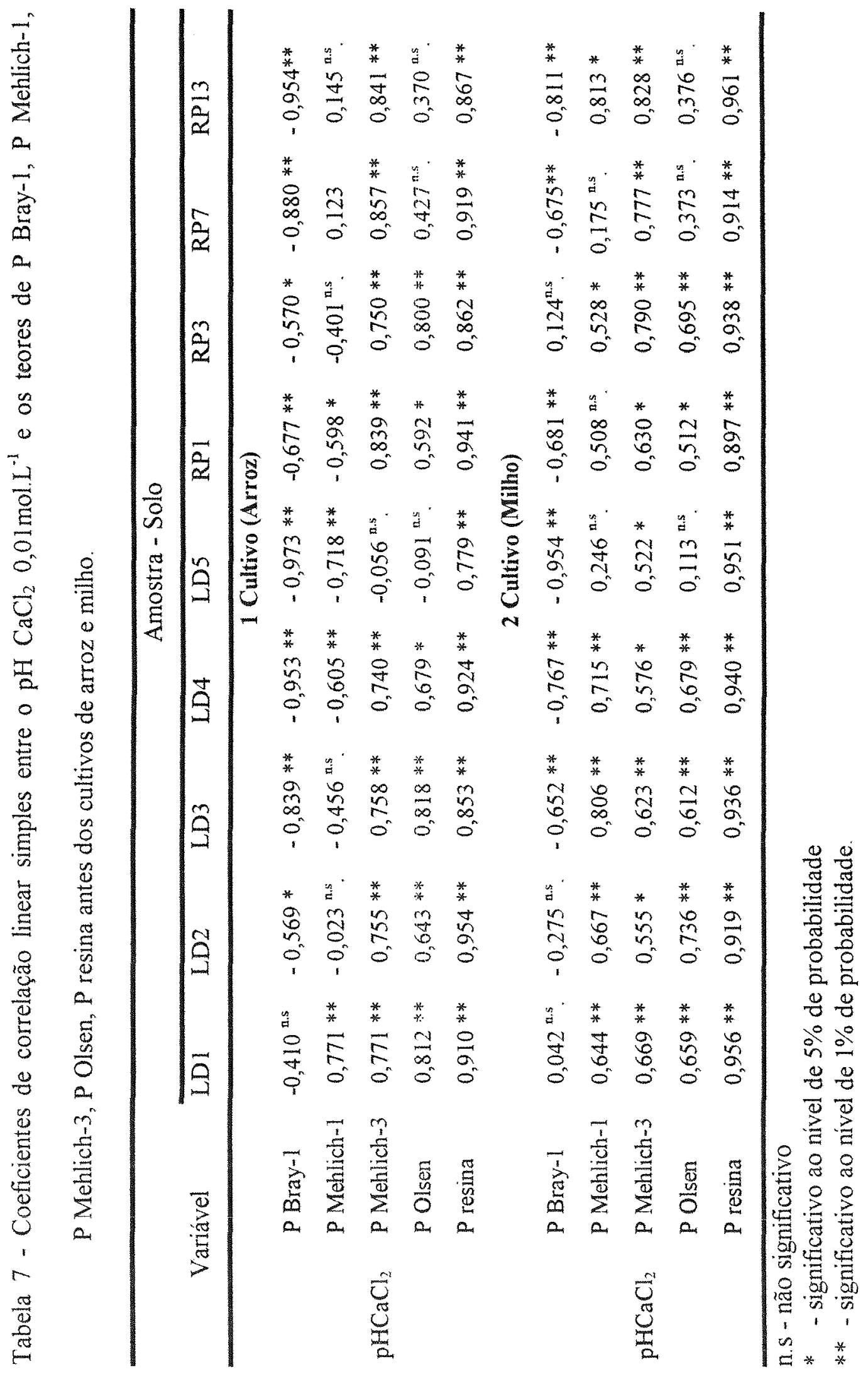


complexação do flúor pela formação de complexos com cálcio livre, após reação do calcário com o $\mathrm{HCl}$ no momento da extração.

No presente trabalho procurou-se verificar a hipótese do consumo de hidrogênio durante o processo de extração. Na Tabela 8 constata-se que a acidez total do extrator Bray-1 foi diminuída com o aumento de doses do corretivo, assim como houve consumo

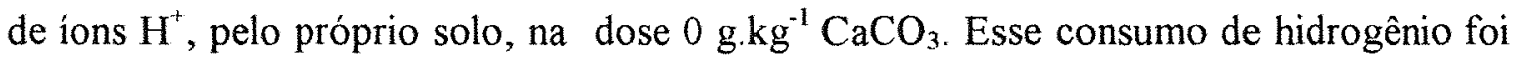
suficiente para ocasionar elevação do pH do extrato (Tabela 9)

A diminuição dos teores de fósforo extraídos por Bray-1 esteve mais relacionada ao processo de diminuição da acidez do extrator, com consequente diminuição de sua capacidade de extração, do que propriamente às mudanças nas formas de fósforo no solo.

A formação de compostos de fósforo ligados ao cálcio (P-Ca) mais estáveis, conforme observaram MENDEZ (1986); BARBOSA FILHO (1986), e sobre as quais o extrator Bray-1 tivesse menor ação, não deve ter influenciado a ação do Bray-1, no período do experimento; como pode ser visto pela variação dos teores de fósforo dos solos, entre cultivos, na dose 0 e $8 \mathrm{~g}^{\mathrm{kg}}{ }^{-1} \mathrm{CaCO}_{3}$ do corretivo (Tabela 6).

$\mathrm{Na}$ dose 0 , quando se compara os teores extraídos de $\mathrm{P}$ Bray-1 nas amostras de solo antes do cultivo do arroz em relação aqueles obtidos antes do cultivo do milho, verifica-se que, com exceção das amostras LD1 e RP3, nas demais amostras houve menor extração de fósforo; ocorrendo ese fenômeno com menor intensidade, na dose 8 g. $\mathrm{kg}^{-1} \mathrm{CaCO}_{3}$, o qual foi observado somente nas amostras de solo LD4, LD5, RP1. De 
Tabela 8 - Volume de $\mathrm{NaOH} 0,025 \mathrm{~mol} \cdot \mathrm{L}^{-1}$ gasto para titular $5 \mathrm{ml}$ de extrato (solo + extrator) de amostras de solo tratadas com diferentes doses de corretivo antes do cultivo de arroz e quantidade de hidrogênio do extrator consumida. Média de três repetições.

\begin{tabular}{|c|c|c|c|c|c|}
\hline \multirow[b]{2}{*}{ Amostra - solo } & \multirow{2}{*}{$\begin{array}{l}\text { Dose de } \\
\text { corretivo }\end{array}$} & \multicolumn{2}{|c|}{ Volume $\mathrm{NaOH}$} & \multicolumn{2}{|c|}{$\mathrm{H}^{+}$consumido } \\
\hline & & Bray-1 & Mehlich-1 & Bray-1 & Mehlich-1 \\
\hline & $-\mathrm{g} \cdot \mathrm{kg}^{-1 \mathrm{CaCO}_{3}}$ & & & $-m$ & \\
\hline & 0 & 2,85 & 15,7 & 0,07 & 0,06 \\
\hline & 1 & 2,85 & 15,0 & 0,07 & 0,09 \\
\hline \multirow[t]{5}{*}{ LD5 } & 2 & 2,62 & 14,8 & 0,08 & 0,10 \\
\hline & 4 & 2,25 & 14,1 & 0,10 & 0,14 \\
\hline & 8 & 1,65 & 13,9 & 0,12 & 0,15 \\
\hline & 0 & 3,30 & 15,8 & 0,06 & 0,05 \\
\hline & 1 & 3,16 & 14,9 & 0,06 & 0,10 \\
\hline \multirow[t]{3}{*}{ RP7 } & 2 & 2,88 & 14,5 & 0,07 & 0,12 \\
\hline & 4 & 2,41 & 14,2 & 0,09 & 0,13 \\
\hline & 8 & 1,54 & 12,0 & 0,12 & 0,24 \\
\hline Extrator & & 4,98 & 16,8 & - & - \\
\hline
\end{tabular}

outra maneira, ao se calcular a diminuição dos teores de P Bray-1, entre cultivos, em valores porcentuais, nas amostras de solo LD4, LD5 e RP1 verifica-se que ela foi de $39 \%, 34 \%, 3 \%$ na dose 0 g. $\mathrm{kg}^{-1} \mathrm{CaCO}_{3}$ e de $5 \%, 15 \%$ e $8 \%$, respectivamente, na dose 8 g. $\mathrm{kg}^{-1} \mathrm{CaCO}_{3}$. Portanto, as maiores reduções de $\mathrm{P}$ Bray-1 ocorreram nas doses mais baixas e não na dose 8, onde é admitido intensa transformação de fósforo para P-Ca, 
Tabela 9 - Valores de $\mathrm{pH}$ dos extratos obtidos com os diferentes extratores antes do cultivo do arroz de amostras de solo tratadas com doses de corretivo.

\begin{tabular}{|c|c|c|c|c|c|c|c|}
\hline \multirow[t]{2}{*}{ Amostra-solo } & \multirow[t]{2}{*}{ Extrator } & \multicolumn{5}{|c|}{ Dose de corretivo $\left(\mathrm{g} \mathrm{kg}^{-1} \mathrm{CaCO}_{3}\right)$} & \multirow[t]{2}{*}{ Extrator } \\
\hline & & $\overline{0}$ & 1 & 2 & 4 & 8 & \\
\hline \multirow[t]{4}{*}{ LD1 } & Bray-1 $1^{1}$ & 4,0 & 3,8 & 4,2 & 4,0 & 4,3 & 2,8 \\
\hline & Mehlich-1 & 1,6 & 1,6 & 1,7 & 1,6 & 1,7 & 1,2 \\
\hline & Mehlich- $3^{2}$ & 3,0 & 3,0 & 3,0 & 3,2 & 3,3 & 2,5 \\
\hline & Olsen ${ }^{i}$ & 8,5 & 8,5 & 8,6 & 8,5 & 8,6 & 8,5 \\
\hline \multirow[t]{4}{*}{ LD2 } & Bray-1 $1^{1}$ & 3,6 & 4,1 & 4,0 & 4,3 & 4,6 & 2,8 \\
\hline & Mehlich-1 & 1,7 & 1,7 & 1,6 & 1,7 & 1,6 & 1,2 \\
\hline & Mehlich- $3^{2}$ & 2,9 & 2,9 & 3,1 & 3,1 & 3,4 & 2,5 \\
\hline & Olsen $^{\mathrm{I}}$ & 8,5 & 8,6 & 8.5 & 8,5 & 8,5 & 8,5 \\
\hline \multirow[t]{4}{*}{ LD3 } & Bray-1 & 3,9 & 3,9 & 3,9 & 3,9 & 4,6 & 2.8 \\
\hline & Mehlich-1 ${ }^{1}$ & 1,6 & 1.6 & 1,7 & 1,6 & 1.8 & 1,2 \\
\hline & Mehlich- $3^{2}$ & 3,0 & 3,0 & 3,1 & 3,2 & 3,3 & 2,5 \\
\hline & Olsen ${ }^{1}$ & 8,5 & 8,5 & 8,6 & 8,5 & 8,6 & 8,5 \\
\hline \multirow[t]{4}{*}{ LD4 } & Bray-1 ${ }^{1}$ & 3,5 & 4,2 & 4,1 & 4,2 & 4,3 & 2,8 \\
\hline & Mehlich-1 & 1,7 & 1,7 & 1,6 & 1,7 & 1.6 & 1,2 \\
\hline & Mehlich-3 $3^{2}$ & 2,9 & 3,0 & 3,1 & 3,2 & 3,4 & 2,5 \\
\hline & Olsen $^{1}$ & 8,6 & 8,5 & 8,5 & 8,6 & 8,5 & 8,5 \\
\hline \multirow[t]{4}{*}{ LD5 } & Bray-1 ${ }^{l}$ & 3,8 & 4,2 & 4,0 & 4,3 & 4,9 & 2,8 \\
\hline & Mehlich-1 & 1.7 & 1,7 & 1,6 & 1,6 & 1,6 & 1,2 \\
\hline & Mehlich $-3^{2}$ & 2,9 & 2,9 & 3,1 & 3,1 & 3,3 & 2,5 \\
\hline & Olsen & 8,5 & 8,6 & 8,5 & 8,5 & 8,5 & 8,5 \\
\hline \multirow[t]{4}{*}{ RPI } & Bray-1 $1^{1}$ & 4,2 & 4,5 & 4,6 & 4,6 & 4,9 & 2,8 \\
\hline & Mehlich-1 & 1,6 & 1,6 & 1,7 & 1,6 & 1.8 & 1,2 \\
\hline & Mehlich- $3^{2}$ & 3,2 & 3,2 & 3,2 & 3,4 & 3,5 & 2.5 \\
\hline & Olsen ${ }^{1}$ & 8,5 & 8,5 & 8,6 & 8,5 & 8,6 & 8,5 \\
\hline \multirow[t]{4}{*}{ RP3 } & Bray-1 ${ }^{1}$ & 3,8 & 4,2 & 4,1 & 4,5 & 4,6 & 3.8 \\
\hline & Mehlich-1 & 1,7 & 1,7 & 1,6 & 1,7 & 1.7 & 1,2 \\
\hline & Mehlich- $3^{2}$ & 3,1 & 3,1 & 3.2 & 3,3 & 3,4 & 2,5 \\
\hline & Olsen ${ }^{1}$ & 8.5 & 8,6 & 8,5 & 8,5 & 8,6 & 8,5 \\
\hline \multirow[t]{4}{*}{ RP7 } & Bray-l ${ }^{1}$ & 3,6 & 4,4 & 4,4 & 4,6 & 4,8 & 2,8 \\
\hline & Mehlich-1 ${ }^{1}$ & 1,7 & 1,7 & 1,6 & 1,7 & 1,6 & 1,2 \\
\hline & Mehlich $-3^{2}$ & 3.0 & 3,1 & 3,2 & 3.2 & 3,5 & 2,5 \\
\hline & Olsen $^{1}$ & 8,6 & 8,6 & 8,5 & 8,5 & 8,5 & 8,5 \\
\hline \multirow[t]{4}{*}{ RP13 } & $B r a y-1^{1}$ & 4,3 & 4,3 & 4,5 & 4.5 & 4,6 & 2.8 \\
\hline & Mehlich-1' & 1.6 & 1,6 & 1,7 & 1,6 & 1,7 & 1,2 \\
\hline & Mehlich- $3^{2}$ & 3,1 & 3.1 & 3,1 & 3.3 & 3,4 & 2.5 \\
\hline & Olsen $^{1}$ & 8,5 & 8.5 & 8,6 & 8.5 & 8.6 & 8.5 \\
\hline
\end{tabular}

1 - Média de três repetições

2 - Sem repetição 
menos solúveis, e sobre as quais o extrator Bray-1 teria menor atuação, como registrado por FEITOSA \& RAIJ (1976); SFREDO et al. (1979); FIGUEROA (1984).

\subsubsection{Extrator Mehlich-1}

Os teores de fósforo extraídos por Mehlich-1 diferiram entre solos e entre doses nos dois cultivos, mas a interação foi significativa somente no experimento com arroz (Tabela 2). Neste, ocorreram diferenças entre solos em todos os níveis de carbonatos aplicados (Tabela 10).

O efeito de doses de corretivo na extração de fósforo pelo Mehlich-1 diferiu entre os dois cultivos. Nas amostras coletadas antes do cultivo de arroz predomina efeito de diminuição da extração com o aumento da dose, e nas amostras coletadas antes do cultivo do milho aconteceu o oposto: tendência de maior extração de P Mehlich-1 com o aumento da dose (Figura 3). No cultivo com arroz, nas amostras de solos onde as regressões foram significativas, elas foram lineares inversas, exceto no solo RP13 cuja regressão foi quadrática. No cultivo com milho, onde não foi observado interação entre doses e solos, os dados ajustaram-se a uma regressão linear direta. Convém destacar que os teores de $\mathrm{P}$ Mehlich-1, no cultivo de milho, foram ligeiramente maiores que os observados no cultivo com arroz, na maioria dos tratamentos.

$\mathrm{Na}$ literatura tem-se registrado comportamento diferente do extrator Mehlich-1 em função do $\mathrm{pH}$ em solos que receberam fonte solúvel de fósforo. Aumentos 
Tabela 10- Teores de fósforo extraídos por Mehlich-1, em mg.dm ${ }^{-3}$, de amostras de solo submetidas a doses de corretivo, em g. $\mathrm{kg}^{-1} \mathrm{CaCO}_{3}$ antes dos cultivos de arroz e milho. Média de três repetições ${ }^{1}$

\begin{tabular}{crrrrrr}
\hline Amostra-solo & \multicolumn{7}{c}{ Dose de corretivo ( $\left.\mathrm{gkg}^{-1} \mathrm{CaCO}_{3}\right)$} \\
\hline & 0 & 1 & 2 & 4 & 8 & Média \\
\hline LD1 & $1,7 \mathrm{f}$ & $1,8 \mathrm{f}$ & $2,0 \mathrm{~g}$ & $2,2 \mathrm{f}$ & $2,2 \mathrm{fg}$ & 1,9 \\
LD2 & $5,5 \mathrm{e}$ & $5,4 \mathrm{de}$ & $5,4 \mathrm{ef}$ & $5,3 \mathrm{e}$ & $5,5 \mathrm{de}$ & 5,4 \\
LD3 & $12,6 \mathrm{c}$ & $12,9 \mathrm{c}$ & $12,9 \mathrm{c}$ & $12,9 \mathrm{c}$ & $10,5 \mathrm{c}$ & 12,4 \\
LD4 & $30,6 \mathrm{~b}$ & $28,4 \mathrm{~b}$ & $29,7 \mathrm{~b}$ & $30,7 \mathrm{~b}$ & $25,1 \mathrm{~b}$ & 28,9 \\
LD5 & $64,1 \mathrm{a}$ & $62,9 \mathrm{a}$ & $61,8 \mathrm{a}$ & $63,7 \mathrm{a}$ & $55,2 \mathrm{a}$ & 61,5 \\
RP1 & $5,7 \mathrm{e}$ & $4,4 \mathrm{e}$ & $4,6 \mathrm{f}$ & $4,7 \mathrm{e}$ & $4,3 \mathrm{ef}$ & 4,7 \\
RP3 & $1,3 \mathrm{f}$ & $1,0 \mathrm{f}$ & $1,4 \mathrm{~g}$ & $1,2 \mathrm{f}$ & $0,9 \mathrm{~g}$ & $.1,2$ \\
RP7 & $7,8 \mathrm{de}$ & $7,5 \mathrm{~d}$ & $7,3 \mathrm{de}$ & $7,9 \mathrm{~d}$ & $7,7 \mathrm{~d}$ & 7,7 \\
RP13 & $8,6 \mathrm{~d}$ & $7,8 \mathrm{~d}$ & $8,3 \mathrm{~d}$ & $11,0 \mathrm{c}$ & $7,5 \mathrm{~d}$ & 8,6 \\
& & & $2^{\circ}$ Cultivo (Milho) & & \\
LD1 & 2,2 & 2,2 & 2,0 & 2,1 & 2,6 & $2,2 \mathrm{~g}$ \\
LD2 & 5,5 & 5,4 & 5,1 & 5,9 & 6,9 & $5,8 \mathrm{f}$ \\
LD3 & 12,1 & 12,5 & 13,6 & 14,9 & 15,7 & $13,8 \mathrm{c}$ \\
LD4 & 32,2 & 33,4 & 33,6 & 36,2 & 36,1 & $34,3 \mathrm{~b}$ \\
LD5 & 66,2 & 65,7 & 64,6 & 65,8 & 68,2 & $66,1 \mathrm{a}$ \\
RP1 & 5,4 & 5,2 & 5,2 & 5,7 & 6,7 & $5,6 \mathrm{f}$ \\
RP3 & 1,5 & 1,8 & 1,7 & 1,9 & 1,9 & $1,7 \mathrm{~g}$ \\
RP7 & 8,2 & 6,9 & 6,5 & 6,9 & 8,8 & $7,4 \mathrm{e}$ \\
RP13 & 8,8 & 8,9 & 8,8 & 10,1 & 12,3 & $9,8 \mathrm{~d}$ \\
\hline
\end{tabular}

1 Médias seguidas pela mesma letra na coluna dentro de cada cultivo, não diferem entre si, ao nível de $5 \%$ pelo teste Tukey. C.V. arroz $=6,25 \%$ e C.V. milho $=8,37 \%$ 


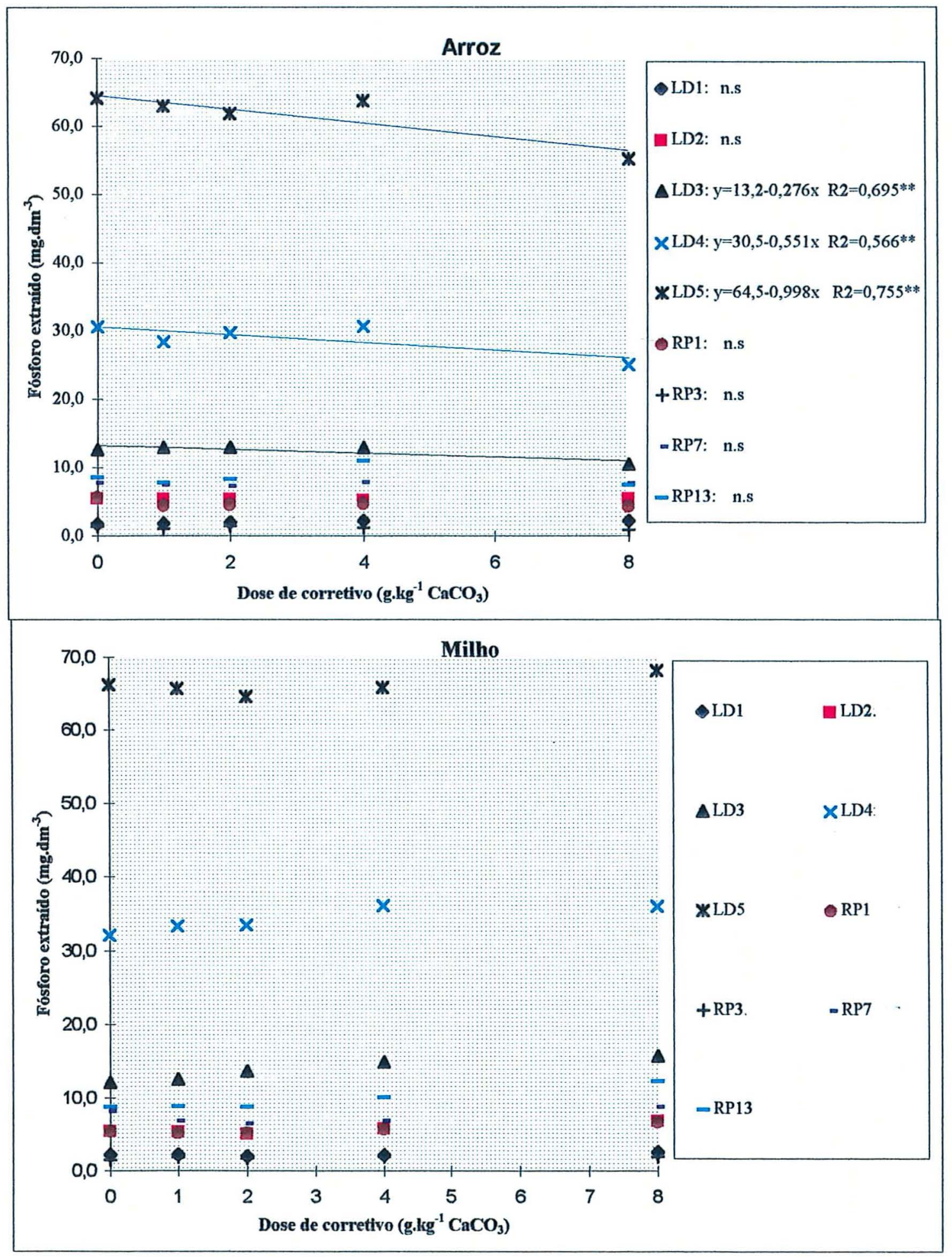

Figura 3 - Fósforo extraído por Mehlich-1, em função de doses de corretivo, nas amostras de solos (LD1...RP13), antes do cultivo de arroz e milho. 
na extração, com o aumento de pH, foram registrados por BRAGA \& DEFELIPO (1972 a, b), por RAIJ \& QUAGGIO (1990), e por PAYTON et al. (1989); enquanto diminuições foram observadas por OLAYA (1988) e VIEGAS (1990), e finalmente nenhuma variação significativa foi observada por MENDEZ (1986) e por RESENDE (1974)

Esses resultados parecem estar associados ao tempo de reação. Na presente pesquisa, o tempo decorrido entre o cultivo com arroz e o do milho foi aproximadamente nove meses, abrangendo o período de cultivo de arroz, quando as amostras de solos foram umedecidas continuamente. Isto deve ter favorecido a formação e estabilização de formas de P-Ca em quantidades suficientes para influenciar a extração por Melhich-1.

PAYTON et al. (1989), trabalhando em condições de campo, verificaram que a aplicação de doses crescentes de corretivo em um solo Ochraqualfs, resultou valores de pH iguais a 4,8,5,4,6,1 e 6,5. Um ano após, aplicaram fósforo e estudaram o efeito residual durante três anos. Verificaram que a produção de batata decresceu entre 20 a $70 \%$ dependendo do $\mathrm{pH}$. Associaram esse efeito a um decréscimo na disponibilidade do fósforo residual do solo, o qual não foi acompanhado por um decréscimo no $\mathrm{P}$ extraído por Mehlich-1.

O extrator Mehlich-1 também apresentou diminuição da acidez com o aumento da dose de corretivo (Tabela 8). Verifica-se que ocorreu maior consumo de hidrogênio em mg. $\mathrm{mL}^{-1}$ de solo, quando comparado ao Bray-1, provavelmente devido à maior acidez total do extrator Mehlich-1. No entanto, os efeitos dessa exaustão foram de menor magnitude no Mehlich-1 que no Bray-1. A solução extratora apresentou pH de 1,2 
(Tabela 9). Em contato com o solo, o pH variou quase sempre de 1,6 a 1,7 independente do tratamento, não obstante o maior consumo de $\mathrm{H}^{+}$nas doses mais altas de corretivo.

A diferença de comportamento na extração entre os dois cultivos parece estar mais associada a mudanças de formas no solo que à exaustão do extrator, embora, possivelmente isto também tenha contribuído. NAIDU et al. (1987) observaram decréscimo na extração de $\mathrm{P}$ com o aumento do $\mathrm{pH}$ e, quando esse foi mantido constante durante a extração, através da autotitulação, não foi observado nenhum decréscimo no fósforo extraído por Mehlich-1.

A correlação entre $\mathrm{pH}$ em $\mathrm{CaCl} 2 \quad 0,01 \mathrm{~mol}^{-1} \mathrm{~L}^{-1}$ e $\mathrm{P}$ Mehlich-1 foi de menor intensidade que a observada para Bray-1 (Tabela 7), assim como os efeitos de pH na extração de Mehlich-1 foram menores

\subsection{3. - Extrator Mehlich-3}

Ocorreram efeitos significativos de solos e doses de corretivo sobre os teores de fósforo extraído por Mehlich-3, bem como foram significativas suas interações, em ambos os cultivos (Tabela 2).

A ordem das amostras, segundo o teor de fósforo extraído foi a mesma nos dois cultivos (Tabela11). No cultivo com arroz houve maior discriminação entre solos que no cultivo com milho, naqueles tratamentos que receberam corretivo. Houve diferenças significativas entre as amostras de terra em todas as doses e em ambos cultivos. 
Tabelal1 - Teores de fósforo extraídos por Mehlich-3, em mg.dm ${ }^{-3}$, de amostras de solo submetidas a doses de corretivo, em g. $\mathrm{kg}^{-1} \mathrm{CaCO}_{3}$, antes dos cultivos de arroz e milho. Média de três repetições'

\begin{tabular}{|c|c|c|c|c|c|}
\hline \multicolumn{6}{|c|}{ Dose de corretivo $\left(\mathrm{g} \cdot \mathrm{kg}^{-1} \mathrm{CaCO}_{3}\right)$} \\
\hline Amostra-solo & 0 & 1 & 2 & 4 & 8 \\
\hline & \multicolumn{5}{|c|}{$1^{\circ}$ Cultivo (Arroz) } \\
\hline LD1 & $1,8 \mathrm{e}$ & $1,7 \mathrm{f}$ & $1,8 \mathrm{~g}$ & $1,9 \mathrm{~g}$ & $2,9 \mathrm{~g}$ \\
\hline LD2 & 3,9 e & $5,0 \mathrm{e}$ & $4,5 \mathrm{f}$ & $5,4 \mathrm{f}$ & $6,2 \mathrm{f}$ \\
\hline LD3 & $13,3 \mathrm{c}$ & $13,6 \mathrm{c}$ & $14,0 \mathrm{~d}$ & $14,7 \mathrm{~d}$ & $15,1 \mathrm{e}$ \\
\hline LD4 & $30,5 \mathrm{~b}$ & $29,1 \mathrm{~b}$ & $30,4 \mathrm{~b}$ & $31,6 \mathrm{~b}$ & $32,9 \mathrm{~b}$ \\
\hline LD5 & $60,6 \mathrm{a}$ & $63,2 \mathrm{a}$ & $60,2 \mathrm{a}$ & $61,8 \mathrm{a}$ & $61,0 \mathrm{a}$ \\
\hline RP1 & $8,2 \mathrm{~d}$ & $7,4 \mathrm{~d}$ & $7,8 \mathrm{e}$ & $9,3 \mathrm{e}$ & $13,1 \mathrm{e}$ \\
\hline RP3 & $3,1 \mathrm{e}$ & $1,9 \mathrm{f}$ & $3,2 \mathrm{fg}$ & $3,4 \mathrm{fg}$ & $5,1 \mathrm{fg}$ \\
\hline RP7 & $14,1 \mathrm{c}$ & $13,3 \mathrm{c}$ & $13,3 \mathrm{~d}$ & $17,6 \mathrm{c}$ & $18,8 \mathrm{~d}$ \\
\hline \multirow[t]{2}{*}{ RP13 } & $14,6 \mathrm{c}$ & $15,2 \mathrm{c}$ & $16,6 \mathrm{c}$ & $19,5 \mathrm{c}$ & $25,5 \mathrm{c}$ \\
\hline & \multicolumn{5}{|c|}{$2^{\circ}$ Cultivo (Milho) } \\
\hline LD 1 & $3,0 \mathrm{f}$ & $2,6 \mathrm{e}$ & $2,8 \mathrm{e}$ & $3,3 \mathrm{e}$ & $4,0 \mathrm{e}$ \\
\hline LD2 & 4,5 ef & $4,8 \mathrm{de}$ & $4,4 \mathrm{de}$ & $4,8 \mathrm{de}$ & $6,1 \mathrm{e}$ \\
\hline LD3 & $10,3 \mathrm{~cd}$ & $11,5 \mathrm{c}$ & $11,6 \mathrm{c}$ & $12,9 \mathrm{c}$ & $13,1 \mathrm{~d}$ \\
\hline LD4 & $22,7 b$ & $24,0 \mathrm{~b}$ & $21,6 \mathrm{~b}$ & $22,6 \mathrm{~b}$ & $29,3 \mathrm{~b}$ \\
\hline LD5 & $52,3 \mathrm{a}$ & $55,3 \mathrm{a}$ & $57,8 \mathrm{a}$ & $58,5 \mathrm{a}$ & $57,4 \mathrm{a}$ \\
\hline RP1 & $6,9 \mathrm{de}$ & $7,6 \mathrm{~d}$ & $7,0 \mathrm{~d}$ & $8,0 \mathrm{~d}$ & $13,6 \mathrm{~d}$ \\
\hline RP3 & $2,8 \mathrm{f}$ & $3,6 \mathrm{e}$ & $3,7 \mathrm{de}$ & $3,6 \mathrm{e}$ & $5,2 \mathrm{e}$ \\
\hline RP7 & $11,2 \mathrm{c}$ & $12,6 \mathrm{c}$ & $11,2 \mathrm{c}$ & $14,4 \mathrm{c}$ & $20,6 \mathrm{c}$ \\
\hline RP13 & $11,4 \mathrm{c}$ & $12,1 \mathrm{c}$ & $12,6 \mathrm{c}$ & $14,5 \mathrm{c}$ & $20,2 \mathrm{c}$ \\
\hline
\end{tabular}

1 - Média seguidas pela mesma letra na coluna dentro de cada, cultivo, não diferem entre si, ao nivel de $5 \%$ pelo teste Tukey. CV arroz $=5,06 \%$ e CV milho $=15,64 \%$ 
A quantidade de fósforo extraida pelo extrator Mehlich-3 aumentou com a dose de carbonatos em quase todas as combinações de solos no dois cultivos, segundo as equações lineares indicadas na Figura 4. Aumentos dos teores extraídos de fósforo, por esse extrator, com aumento de $\mathrm{pH}$ foram registrados em condições de campo por SIMARD \& LAPIERRE (1994) e em casa de vegetação por OLAYA (1988).

Na Tabela 9 observa-se que ocorreu diminuição da acidez do extrator Mehlich-3 devido ao efeito de doses e ao contato com o solo. $\mathrm{O} \mathrm{pH}$ inicial do extrator puro foi de 2,5 e, na presença de solo, o seu pH atingiu valor 3,0 e aumentou com as doses até atingir $\mathrm{pH}$ ao redor de 3,5 na dose $8 \mathrm{~g} \mathrm{~kg}^{-1} \mathrm{CaCO}_{3}$. Esta diminuição de acidez do extrator não comprometeu o poder de extração, já que os teores extraídos aumentaram com a dose do corretivo.

$\mathrm{O}$ extrator Mehlich-3 apresenta acidez ativa $(\mathrm{pH}=3,5)$ menor que o extrator Mehlich-1 $(\mathrm{pH}=1,2)$ mas, a acidez total $\left(\mathrm{CH}_{3} \mathrm{COOH} \quad 0,2\right.$ mol.L $\mathrm{L}^{-1}+\mathrm{NH}_{4} \mathrm{NO}_{3} \quad 0,02$ mol. $\left.\mathrm{L}^{-1}+\mathrm{NH}_{4} \mathrm{~F} \quad 0,015 \mathrm{~mol} \cdot \mathrm{L}^{-1}+\mathrm{HNO}_{3} 0,013 \mathrm{~mol} \cdot \mathrm{L}^{-1}+\mathrm{EDTA} 0,01 \mathrm{~mol} \cdot \mathrm{L}^{-1}\right)$ é maior que a do extrator Mehlich-1 $\left(\mathrm{H}_{2} \mathrm{SO}_{4} 0,0125 \mathrm{~mol} . \mathrm{L}^{-1}+\mathrm{HCl} 0,05 \mathrm{~mol} . \mathrm{L}^{-1}\right)$. Outro aspecto é que essa acidez é caracterizada por um ácido mais fraco (acido acético) que tampona o meio e atenua os efeitos de consumo de íons hidrogênio. Apesar da natureza ácida desses extratores, os resultados das análises apontam para modo de ação diferentes entre si. A acidez ativa mais fraca do extrator Mehlich-3 exerce menor influência nas formas de P-Ca do que o extrator Mehlich-1, justificando a menor extração por Mehlich-3, nas amostras antes do cultivo do milho. 

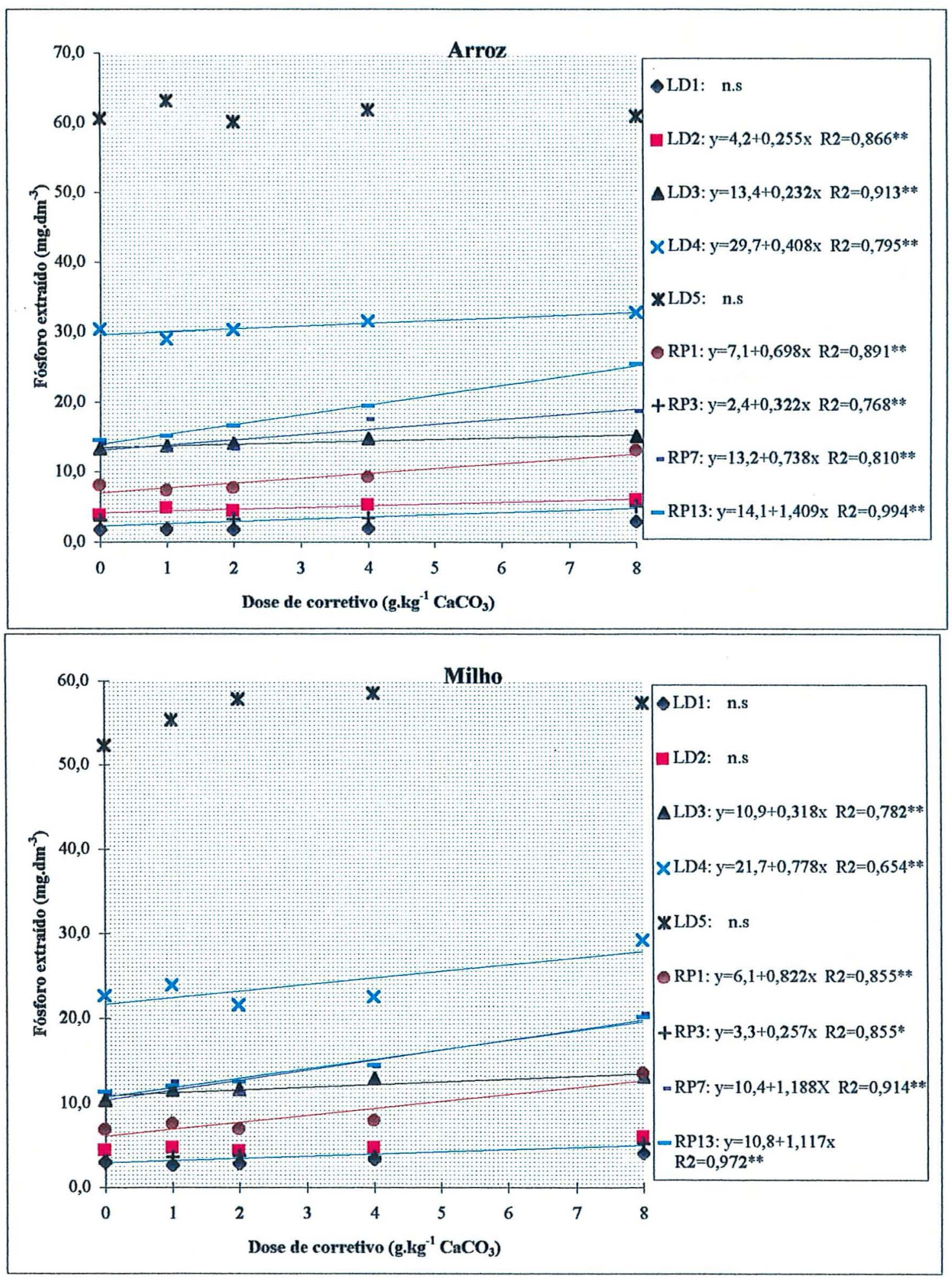

Figura 4 - Fósforo extraído por Mehlich-3, em função de doses de corretivo, nas amostras de solos (LD1...RP13), antes do cultivo de arroz e milho. 
Os coeficientes de correlação entre $\mathrm{pH}$ em $\mathrm{CaCl}_{2} \quad 0,01$ mol. $\mathrm{L}^{-1}$ e $\mathrm{P}$ Mehlich-3 dentro de cada solo (Tabela 7) foram quase sempre maiores que os observados entre $\mathrm{pH}$ e P Mehlich-1, no experimento com arroz em todos os solos. No experimento com milho, observa-se que houve efeito da localização dos solos: os coeficientes de correlação para Mehlich-3 foram geralmente menores que os para Mehlich-1 nos solos provenientes de Londrina-PR e maiores nos solos provenientes de Ribeirão Preto-SP.

\subsection{4. - Extrator Olsen}

Os teores de fósforo extraídos por Olsen diferiram entre solos, dose e foi significativa a interação dose $\mathrm{x}$ solo (Tabela 2). Houve diferenças significativas entre solos, em todas as doses de corretivo (Tabelal2).

A extração de fósforo por Olsen foi influenciada pelas doses do corretivo. Diferentemente do observado com os outros extratores, em quase todos os solos os teores de P Olsen inicialmente decresceram com o aumento da dose de corretivo,

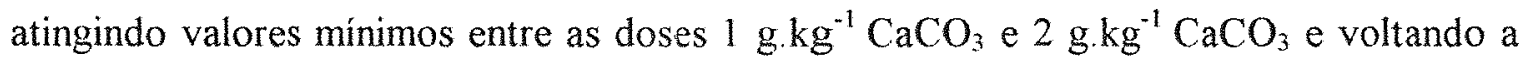
elevar-se até a dose $8 \mathrm{~g} \mathrm{~kg}^{-1} \mathrm{CaCO}_{3}$, na qual os teores extraídos foram superiores aos obtidos na dose $0 \mathrm{~g} \cdot \mathrm{kg}^{-1} \mathrm{CaCO}_{3}$. A exceção ficou para o solo $\mathrm{LD} 5$, no cultivo do arroz, cujo valor máximo foi observado na dose $0 \mathrm{~g} \cdot \mathrm{kg}^{-1} \mathrm{CaCO}_{3}$ e o valor mínimo na dose 1 g. $\mathrm{kg}^{-1} \mathrm{CaCO}_{3}$.

Considerando-se cada solo separadamente, verificou-se que na maioria dos solos os teores de P Olsen em função de doses ajustaram-se ao modelo quadrático (Figura 5) 
Tabela12 - Teores de fósforo extraídos por Olsen, em $\mathrm{mg} \cdot \mathrm{dm}^{-3}$, de amostras de solo submetidas a doses de corretivo, em $\mathrm{g} \cdot \mathrm{kg}^{-1} \mathrm{CaCO}_{3}$, antes dos cultivos de arroz e milho. Média de três repetições ${ }^{1}$.

\begin{tabular}{|c|c|c|c|c|c|}
\hline \multirow[b]{2}{*}{ Amostra-solo } & \multicolumn{4}{|c|}{ Dose de corretivo (g.kg ${ }^{\text {'1 }} \mathrm{CaCO}_{3}$ ) } & \multirow[b]{2}{*}{8} \\
\hline & 0 & 1 & 2 & 4 & \\
\hline & \multicolumn{5}{|c|}{$1^{\circ}$ Cultivo (Arroz) } \\
\hline LDI & $2,5 \mathrm{~g}$ & $2,5 \mathrm{f}$ & $2,7 \mathrm{e}$ & $3,4 \mathrm{e}$ & $5,6 \mathrm{~g}$ \\
\hline LD2 & $7,0 \mathrm{f}$ & $5,9 \mathrm{e}$ & $5,6 \mathrm{e}$ & $6,4 \mathrm{e}$ & $9,3 \mathrm{f}$ \\
\hline LD3 & $13,5 \mathrm{de}$ & $12,1 \mathrm{~d}$ & $13,8 \mathrm{c}$ & $15,6 \mathrm{c}$ & $18,4 \mathrm{~d}$ \\
\hline LD4 & $30,2 \mathrm{~b}$ & $28,6 b$ & $27,0 \mathrm{~b}$ & $30,8 \mathrm{~b}$ & $36,0 \mathrm{~b}$ \\
\hline LD5 & $56,8 \mathrm{a}$ & $48,7 a$ & $50,7 \mathrm{a}$ & $50,1 \mathrm{a}$ & $53,8 \mathrm{a}$ \\
\hline RPI & $10,6 \mathrm{e}$ & $10,9 d$ & $9,7 \mathrm{~d}$ & $10,6 \mathrm{~d}$ & $14,0 \mathrm{e}$ \\
\hline RP3 & $2,8 \mathrm{~g}$ & $2,9 \mathrm{ef}$ & $3,3 \mathrm{e}$ & $3,4 \mathrm{e}$ & $4,7 \mathrm{~g}$ \\
\hline RP7 & $15,0 \mathrm{~d}$ & $14,1 \mathrm{~d}$ & $12,7 \mathrm{~cd}$ & $13,4 \mathrm{~cd}$ & $17,1 \mathrm{de}$ \\
\hline \multirow[t]{2}{*}{ RP13 } & $18,5 \mathrm{c}$ & $18,2 \mathrm{c}$ & $15,0 \mathrm{c}$ & $16,5 \mathrm{c}$ & $22,9 \mathrm{c}$ \\
\hline & \multicolumn{5}{|c|}{$2^{\circ}$ Cultivo (Milho) } \\
\hline LD1 & $3,6 \mathrm{f}$ & $2,3 \mathrm{~g}$ & $2,4 \mathrm{f}$ & $3,3 \mathrm{gh}$ & $4,9 \mathrm{~g}$ \\
\hline LD2 & $5,0 \mathrm{f}$ & $5,1 \mathrm{fg}$ & 4,8 ef & $5,6 \mathrm{fg}$ & $9,0 \mathrm{f}$ \\
\hline LD3 & $10,7 \mathrm{de}$ & $9,2 \mathrm{de}$ & $9,9 \mathrm{~d}$ & $10,7 \mathrm{de}$ & $17,2 \mathrm{~cd}$ \\
\hline LD4 & $24,1 \mathrm{~b}$ & $22,7 b$ & $22,9 \mathrm{~b}$ & $25,0 \mathrm{~b}$ & $32,0 \mathrm{~b}$ \\
\hline LD5 & $50,1 \mathrm{a}$ & $42,0 \mathrm{a}$ & $43,2 \mathrm{a}$ & 38,1 a & $50,9 \mathrm{a}$ \\
\hline RP1 & $9,0 \mathrm{e}$ & 7,9 ef & $6,3 \mathrm{e}$ & 8,0 ef & $13,8 \mathrm{e}$ \\
\hline RP3 & $2,2 \mathrm{f}$ & $2,5 \mathrm{~g}$ & $2,6 \mathrm{f}$ & $2,2 \mathrm{~h}$ & $4,1 \mathrm{~g}$ \\
\hline RP7 & $12,2 \mathrm{~d}$ & $12,1 \mathrm{~d}$ & $10,9 \mathrm{~d}$ & $11,4 \mathrm{~d}$ & $15,0 \mathrm{de}$ \\
\hline RP13 & $17,0 \mathrm{c}$ & $15,3 \mathrm{c}$ & $15,0 \mathrm{c}$ & $15,5 \mathrm{c}$ & $18,5 \mathrm{c}$ \\
\hline
\end{tabular}

1 - Médias seguidas pela mesma letra minúscula, na coluna (solos), não diferem entre si, ao nivel de $5 \%$ pelo teste Tukey. C.V. arroz $=7,46 \%$ e C.V. milho $=7,89 \%$. 

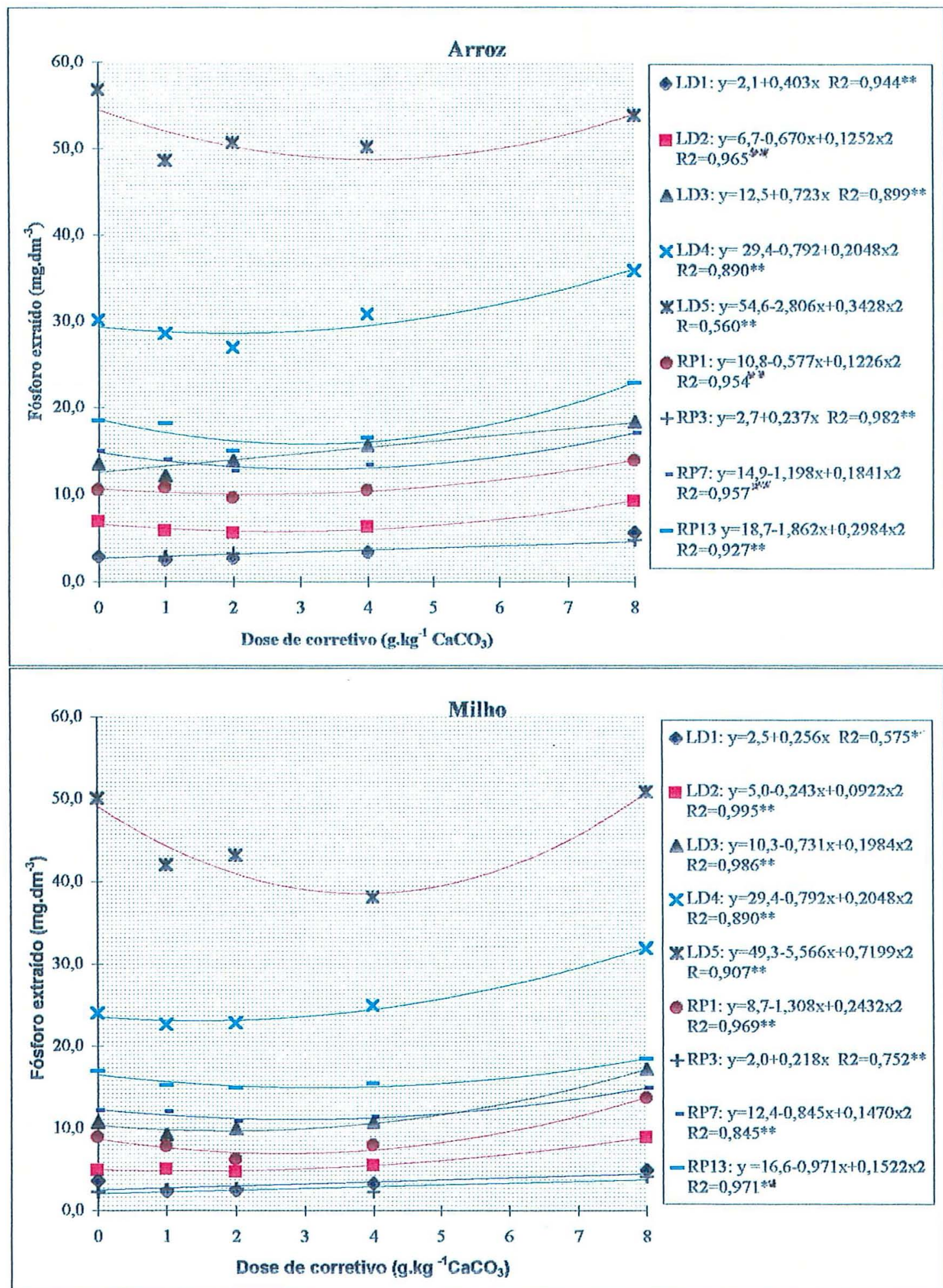

Figura 5 - Fósforo extraído por Olsen,em função de doses de corretivo, nas amostras de solos (LD1...RP13), antes do cultivo de arroz e milho. 
Não houve ajuste ao modelo quadrático nos solos LD1, LD3 e RP3 para o arroz e solos RP3 e LD1 para o milho: nestes solos os dados ajustaram-se ao modelo linear.

Aumentos de P Olsen com o $\mathrm{pH}$ foram registrados por BRAGA \& DEFELIPO (1972 a,b) e por MENDEZ (1986), decréscimos por RAIJ \& QUAGGIO (1990), e alteração não significativa por CAJUSTE et al. (1994). Esses efeitos parecem estar associados à faixa de $\mathrm{pH}$ considerada na avaliação do fósforo extraído por Olsen. $\mathrm{Na}$ presente pesquisa, o intervalo de $\mathrm{pH}$ em $\mathrm{CaCl} 20,01 \mathrm{M}$ possibilitado pelas doses 1 e 2 g. $\mathrm{kg}^{-1} \mathrm{CaCO}_{3}$ foi de 4,2 a 5,5 (Tabela 3 ).

NAIDU et al. (1987) obtiveram relação semelhante entre pH e P Olsen em quatro solos diferentes, submetidos a doses de $\mathrm{Ca}(\mathrm{OH})_{2}$ e fósforo, nesta seqüência. Registraram intervalo de $\mathrm{pH}$ entre 3 e 8 , e extração mínima de P Olsen entre pH 5,5 e 6,0. A extração aumentou quando os índices estavam acima destes valores, particularmente nos solos que receberam doses altas de fósforo. Atribuíram este fenômeno a dois efeitos opostos de equilibrio de solubilidade ocorrendo durante a extração de $\mathrm{P}$ Olsen: uma interação entre $\mathrm{Ca}^{2+}$ e $\mathrm{CO}_{3}{ }^{2-}$ e também entre $\mathrm{Ca}$ e o P liberado. A rápida liberação de $\mathrm{P}$ sorvido durante a extração de Olsen de solos tratados com calcário com pH elevados à faixa de 5,5-6,0, aumentaria a concentração de $\mathrm{P}$ em níveis que provavelmente causariam precipitação do fosfato como compostos de $\mathrm{P}-\mathrm{Ca}$. Em valores de $\mathrm{pH}$ mais altos a reação entre $\mathrm{Ca}^{2+}$ e $\mathrm{CO}_{3}{ }^{2-}$ formando $\mathrm{CaCO}_{3}$, reduziria consideravelmente a concentração de $\mathrm{Ca}$ no meio, minimizando as reações deste com o P, como sugerido por OLSEN et al. (1954). 
Nos solos LD1 e RP3, com teores de P Olsen menor que 3,0 mg. $\mathrm{dm}^{-3}$, o efeito de diminuição de $\mathrm{P}$ Olsen nos valores intermediários de $\mathrm{pH}$ não ficaram bem caracterizados. No solo LD5, que apresentou maior teor P Olsen na dose inicial $(\mathrm{pH}$ 3,7), ocorreu decréscimo entre as doses 1 e $4 \mathrm{~g} \cdot \mathrm{kg}^{-1} \mathrm{CaCO}_{3}(\mathrm{pH} \mathrm{4,2}$ a 5,6) e voltando a

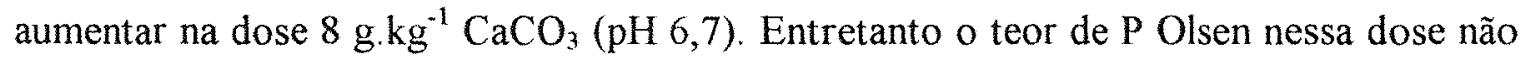
superou o teor na dose $0 \mathrm{~g} \cdot \mathrm{kg}^{-1} \mathrm{CaCO} 3$ no cultivo de arroz e foi praticamente igual no experimento com milho. $O$ efeito do teor de fósforo nesse fenômeno, também foi registrado por NAIDU et al. (1987).

\subsubsection{Extrator Resina}

O fósforo extraído por resina foi influenciado significativamente pelos fatores solos e dose de carbonatos, tendo sido significativa a interação doses x solos (Tabela 2). Foram observadas diferenças entre solos em todas as doses em ambos os cultivos (Tabela13). Dentro de cada dose foi mantida a mesma seqüência de médias de solos no cultivo com arroz e milho, podendo-se inferir que não houve alteração de formas de fósforo extraídas pela resina, entre solos, entre cultivos.

A aplicação do corretivo aumentou o fósforo extraído pela resina antes do cultivo do arroz e seus efeitos permaneceram até a época do cultivo do milho. O P resina cresceu com as doses na seqüência $0,1,2,4 \mathrm{e} 8 \mathrm{~g} \cdot \mathrm{kg}^{-1} \mathrm{CaCO}_{3}$ em ambas as épocas de amostragem, sendo que a relação dose de corretivo x $\mathrm{P}$ resina foi fortemente linear 
Tabela13 - Teores de fósforo extraídos por resina, em $\mathrm{mg} \cdot \mathrm{dm}^{-3}$, de amostras de solos submetidas a doses de corretivo, em g. $\mathrm{kg}^{-1} \mathrm{CaCO}_{3}$, antes dos cultivos de arroz e milho. Média de três repetições ${ }^{\mathrm{l}}$.

\begin{tabular}{|c|c|c|c|c|c|}
\hline \multirow[t]{2}{*}{ Amostra-solo } & \multicolumn{5}{|c|}{ Dose de corretivo $\left(\mathrm{g} \mathrm{kg}^{-1} \mathrm{CaCO}_{3}\right)$} \\
\hline & 0 & 1 & 2 & 4 & 8 \\
\hline & \multicolumn{5}{|c|}{$1^{\circ}$ Cultivo (Arroz) } \\
\hline LDI & $7,5 \mathrm{f}$ & $6,9 \mathrm{~d}$ & $7,9 \mathrm{~d}$ & $12,3 \mathrm{e}$ & $13,5 \mathrm{~g}$ \\
\hline LD2 & 14,5 ef & $15,3 \mathrm{~d}$ & $17,2 \mathrm{~d}$ & $21,4 \mathrm{e}$ & $29,2 \mathrm{f}$ \\
\hline LD3 & $34,6 \mathrm{~cd}$ & $32,2 \mathrm{c}$ & $37,1 \mathrm{c}$ & $47,2 \mathrm{~cd}$ & $49,2 \mathrm{e}$ \\
\hline LD4 & $67,4 \mathrm{~b}$ & $75,2 \mathrm{~b}$ & $76,9 b$ & $90,8 \mathrm{~b}$ & $109,6 \mathrm{~b}$ \\
\hline LD5 & $116,1 \mathrm{a}$ & $113,8 \mathrm{a}$ & $127,0 \mathrm{a}$ & $135,5 \mathrm{a}$ & $146,9 \mathrm{a}$ \\
\hline RP1 & 25,7 de & $31,6 \mathrm{c}$ & $37,3 \mathrm{c}$ & $42,4 \mathrm{~d}$ & $57,1 \mathrm{de}$ \\
\hline RP3 & $10,0 \mathrm{f}$ & $9,2 \mathrm{~d}$ & $11,6 \mathrm{~d}$ & $13,0 \mathrm{e}$ & $18,5 \mathrm{fg}$ \\
\hline RP7 & $35,2 \mathrm{~cd}$ & $38,6 \mathrm{c}$ & $41,5 \mathrm{c}$ & $60,0 \mathrm{c}$ & $69,5 \mathrm{~d}$ \\
\hline \multirow[t]{2}{*}{ RP13 } & $43,6 \mathrm{c}$ & $42,5 \mathrm{c}$ & $50,8 \mathrm{c}$ & $76,0 \mathrm{~b}$ & $90,6 \mathrm{c}$ \\
\hline & \multicolumn{5}{|c|}{$2^{\circ}$ Cultivo (Milho) } \\
\hline LD1 & $4,4 \mathrm{~d}$ & $4,4 \mathrm{e}$ & $6,0 \mathrm{e}$ & $9,5 \mathrm{~d}$ & $15,4 \mathrm{~g}$ \\
\hline $\mathrm{LD} 2$ & $7,0 \mathrm{~d}$ & $10,4 \mathrm{e}$ & $10,9 \mathrm{e}$ & $16,6 \mathrm{~d}$ & $27,3 \mathrm{f}$ \\
\hline LD3 & $23,6 \mathrm{c}$ & $28,6 \mathrm{~cd}$ & $29,0 \mathrm{~d}$ & $42,4 \mathrm{c}$ & $46,3 \mathrm{e}$ \\
\hline LD4 & $48,6 \mathrm{~b}$ & $54,8 \mathrm{~b}$ & $66,4 b$ & $78,0 \mathrm{~b}$ & $102,4 \mathrm{~b}$ \\
\hline LD5 & $87,1 \mathrm{a}$ & $89,4 a$ & $99,3 \mathrm{a}$ & $128,4 \mathrm{a}$ & $149,8 \mathrm{a}$ \\
\hline RPI & $18,9 c$ & $22,3 \mathrm{~d}$ & $28,1 \mathrm{~d}$ & $38,3 \mathrm{c}$ & 56,1 de \\
\hline RP3 & $7,2 \mathrm{~d}$ & $8,3 \mathrm{e}$ & $10,0 \mathrm{e}$ & $13,3 \mathrm{~d}$ & $19,2 \mathrm{fg}$ \\
\hline RP7 & $24,4 \mathrm{c}$ & $31,5 \mathrm{~cd}$ & $32,8 \mathrm{~cd}$ & $46,5 \mathrm{c}$ & $65,8 \mathrm{~d}$ \\
\hline RP13 & $26,5 \mathrm{c}$ & $34,5 \mathrm{c}$ & $41,6 \mathrm{c}$ & $68,5 \mathrm{~b}$ & $91,4 \mathrm{c}$ \\
\hline
\end{tabular}

1 - Médias seguidas pela mesma letra na coluna, dentro de cada cultivo, não diferem entre si, ao nivel de $5 \%$ pelo teste Tukey. CV arroz $=11,67 \% ; \mathrm{CV}$ milho $=9,28 \%$. 

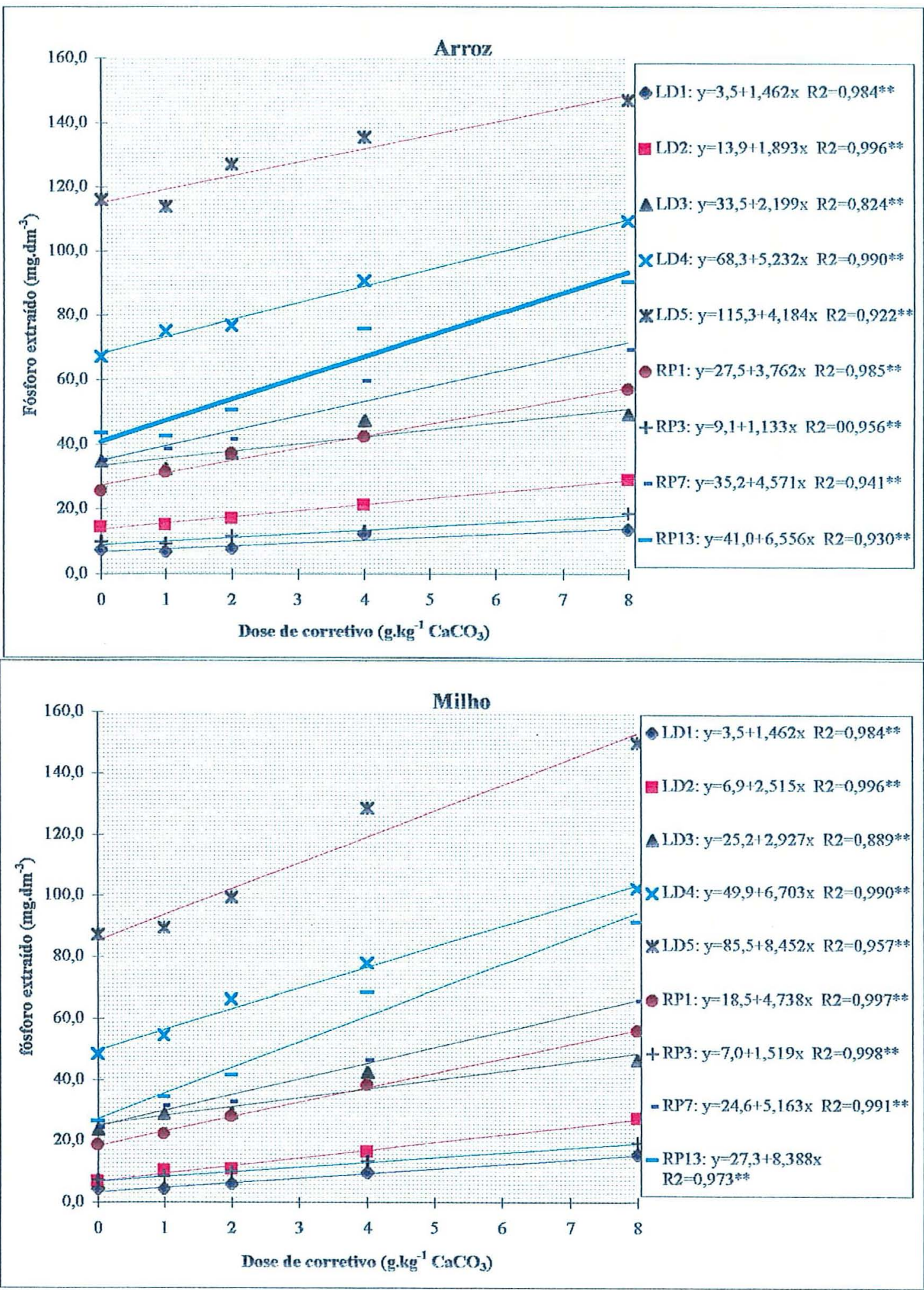

Figura 6 - Fósforo extraído por resina, em função de doses de corretivo, nas amostras de solos (LD1...RP13), antes do cultivo de arroz e milho. 
(Figura 6). De modo similar, a relação $\mathrm{pH}$ em $\mathrm{CaCl} 2 \quad 0,01$ mol.L $\mathrm{L}^{-1}$ e $\mathrm{P}$ resina apresentou elevados coeficientes de correlação, altamente significativos (Tabela 7).

Os resultados aqui obtidos são concordantes com os relatados por TAYLOR \& GURNEY (1965b), e por OLAYA (1988), em condições de casa de vegetação, e por RAIJ \& QUAGGIO (1990) em condições de campo, entre outros. VIEGAS (1990) relata decréscimo de $\mathrm{P}$ resina até um valor mínimo no pH 5,5, com aumento da extração quando o pH foi elevado a 6,5, naqueles solos que apresentavam alumínio trocável maior que $10 \mathrm{mmol}_{\mathrm{c}} \cdot \mathrm{L}^{-1}$

Na Figura 6 observa-se que predominou efeito crescente de doses na extração de $\mathrm{P}$ resina. Não houve, em nenhum solo, decréscimo significativo de $\mathrm{P}$ resina com aumento de dose. A quase perfeita correlação entre dose, $\mathrm{pH}$ em $\mathrm{CaCl} 20,01 \mathrm{~mol} \cdot \mathrm{L}^{-1} \mathrm{e}$ resina (Tabela 7) confirma isto.

Com a elevação do $\mathrm{pH}$, admite-se aumento da solubilidade de parte dos compostos de P-Fe, P-Al (LINDSAY \& MORENO, 1960, HSU, 1964), formação de compostos de P-Ca meta-estáveis que são mais solúveis que os compostos P-Fe e P-Al que ocorrem nas condições ácidas. O extrator Resina-HCO3- teria eficiente ação sobre esses compostos de P-Ca meta-estáveis. Outro aspecto que deve ser considerado é o fato da resina funcionar como um dreno contínuo, evitando readsorção secundária de compostos de fósforo como aqueles relatados para o extrator Bray-1 por RODRIGUES \& MENDONZA (1993). 


\subsection{6. - Os extratores}

Os extratores apresentaram capacidade de extração distinta do fósforo do solo, bem como sensibilidades diferentes e, em alguns casos, opostas aos efeitos provocados pela aplicação dos corretivos e elevação do $\mathrm{pH}$ do solo (Figura $7,8,9,10$ ). Essas sensibilidades demonstraram estar associadas ao modo de açăo do extrator, às interações fósforo x calagem e, provavelmente aos efeitos dos íons $\mathrm{OH}^{-}, \mathrm{CO}^{*}$ e $\mathrm{HCO}_{3}^{-}$nos componentes de ação do extrator.

O extrator Bray-1 teve sua capacidade de extração reduzida pelo aumento da dose de corretivo. Atribuiu-se este fenômeno a um processo de diminuição da capacidade de extração do extrator, provocada pelo consumo de íons hidrogênio, devido ao aumento de radicais básicos no solo, com a adição de carbonatos.

Com calagem ocorrem mudanças nas formas fósforo no solo. Por outro lado, com o tempo, admite-se uma diminuiçăo da solubilidade das formas de fósforo que se tornam mais estáveis, reduzindo a disponibilidade (SAMPLE, et al, 1980; BARROW, 1980). A resina demonstrou ter sensibilidade especifica para detectar essas formas metaestáveis de compostos de fosfatos bicálcicos mais solúveis que as formas $\mathrm{P}-\mathrm{Al}$ e/ou P-Fe, ao mesmo tempo que indicou diminuição do fósforo disponivel após o cultivo do arroz (Figura 11) bem como, manteve a sensibilidade na detecção das variações de $P$ disponível em função de $\mathrm{pH}$ 


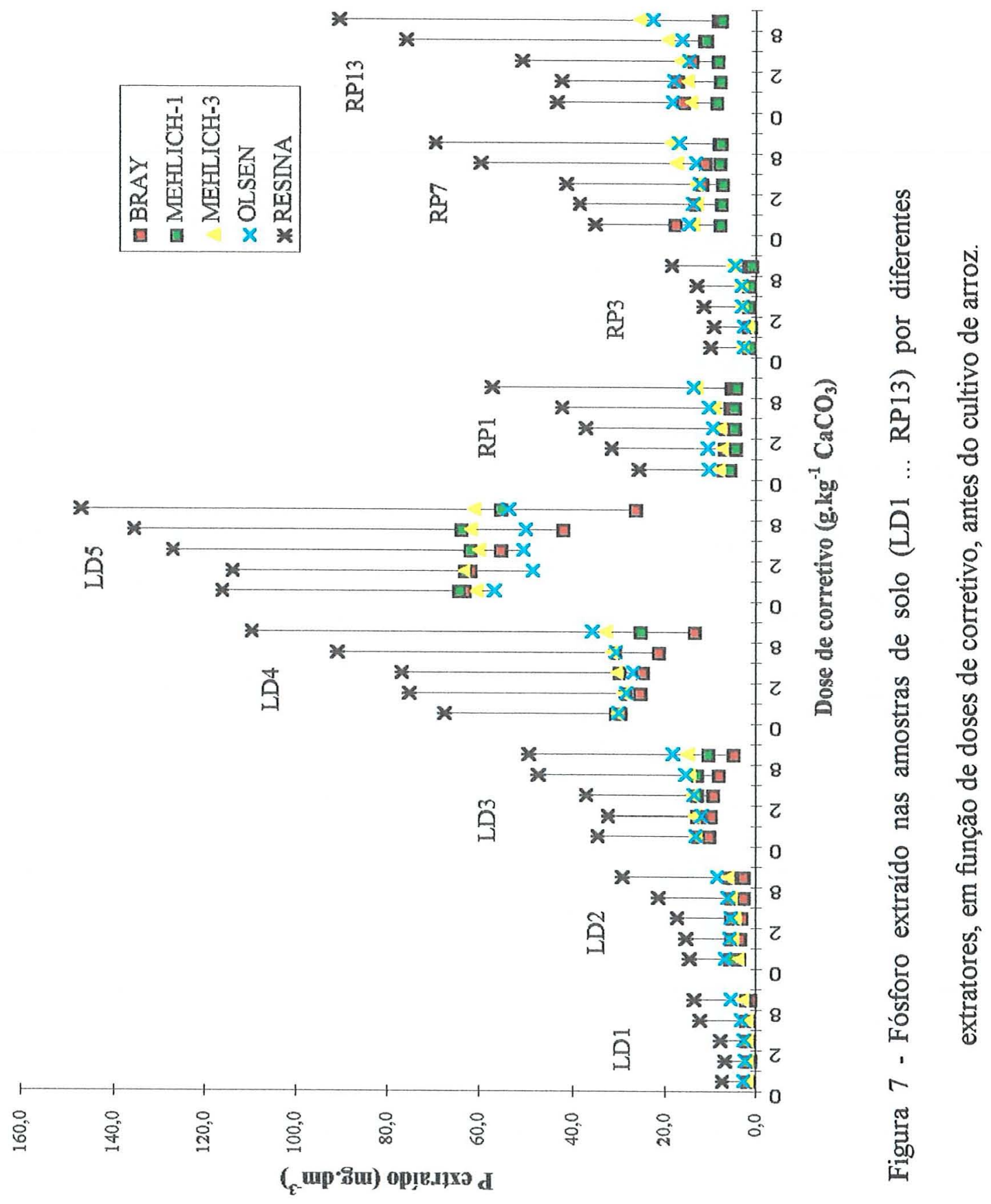




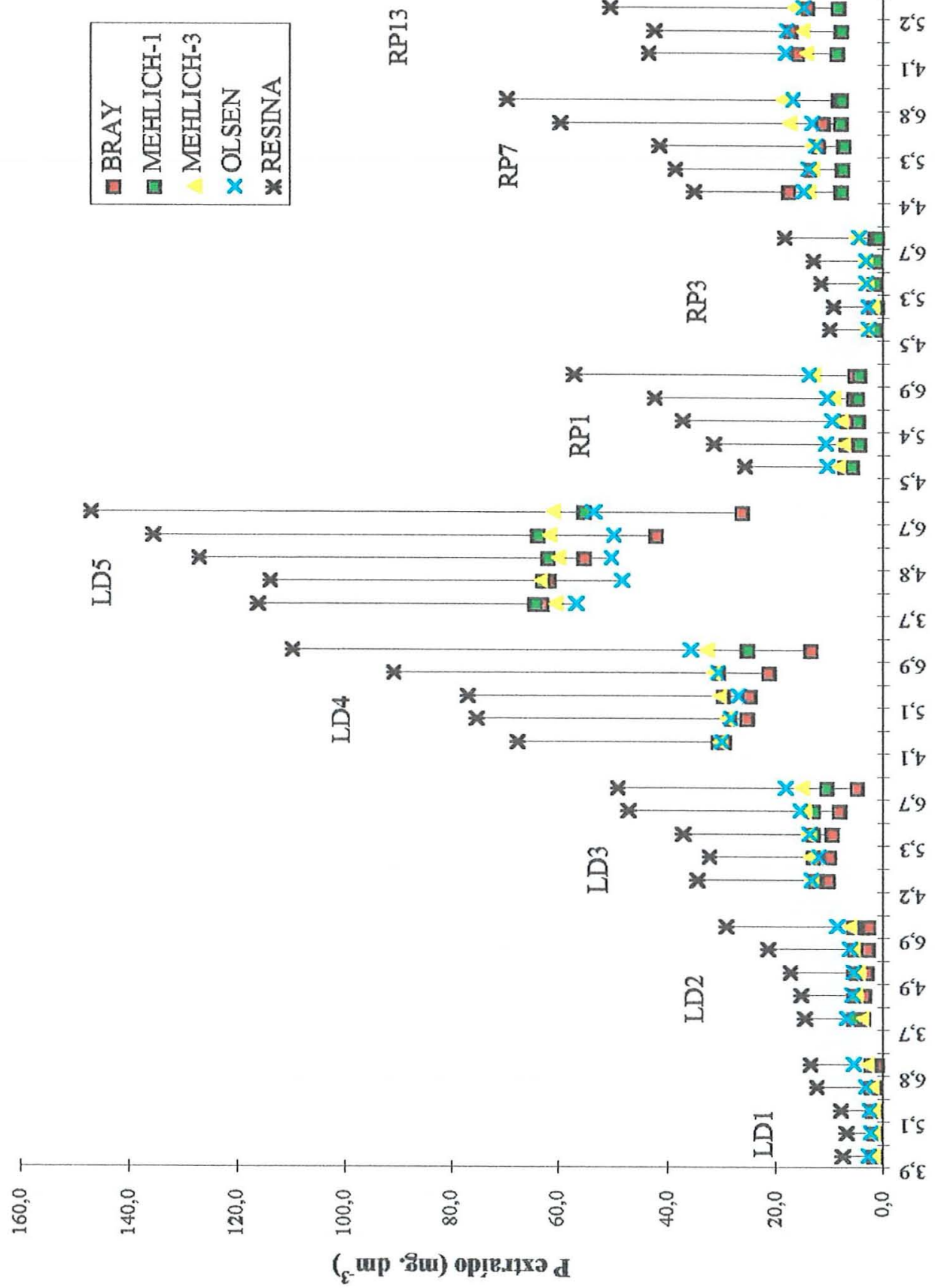



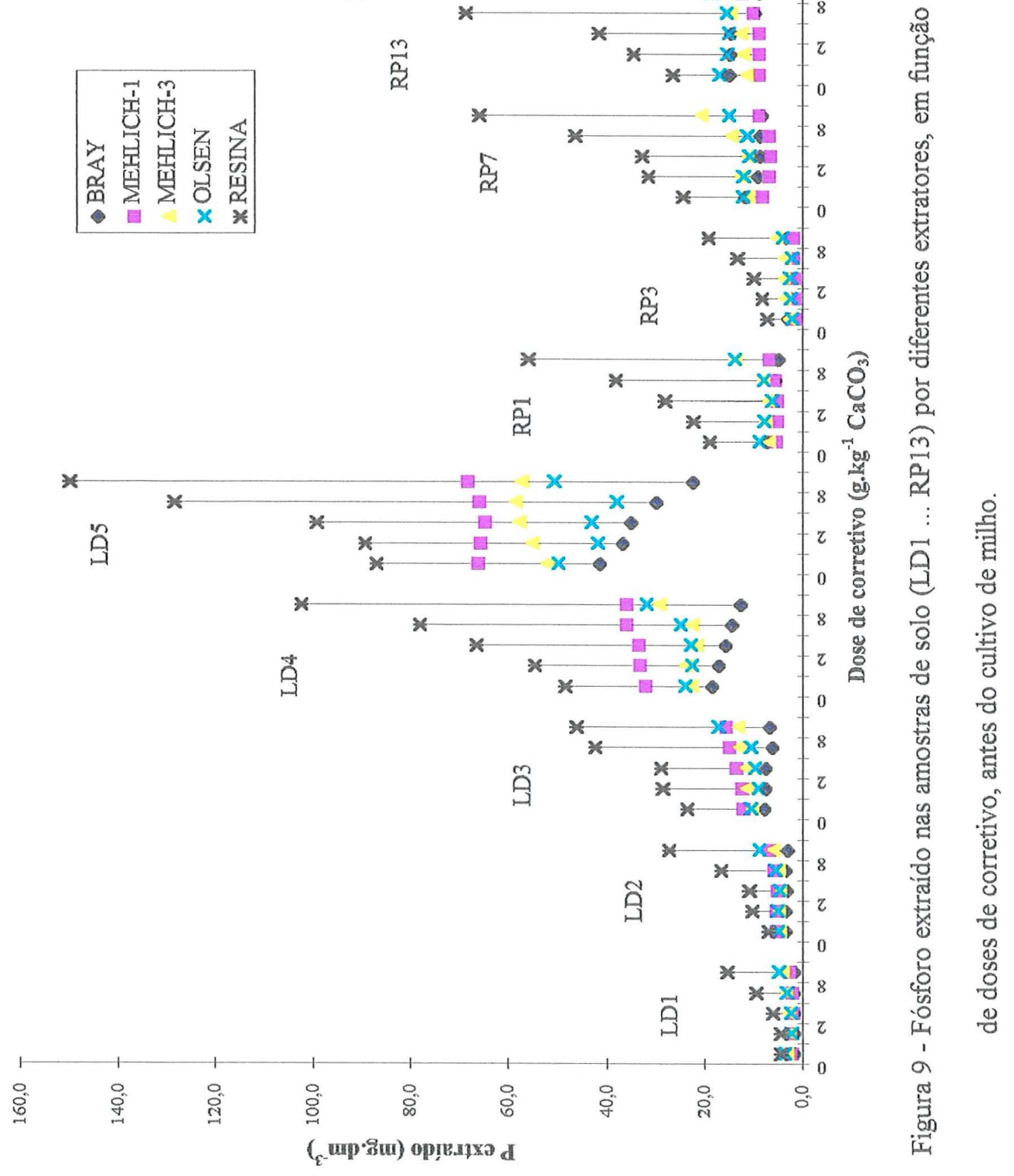


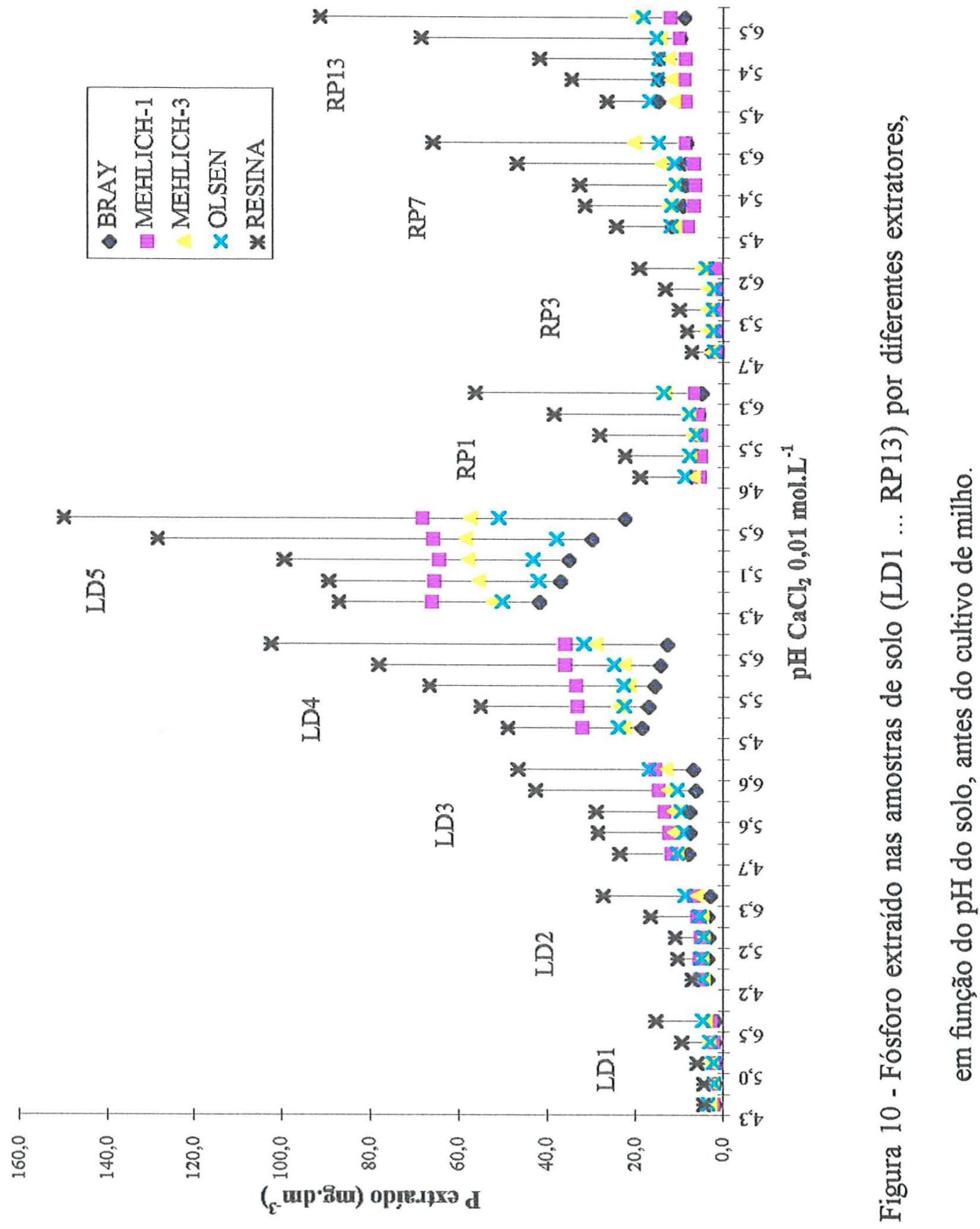




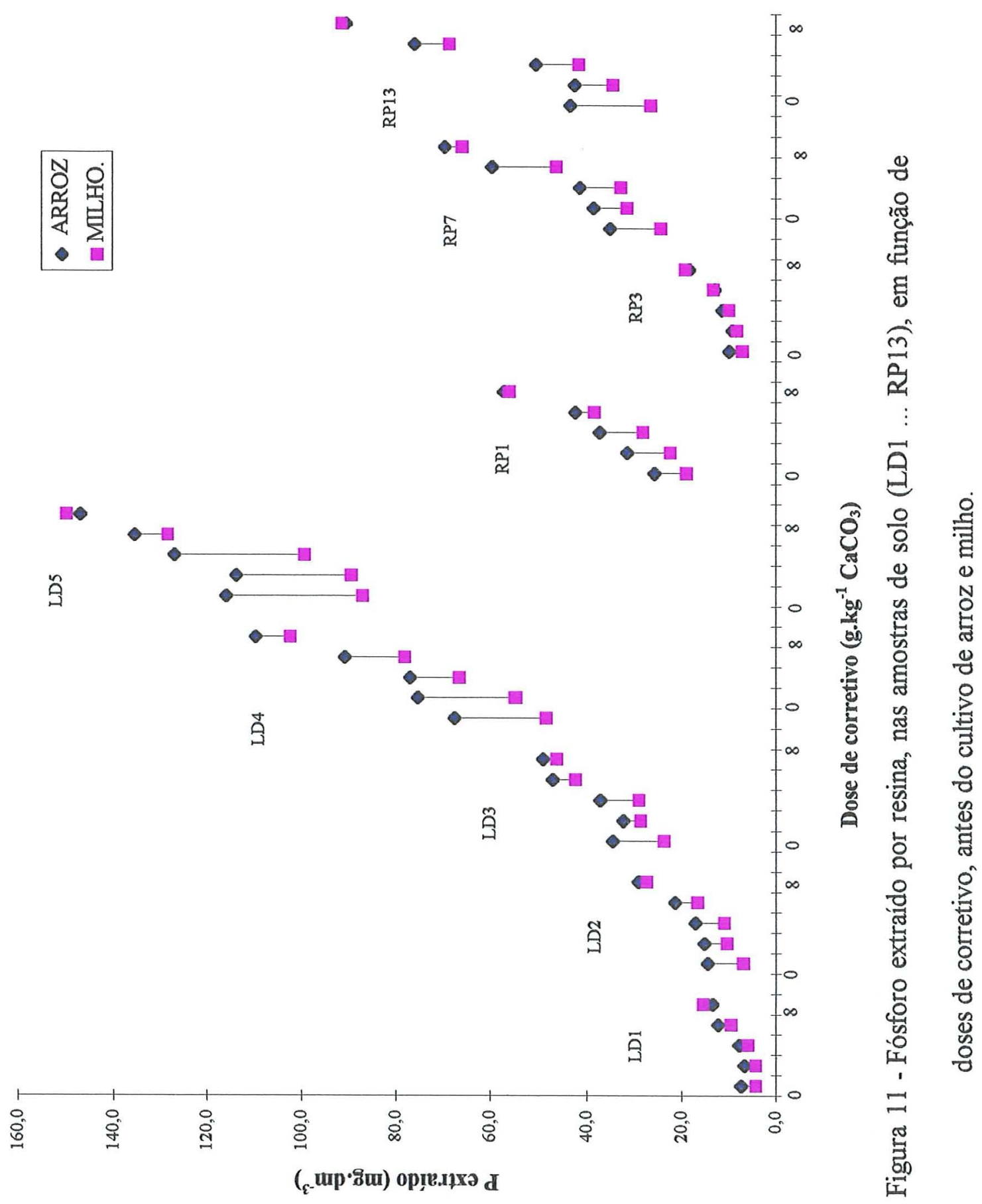


Além do efeito de tempo na quantidade de fósforo disponivel, diminuindo-o, outro aspecto é que houve absorção de nutrientes pelas plantas de arroz, o que deveria conduzir, também, à diminuição nos teores de P disponível. Nesse sentido uma adequada avaliação do fósforo disponível por qualquer extrator deveria refletir essa variação; o que seria coerente com a, normalmente observada, tendência dos teores de $\mathrm{P}$ lábil diminuírem com o tempo (BARROW,1980).

Para os extratores Bray-1, Mehlich-3, e Olsen também houve diminuição de um cultivo para outro, nos teores extraídos de fósforo na maioria dos solos, notadamente naqueles com teores iniciais mais altos (Figura 12, 13, 14). Não houve alteração no comportamento desses extratores entre cultivos como se pode verificar pelas equações de regressão entre doses e fósforo extraído.

O extrator Mehlich-1 apresentou mudança de comportamento entre um cultivo e outro. No cultivo com arroz a sua capacidade de extração foi diminuída em função da calagem e no cultivo com milho ela aumentou ( Figura15). Este fato aponta para mudança de formas de P no solo, mas em contrapartida, apresenta uma limitação que foi a de não indicar a diminuição dos teores de $\mathrm{P}$ disponível que seria esperada em função de readsorção do fósforo pelo solo e da sua absorção pelas plantas de arroz

Os coeficientes de correlação linear simples (Tabela 14), obtidos quando se correlacionou, entre si, os teores extraídos pelos extratores dentro de cada solo, também demonstram os efeitos relatados nas discussões doses $\mathrm{x}$ fósforo extraído por esses extratores. Os coeficientes de correlação negativos obtidos entre P Bray-1, e P Mehlich-3 


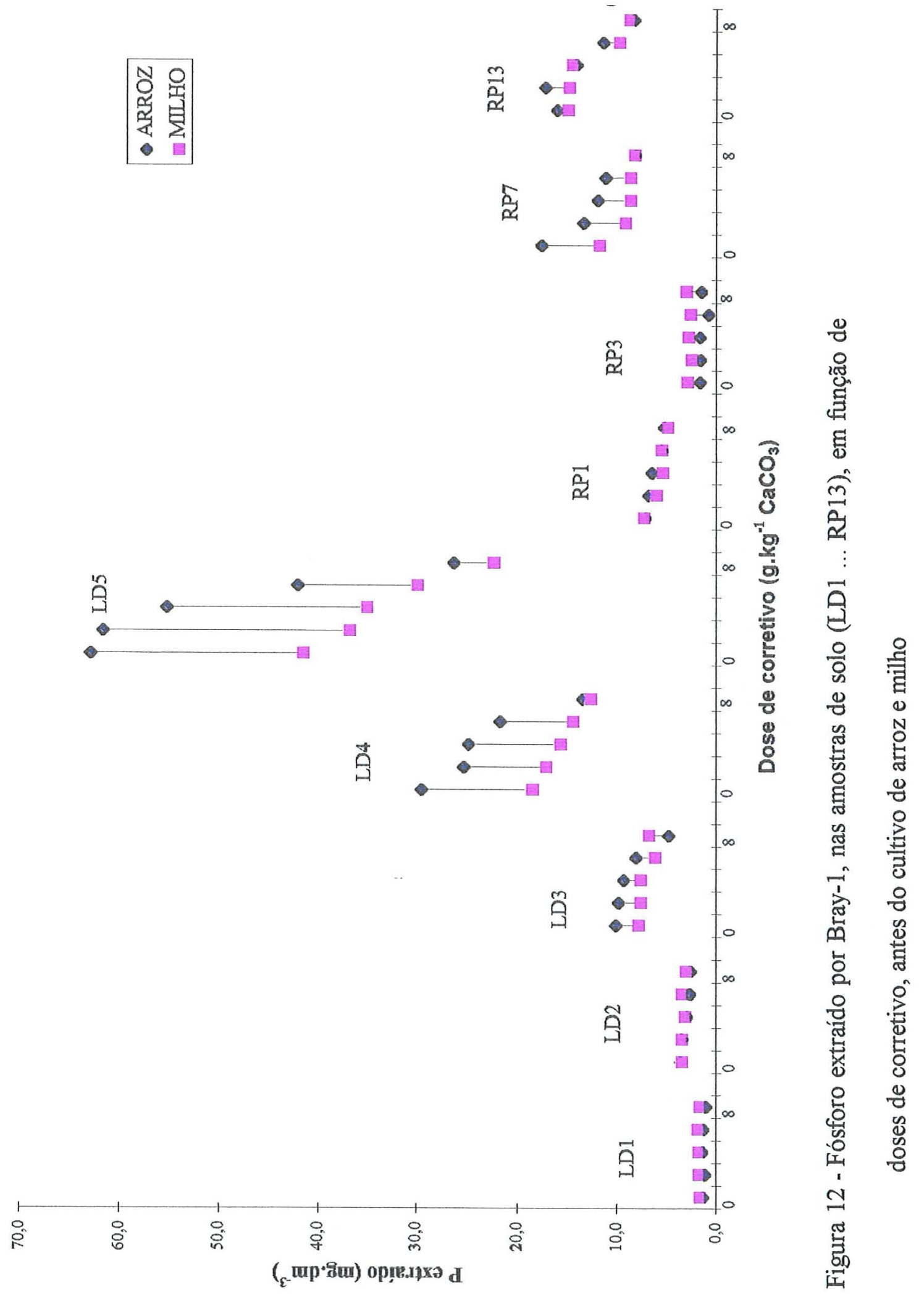



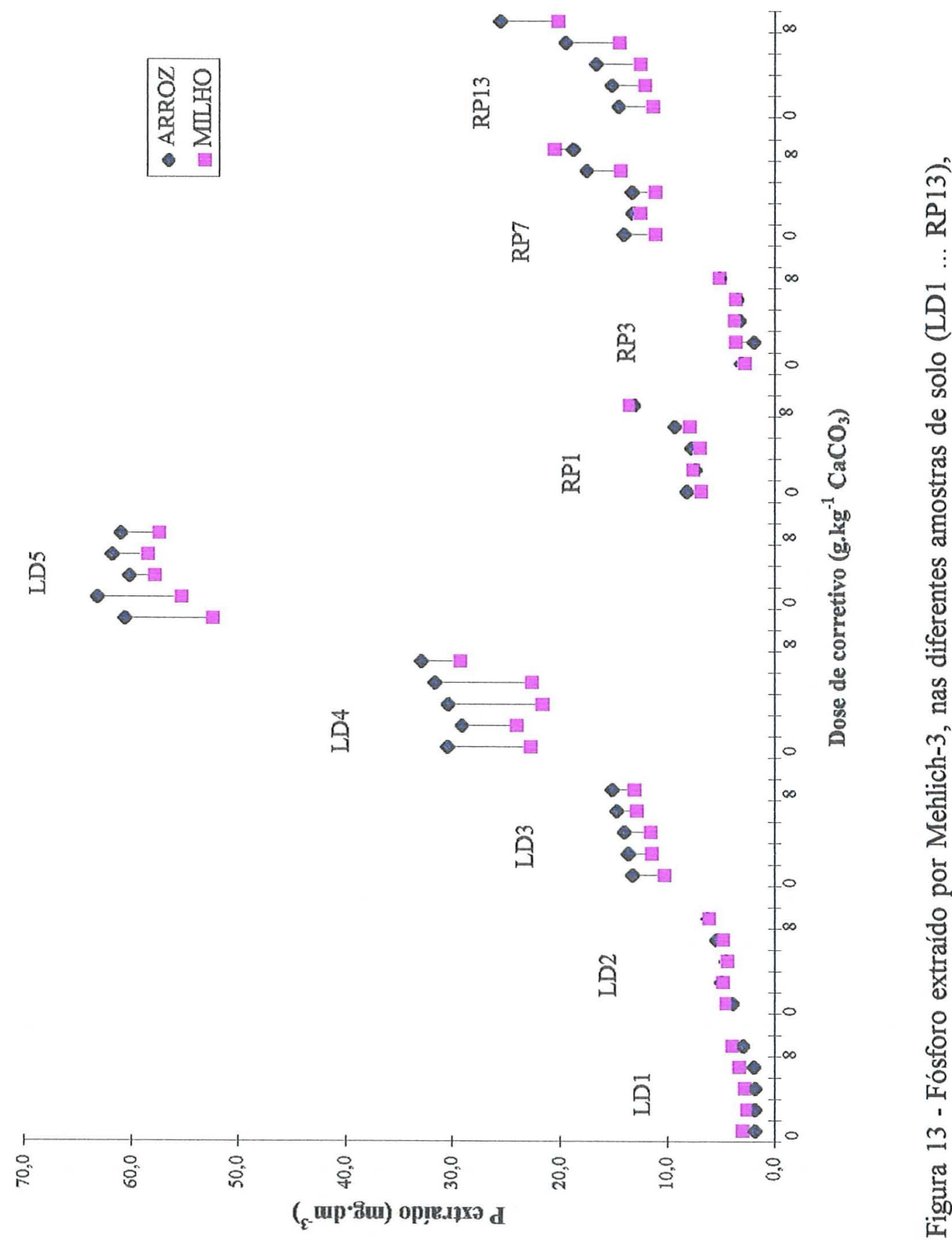

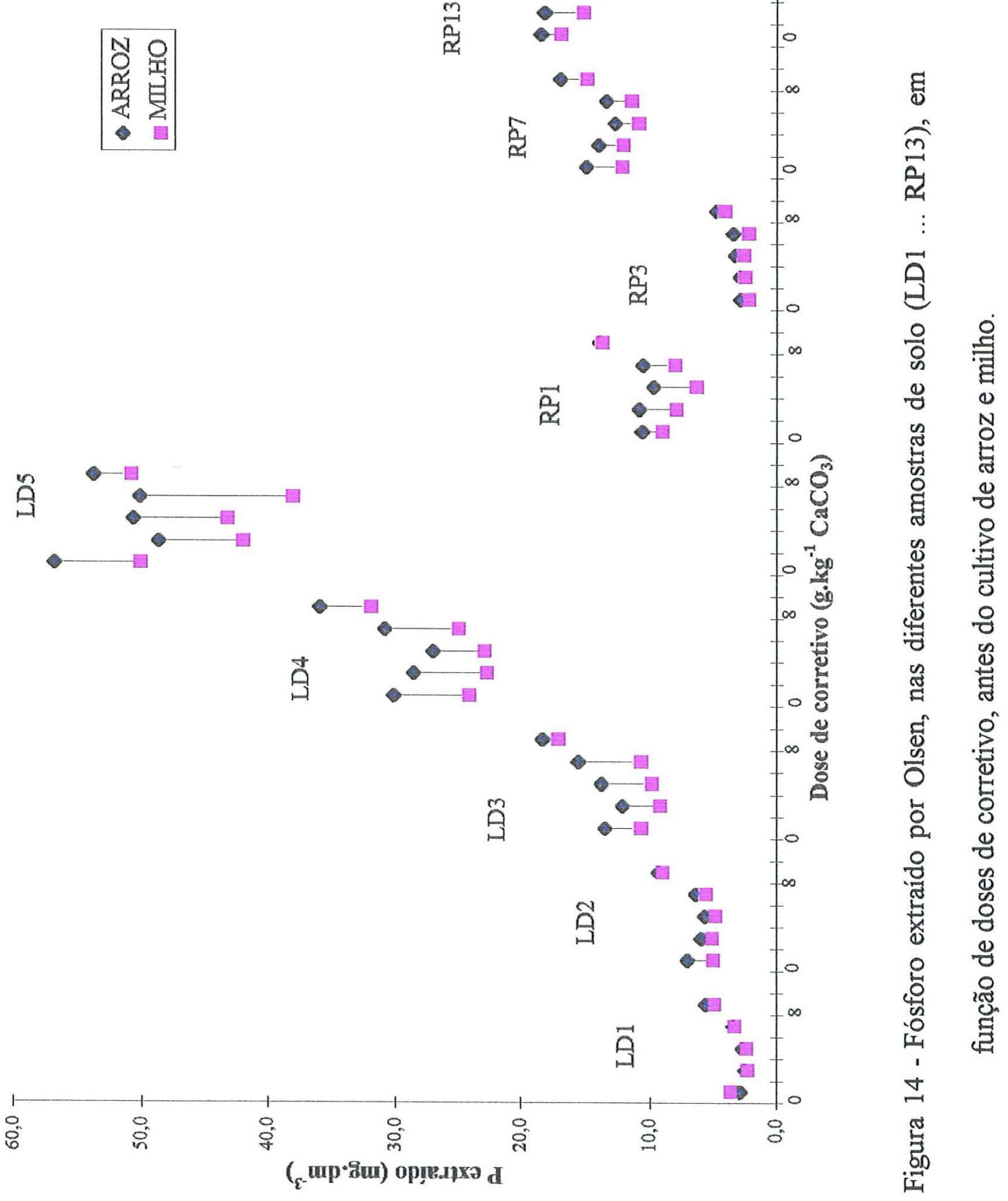

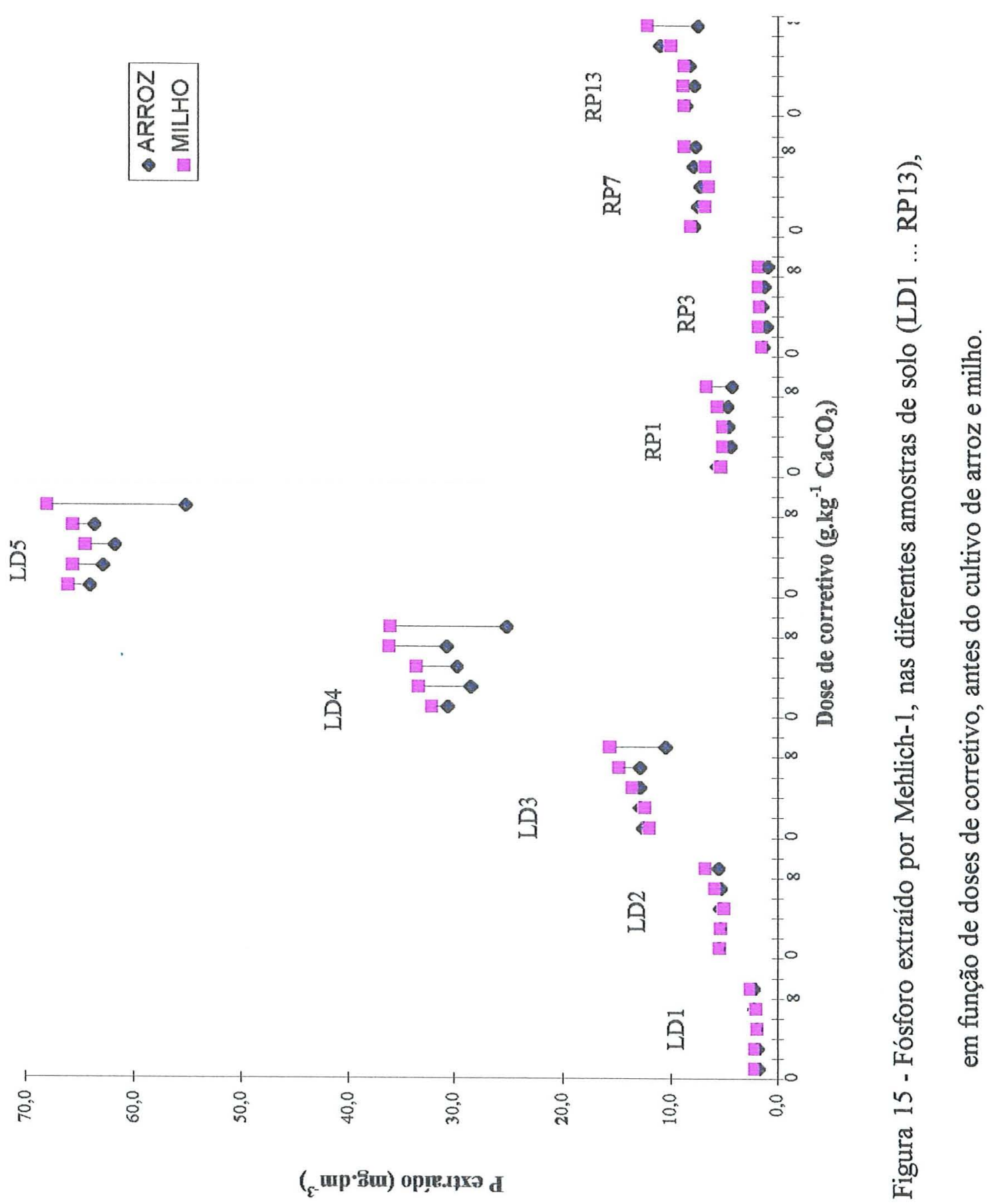
$\mathrm{P}$ Olsen e $\mathrm{P}$ resina, na maioria dos solos, em ambos os cultivos, especialmente entre $\mathrm{P}$ Bray-1 e P resina, confirmam os comportamentos opostos desses extratores. De outra maneira, o comportamento similar dos extratores $\mathrm{P}$ Mehlich-3 e $\mathrm{P}$ resina é ratificado pelos coeficientes de correlação positivo destes extratores entre si. Não obstante a depressão dos teores de P Olsen nas doses intermediárias, os efeitos de elevação dos teores de P Olsen nas doses maiores explicam os coeficientes de correlação positivo entre esse extrator e os extratores Mehlich-3 e resina.

Em relação às quantidades extraídas tem-se que o extrator resina apresentou maior poder de extração e o extrator Bray-1 o menor. Pode-se estabelecer a sequêencia de poder de extração, em ordem crescente, Bray-1, Mehlich-1, Olsen, Mehlich-3 e Resina nas amostras coletadas antes do cultivo com arroz e Bray-1, Olsen, Mehlich-3, Mehlich-1 e Resina naquelas colhidas antes do milho. Em alguns tratamentos a resina apresentou uma capacidade de extração até cinco vezes superior aos outros extratores (Figura 7, 8, $9,10)$

Verifica-se na Figura 6 , que a inclinação $\Delta \mathrm{P}$ resina/ $\Delta$ dose (coeficiente angular) da reta de regressão aumentou, do cultivo de arroz para o cultivo de milho; bem como os valores de $\mathrm{r}$ para a relação $\mathrm{pH} \mathrm{CaCl} 20,01 \mathrm{~mol} \cdot \mathrm{L}^{-1} \times \mathrm{P}$ resina (Tabela 7). Este fato aponta para aumento da sensibilidade da resina, apesar de a quantidade de fósforo extraída antes do cultivo do arroz ter sido maior que naquelas antes do cultivo do milho (Figura 11), demonstrando que a sensibilidade do extrator independe das quantidades extraidas.

A capacidade de extração de um extrator é bastante influenciada pelo fator solo como registrado por SILVA (1991) e por tratamentos a ele aplicados, tais como fontes de fósforo, como verificado por BRASIL (1994). 


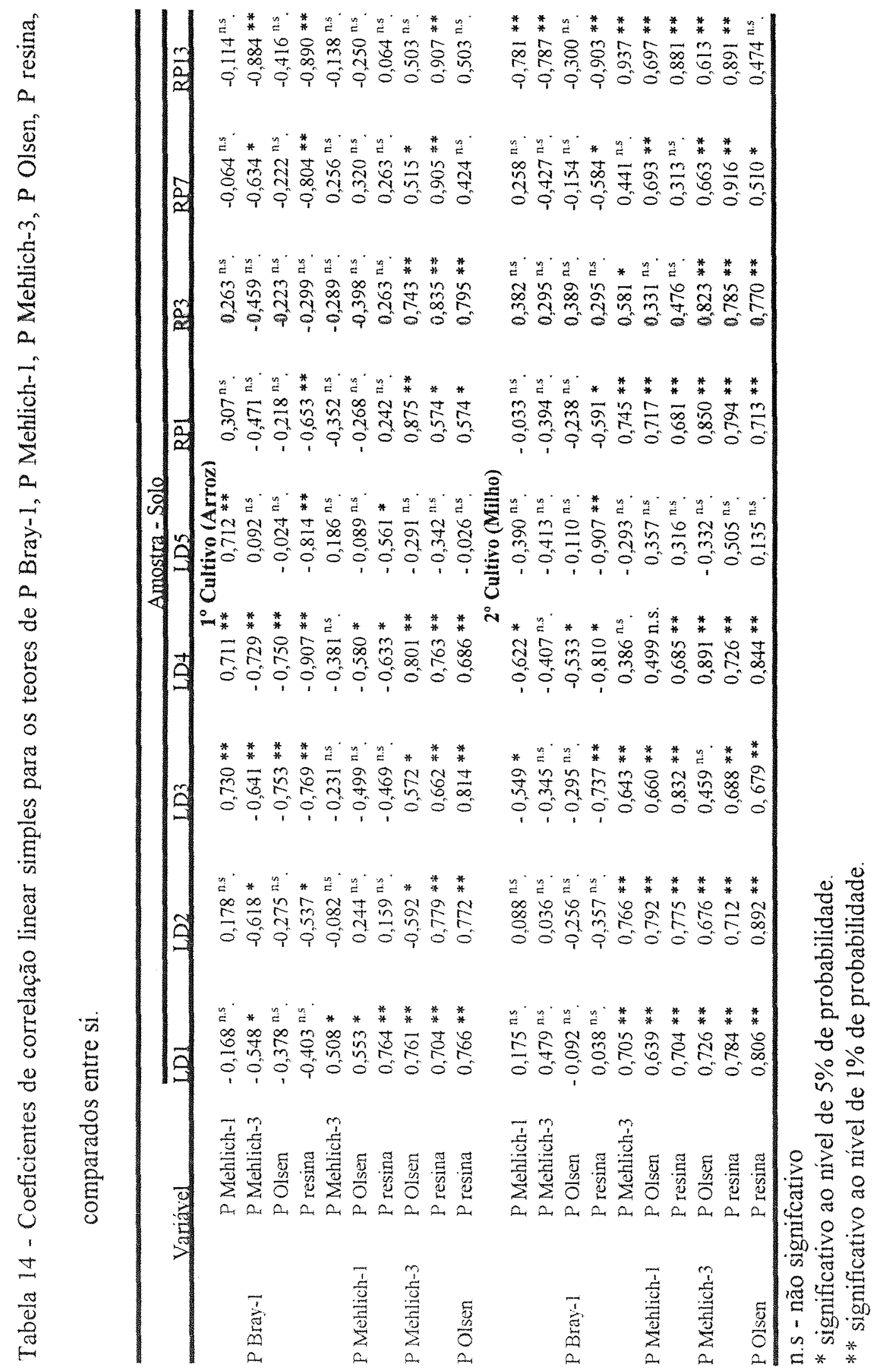




\section{3. - Parâmetros da planta}

\subsection{1. - Matéria seca da parte aérea}

A matéria seca da parte aérea variou em função de solo, doses de carbonatos, tendo sido significativa a interação solos $x$ doses em ambos cultivos (Tabela 2). A produção de matéria seca, em função de solos e doses, apresentou comportamentos distintos entre cultivos (Tabela 15).

A produção de matéria seca de arroz diminuiu com a dose de carbonatos e a de milho apresentou maior crescimento nas dose intermediárias e mínima produção na dose $8 \mathrm{~g} \cdot \mathrm{kg}^{-1} \mathrm{CaCO}_{3}$, com exceção da amostra RP3.

Houve mudança no efeito de solos (teor de P) na produção de matéria seca, dentro de cada dose, em ambos os cultivos. Para as doses mais baixas de carbonatos houve alta diferenciação entre amostras quanto à produção de matéria seca de arroz, permitindo separar as médias em quatro ou cinco grupos significativamente diferentes entre si. Para a dose maior $\left(8 \mathrm{~g}^{\mathrm{kg}}{ }^{-1} \mathrm{CaCO}_{3}\right)$, contudo, o grau de diferenciação foi menor, destacando-se apenas uma média (LD5) das demais. Fato semelhante ocorreu com a produção de matéria seca pelas plantas de milho. Esses fatos demonstram que na dose mais alta de carbonatos, outros efeitos indiretos da aplicação desse corretivo sobre a produção de matéria seca preponderaram sobre os efeitos do fósforo do solo (Figura 16, 17). 
Tabela 15 - Matéria seca acumulada da parte aérea de plantas de arroz e milho, em g/vaso, cultivadas nas amostras de solo submetidas a doses de corretivo, em g. $\mathrm{kg}^{-1} \mathrm{CaCO}_{3}$. Média de três repetições ${ }^{1}$.

\begin{tabular}{lccccc}
\hline Amostra-solo & \multicolumn{5}{c}{ Dose de corretivo $\left(\mathrm{g} k g^{-1} \mathrm{CaCO}_{3}\right)$} \\
\cline { 2 - 6 } & 0 & 1 & \multicolumn{5}{c}{$\mathbf{1}^{\circ}$ Cultivo (Arroz) } \\
\cline { 2 - 6 } LD1 & $5,37 \mathrm{e}$ & $4,58 \mathrm{e}$ & $3,57 \mathrm{~d}$ & $1,94 \mathrm{e}$ & $0,57 \mathrm{~b}$ \\
LD2 & $14,10 \mathrm{~d}$ & $14,04 \mathrm{~d}$ & $15,59 \mathrm{c}$ & $12,43 \mathrm{~d}$ & $0,69 \mathrm{~b}$ \\
LD3 & $24,60 \mathrm{~b}$ & $24,14 \mathrm{~b}$ & $21,85 \mathrm{~b}$ & $18,73 \mathrm{c}$ & $1,04 \mathrm{~b}$ \\
LD4 & $30,39 \mathrm{a}$ & $29,50 \mathrm{a}$ & $28,03 \mathrm{a}$ & $23,80 \mathrm{ab}$ & $2,52 \mathrm{~b}$ \\
LD5 & $30,15 \mathrm{a}$ & $30,55 \mathrm{a}$ & $28,66 \mathrm{a}$ & $25,59 \mathrm{a}$ & $16,40 \mathrm{a}$ \\
RP1 & $18,91 \mathrm{c}$ & $18,05 \mathrm{~cd}$ & $18,07 \mathrm{bc}$ & $17,05 \mathrm{c}$ & $3,09 \mathrm{~b}$ \\
RP3 & $5,96 \mathrm{e}$ & $4,90 \mathrm{e}$ & $3,55 \mathrm{~d}$ & $2,72 \mathrm{e}$ & $1,31 \mathrm{~b}$ \\
RP7 & $22,95 \mathrm{bc}$ & $20,53 \mathrm{bc}$ & $20,77 \mathrm{~b}$ & $18,00 \mathrm{c}$ & $2,04 \mathrm{~b}$ \\
RP13 & $19,97 \mathrm{c}$ & $21,23 \mathrm{bc}$ & $20,52 \mathrm{~b}$ & $19,77 \mathrm{bc}$ & $3,44 \mathrm{~b}$ \\
& & & $2^{\circ}$ Cultivo (Milho) & \\
LD1 & $2,44 \mathrm{~d}$ & $2,54 \mathrm{e}$ & $3,04 \mathrm{~d}$ & $2,30 \mathrm{e}$ & $2,32 \mathrm{~b}$ \\
LD2 & $2,79 \mathrm{~cd}$ & $3,54 \mathrm{cde}$ & $3,67 \mathrm{~cd}$ & $3,54 \mathrm{de}$ & $2,48 \mathrm{~b}$ \\
LD3 & $3,56 \mathrm{bcd}$ & $4,35 \mathrm{bcd}$ & $4,89 \mathrm{bc}$ & $3,80 \mathrm{de}$ & $2,54 \mathrm{~b}$ \\
LD4 & $4,48 \mathrm{abc}$ & $5,00 \mathrm{abc}$ & $5,70 \mathrm{ab}$ & $4,46 \mathrm{~cd}$ & $3,22 \mathrm{ab}$ \\
LD5 & $5,49 \mathrm{a}$ & $5,89 \mathrm{ab}$ & $6,89 \mathrm{a}$ & $5,18 \mathrm{~cd}$ & $3,44 \mathrm{ab}$ \\
RP1 & $5,12 \mathrm{ab}$ & $5,64 \mathrm{ab}$ & $5,97 \mathrm{ab}$ & $5,92 \mathrm{bc}$ & $2,88 \mathrm{ab}$ \\
RP3 & $2,44 \mathrm{~d}$ & $2,81 \mathrm{de}$ & $3,04 \mathrm{~d}$ & $3,73 \mathrm{de}$ & $3,12 \mathrm{ab}$ \\
RP7 & $5,37 \mathrm{a}$ & $5,72 \mathrm{ab}$ & $7,22 \mathrm{a}$ & $7,92 \mathrm{a}$ & $3,10 \mathrm{ab}$ \\
RP13 & $5,53 \mathrm{a}$ & $6,29 \mathrm{a}$ & $7,29 \mathrm{a}$ & $7,16 \mathrm{ab}$ & $4,49 \mathrm{a}$ \\
\hline
\end{tabular}

l - Médias seguidas pela mesma letra na coluna, dentro de cada cultivo, não diferem entre si, ao nivel de $5 \%$ pelo teste Tukey. CV arroz $=11,23 \%$; CV milho $=15,49 \%$ 


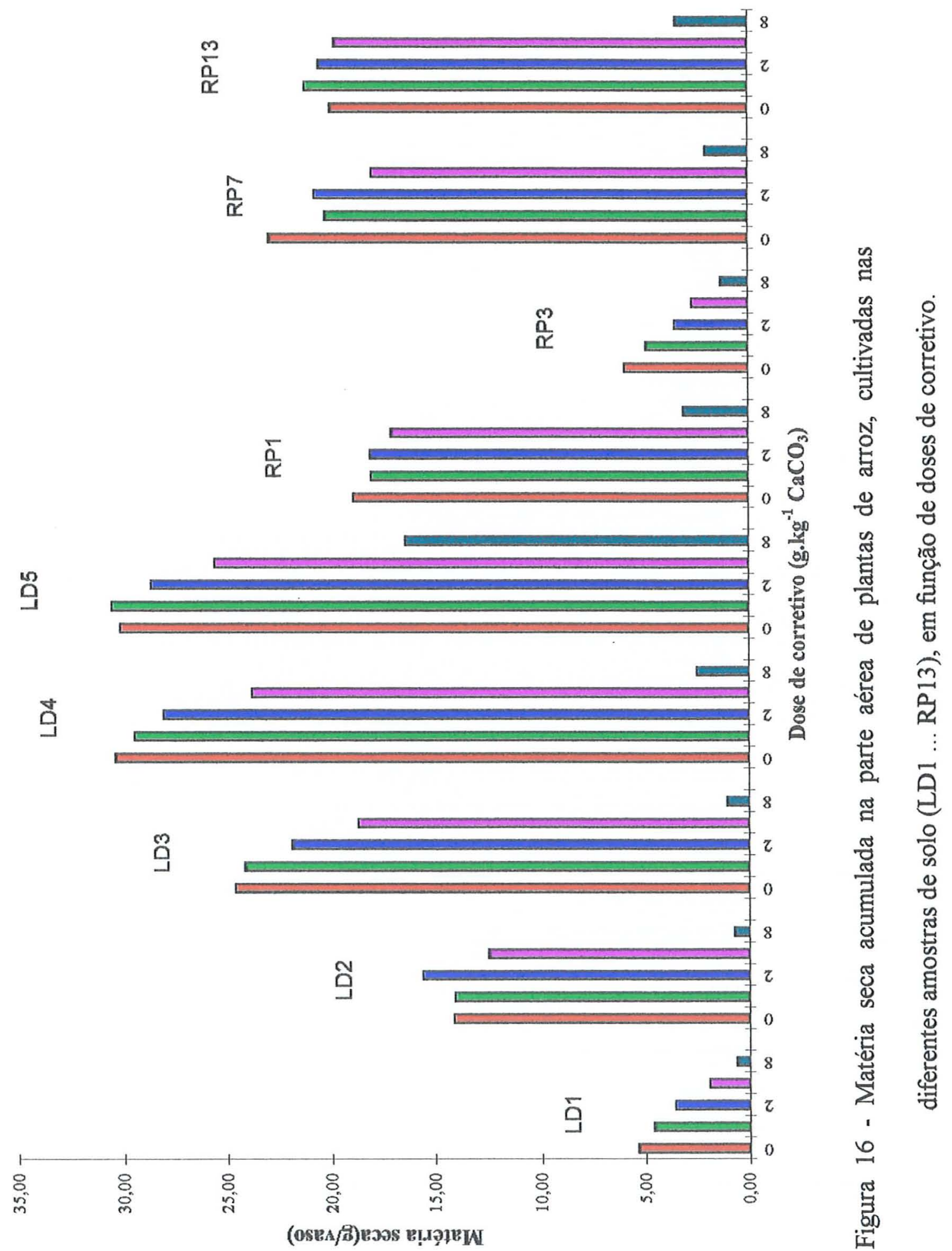




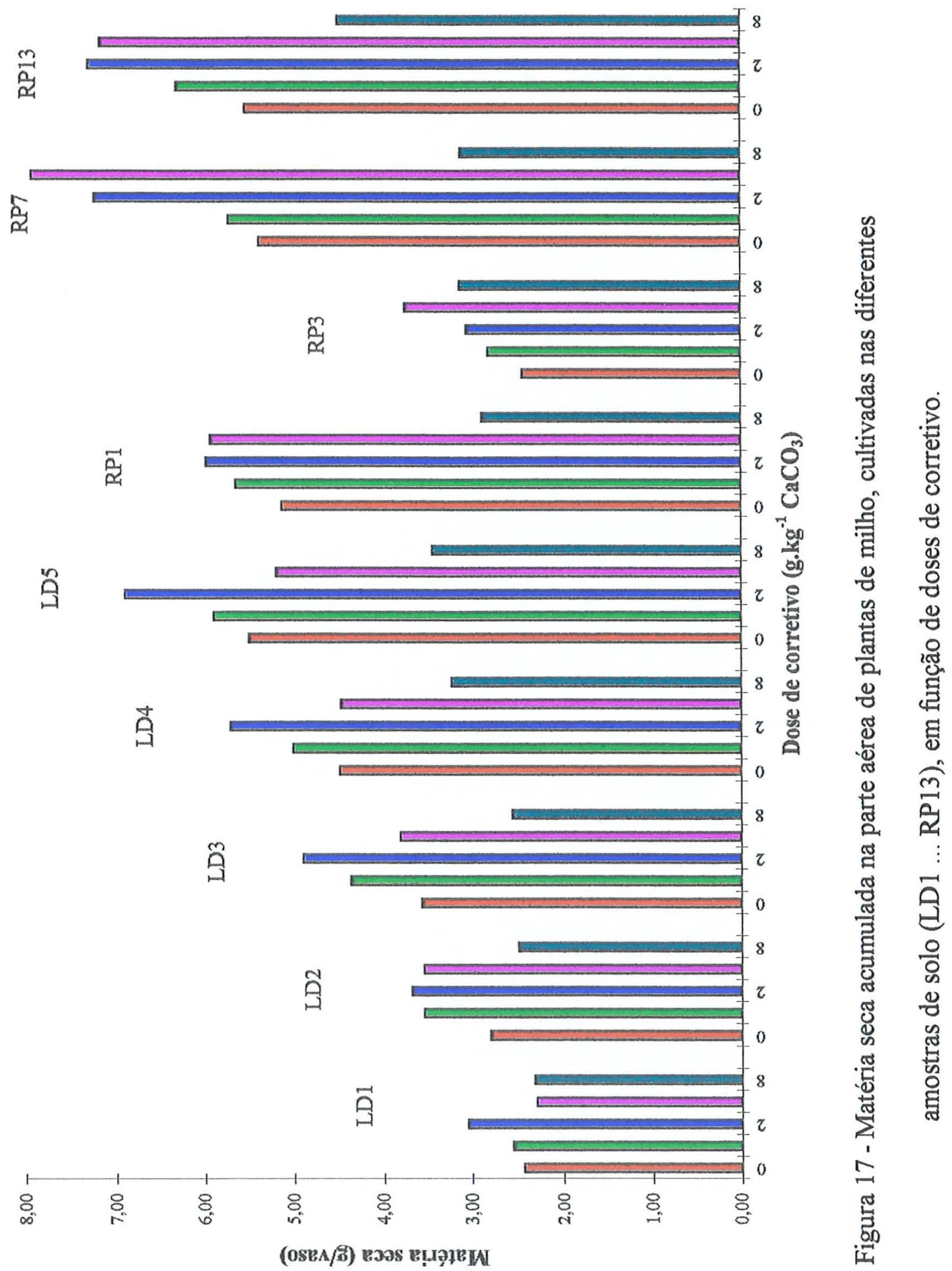


Convém destacar que as plantas de arroz em todos os casos apresentaram drástica redução na produção de matéria seca, mostrando, mais uma vez, a preponderância dos efeitos de calagem no crescimento da variedade IAC-165 de arroz, sobre os efeitos do teor de $\mathrm{P}$ das amostras de solo.

A relação dose e produção de matéria seca de arroz ajustou-se ao modelo linear somente nos solos LD1, RP3 e ao modelo quadrático nos demais solos (Figura 18). Nestes, o ajuste ao modelo quadrático deveu-se ao ajuste dos dados à seção decrescente da parábola, em virtude do decréscimo crescente da produção de matéria seca, sobretudo entre as doses 4 e $8 \mathrm{~g}^{-\mathrm{kg}^{-1}} \mathrm{CaCO}_{3}$

A resposta das plantas de milho à aplicação de corretivos foi diferente da resposta do arroz. Inicialmente, a matéria seca aumentou até a dose 2 ou $4 \mathrm{~g}^{\mathrm{kg}}{ }^{-1} \mathrm{CaCO}_{3}$, dependendo do solo. Os dados ajustaram-se ao modelo quadrático na maioria dos solos, com exceção do solo LD1 e RP3 onde não houve ajuste a nenhum dos modelos testados. (Figura 18).

Para se determinar a dose que ocasionaria a produção máxima de matéria seca de milho nos solos onde o ajuste foi possível, a relação d'y/dx foi igualada a zero. Substituiu-se o valor da dose máxima na equação de regressão que relacionou doses x pH (Tabela 4). Estimou-se a máxima produção, os valores de pH (Tabela16). A amplitude das doses para máxima produção foi 2,0 a $3,55 \mathrm{~g} \mathrm{~kg}^{-1} \mathrm{CaCO}_{3}$. Contudo, com exceção do solo LD5, onde o pH para produção máxima foi 4,9 , nos demais solos este $\mathrm{pH}$ oscilou entre 5,4 a 5,6. Este fato mais uma vez demonstra que a calagem exerceu preponderância nos efeitos, interferindo no equilibrio de nutrientes. 


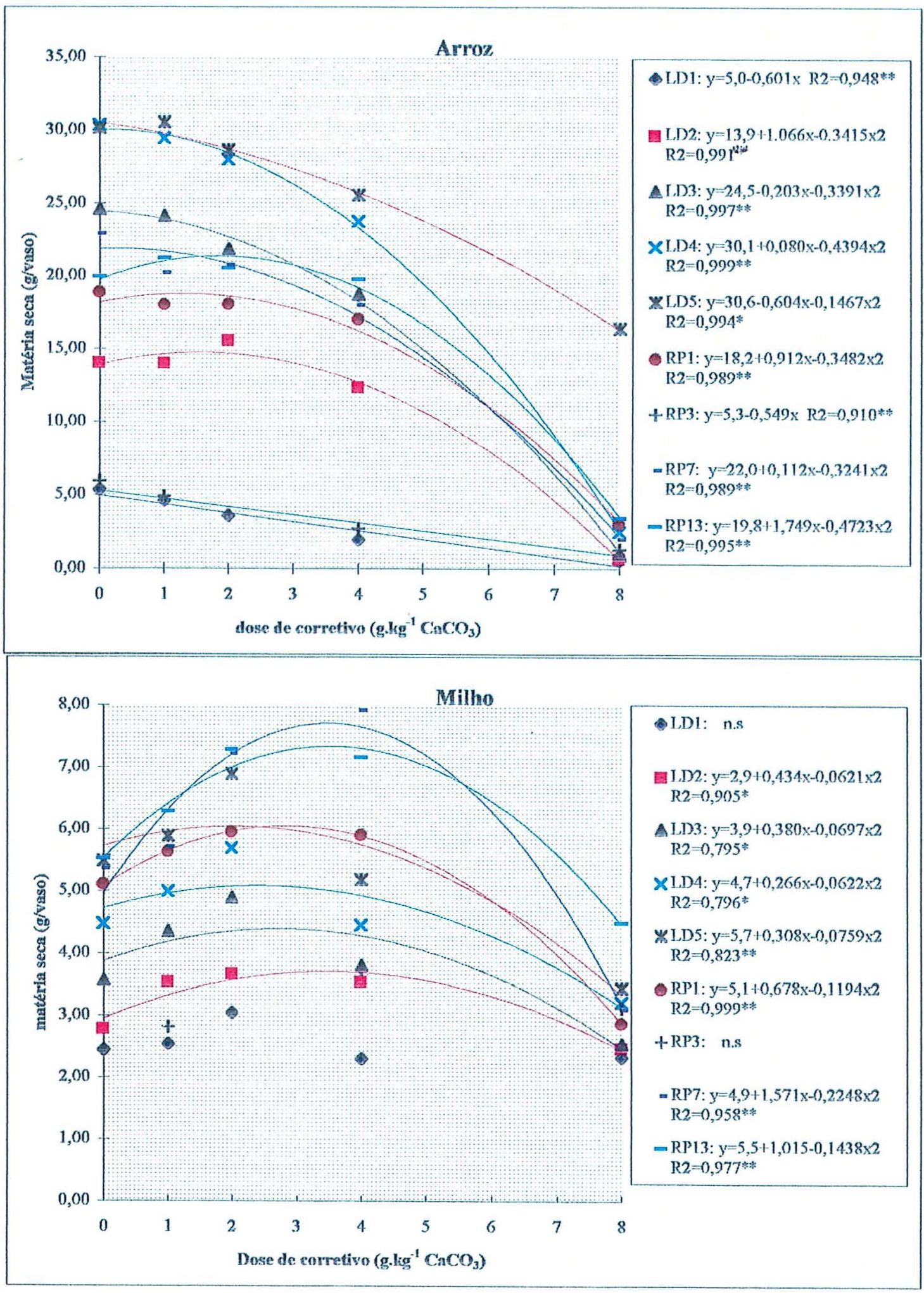

Figura 18 - Matéria seca da parte aérea de arroz e milho, cultivadas nas amostras de so. lo (LD1...RP13), em função de doses de corretivo. 
Tabelal6 - Dose de corretivo, em g. $\mathrm{kg}^{-1} \mathrm{CaCO}_{3}{ }^{3}$ estimada para se obter a produção máxima de matéria seca de plantas de milho e valores de matéria seca e pH $\mathrm{CaCl}_{2} 0,01$ mol. $\mathrm{L}^{-1}$ na dose 0 e dose para máxima produção de matéria seca.

\begin{tabular}{|c|c|c|c|c|c|}
\hline \multirow[t]{2}{*}{ Amostra-solo } & \multirow{2}{*}{$\begin{array}{l}\text { Dose de } \\
\text { corretivo } \\
\text { para produção } \\
\text { máxima }^{1}\end{array}$} & \multicolumn{2}{|c|}{$\mathrm{pH} \mathrm{CaCl} 20,01 \mathrm{~mol} . \mathrm{L}^{.1}$} & \multicolumn{2}{|c|}{ Matéria seca } \\
\hline & & Dose $0^{2}$ & $\begin{array}{l}\text { Dose para } \\
\text { produção } \\
\text { máxima }^{l}\end{array}$ & Dose $0^{2}$ & Máxima $^{1}$ \\
\hline & $-\mathrm{g} \cdot \mathrm{kg}^{-\mathrm{CaCO}_{3}-\cdots}$ & & & & \\
\hline LD2 & 3,50 & 4,2 & 5,4 & 2,79 & 3,72 \\
\hline LD3 & 2,75 & 4,7 & 5,6 & 3,56 & 4,39 \\
\hline LD4 & 2,40 & 4,8 & 5,4 & 4,48 & 5,09 \\
\hline LD5 & 2,00 & 4,3 & 4,9 & 5,49 & 6,05 \\
\hline RP1 & 2,80 & 4,6 & 5,5 & 5,12 & 7,94 \\
\hline RP7 & 3,50 & 4,6 & 5,5 & 5,37 & 7,72 \\
\hline RP13 & 3,55 & 4,5 & 5,6 & 5,53 & 7,35 \\
\hline
\end{tabular}

1 - Valores estimados

2 - Valores observados

\subsection{2. - Teor de fósforo na parte aérea}

Os teores de fósforo na parte aérea de plantas de arroz e milho, expresso em g. $\mathrm{kg}^{-1}$, foram influenciados pelos fatores solos, doses, e suas interações (Tabela 2). Foram influenciados pelo "status" de fósforo no solo: os maiores teores de fósforo na parte aérea das plantas de arroz foram observados naquelas plantas crescidas nos solos que apresentaram os mais altos teores de fósforo, LD5, LD4, e RP13 (Tabela17). No milho, 
Tabela17 - Teores de fósforo na parte aérea de plantas de arroz e milho, em g. $\mathrm{kg}^{-1}$. cultivadas nas diferentes amostras de solos submetidas a doses de corretivo, em g. $\mathrm{kg}^{-1} \mathrm{Ca} \mathrm{CO}_{3}$. Média de três repetições.

\begin{tabular}{clllll}
\hline Amostra solo & \multicolumn{5}{c}{ Dose de Corretivo (g.kg $\left.\mathrm{Ca} \mathrm{CO}_{3}\right)}$, \\
\cline { 2 - 6 } & 0 & \multicolumn{5}{c}{$\mathbf{1}^{\circ}$ Cultivo (Arroz) } \\
\hline LD1 & $0,808 \mathrm{c}$ & $0,758 \mathrm{c}$ & $1,008 \mathrm{bcd}$ & $0,736 \mathrm{c}$ & $0,438 \mathrm{c}$ \\
LD2 & $1,188 \mathrm{ab}$ & $0,917 \mathrm{bc}$ & $0,903 \mathrm{~cd}$ & $0,934 \mathrm{bc}$ & $0,886 \mathrm{~b}$ \\
LD3 & $1,000 \mathrm{bc}$ & $0,956 \mathrm{bc}$ & $1,079 \mathrm{bcd}$ & $1,228 \mathrm{ab}$ & $0,890 \mathrm{~b}$ \\
LD4 & $1,184 \mathrm{ab}$ & $1,175 \mathrm{~b}$ & $1,324 \mathrm{ab}$ & $1,210 \mathrm{ab}$ & $1,579 \mathrm{a}$ \\
LD5 & $1,359 \mathrm{a}$ & $1,522 \mathrm{a}$ & $1,596 \mathrm{a}$ & $1,596 \mathrm{a}$ & $1,372 \mathrm{a}$ \\
RP1 & $1,009 \mathrm{bc}$ & $0,908 \mathrm{bc}$ & $1,013 \mathrm{bcd}$ & $1,066 \mathrm{abc}$ & $1,675 \mathrm{a}$ \\
RP3 & $0,820 \mathrm{c}$ & $0,719 \mathrm{c}$ & $0,833 \mathrm{~d}$ & $1,039 \mathrm{abc}$ & $0,996 \mathrm{~b}$ \\
RP7 & $1,022 \mathrm{abc}$ & $1,140 \mathrm{~b}$ & $1,188 \mathrm{bc}$ & $1,144 \mathrm{ab}$ & $1,372 \mathrm{a}$ \\
RP13 & $1,057 \mathrm{abc}$ & $0,996 \mathrm{bc}$ & $1,238 \mathrm{bc}$ & $1,171 \mathrm{ab}$ & $1,546 \mathrm{a}$ \\
& & & $2^{\circ}$ Cultivo (Millo) & \\
LD1 & $0,809 \mathrm{~d}$ & $0,813 \mathrm{e}$ & $0,883 \mathrm{~d}$ & $0,866 \mathrm{e}$ & $0,733 \mathrm{~b}$ \\
LD2 & $0,822 \mathrm{~d}$ & $1,119 \mathrm{cde}$ & $1,119 \mathrm{cde}$ & $1,236 \mathrm{bcd}$ & $0,722 \mathrm{~b}$ \\
LD3 & $1,402 \mathrm{ab}$ & $1,494 \mathrm{abc}$ & $1,473 \mathrm{abc}$ & $1,573 \mathrm{abc}$ & $0,800 \mathrm{~b}$ \\
LD4 & $1,045 \mathrm{bcd}$ & $1,284 \mathrm{bcd}$ & $1,464 \mathrm{abc}$ & $1,857 \mathrm{a}$ & $0,892 \mathrm{~b}$ \\
LD5 & $1,158 \mathrm{abcd}$ & $1,302 \mathrm{bcd}$ & $1350 \mathrm{abc}$ & $1,257 \mathrm{bcde}$ & $1,002 \mathrm{ab}$ \\
RP1 & $1,433 \mathrm{ab}$ & $1,560 \mathrm{abc}$ & $1,634 \mathrm{ab}$ & $1,407 \mathrm{bcd}$ & $0,896 \mathrm{~b}$ \\
RP3 & $0,949 \mathrm{~cd}$ & $0,930 \mathrm{de}$ & $1,058 \mathrm{~cd}$ & $1,046 \mathrm{de}$ & $0,844 \mathrm{~b}$ \\
RP7 & $1,293 \mathrm{abc}$ & $1,621 \mathrm{ab}$ & $1,758 \mathrm{a}$ & $1,473 \mathrm{abcd}$ & $1,154 \mathrm{ab}$ \\
RP13 & $1,525 \mathrm{a}$ & $1,765 \mathrm{a}$ & $1,721 \mathrm{a}$ & $1,656 \mathrm{ab}$ & $1,381 \mathrm{a}$ \\
\hline
\end{tabular}

Médias seguidas pela mesma letra na coluna dentro de cada cultivo, não diferem entre si, ao nivel de $5 \%$ pelo teste Tukey. CV arroz $=12,03 \%, \mathrm{CV}$ milho $=13,90 \%$ 
os maiores teores de fóstoro ocorreram nas plantas cultivadas nas amostras RP7 e RP13, as mesmas que produziram as maiores quantidades de matéria seca (Tabela 15).

Os efeitos de solo ("status" de fósforo) nos teores de P na parte aérea de plantas de arroz e milho foram observados em todas as doses do corretivo (Tabela17). Entretanto, os efeitos de solos diminuiram na dose $8 \mathrm{~g} . \mathrm{kg}^{-1}$, tanto nas plantas de arroz como de milho. As amostras de solos que nas doses menores de corretivo as plantas apresentaram diferenças entre si, quanto aos teores de $\mathrm{P}$ na parte aérea, na dose 8 os teores de P na planta foram semelhantes entre si. Com o aumento das doses de corretivo o teor de fósforo no solo passou a exercer efeito de menor intensidade na absorção, passando a predominar outros efeitos do $\mathrm{pH}$ sobre a dinâmica dos nutrientes.

As doses de corretivo influenciaram o teor de fósforo em ambas as plantas, predominando a natureza do efeito linear direto no arroz e quadrático, com ponto de máxima, no milho (Figura 19).

O aumento do teor de fósforo na parte aérea de arroz deveu-se ao efeito de concentração, conseqüência do menor crescimento das plantas nas doses mais altas do corretivo. Com exceção do solo LD2, os teores de fósforo (Figura 20) observados nas plantas foram maiores nas doses de corretivo mais altas acima daquelas que possibilitaram maior acúmulo de matéria seca (Figura 16), que decresceu quando se aumentou as doses. Infere-se aqui que inicialmente ocorreu maior absorção nas doses maiores, não havendo, porém, conversão de matéria seca.

Nas plantas de milho as relações doses de carbonatos e teor de P foram quadráticas, com ponto de máximo (Figura 19). A partir destas equações estimou-se a 


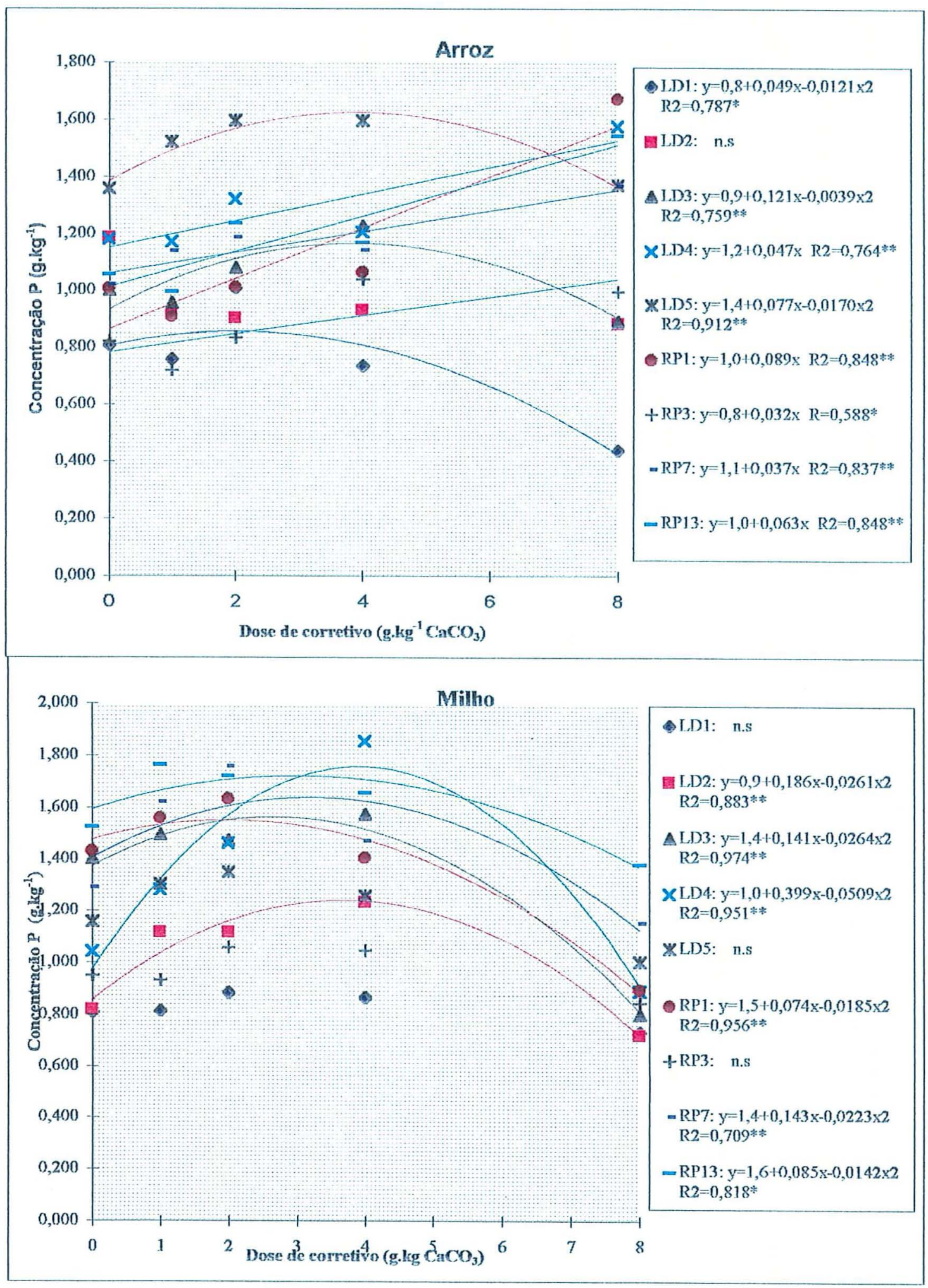

Figura 19 - Teores de fósforo na parte aérea de plantas de arroz e milho, nas amostras de solo (LD1...RP13), submetidas a doses de corretivo. 


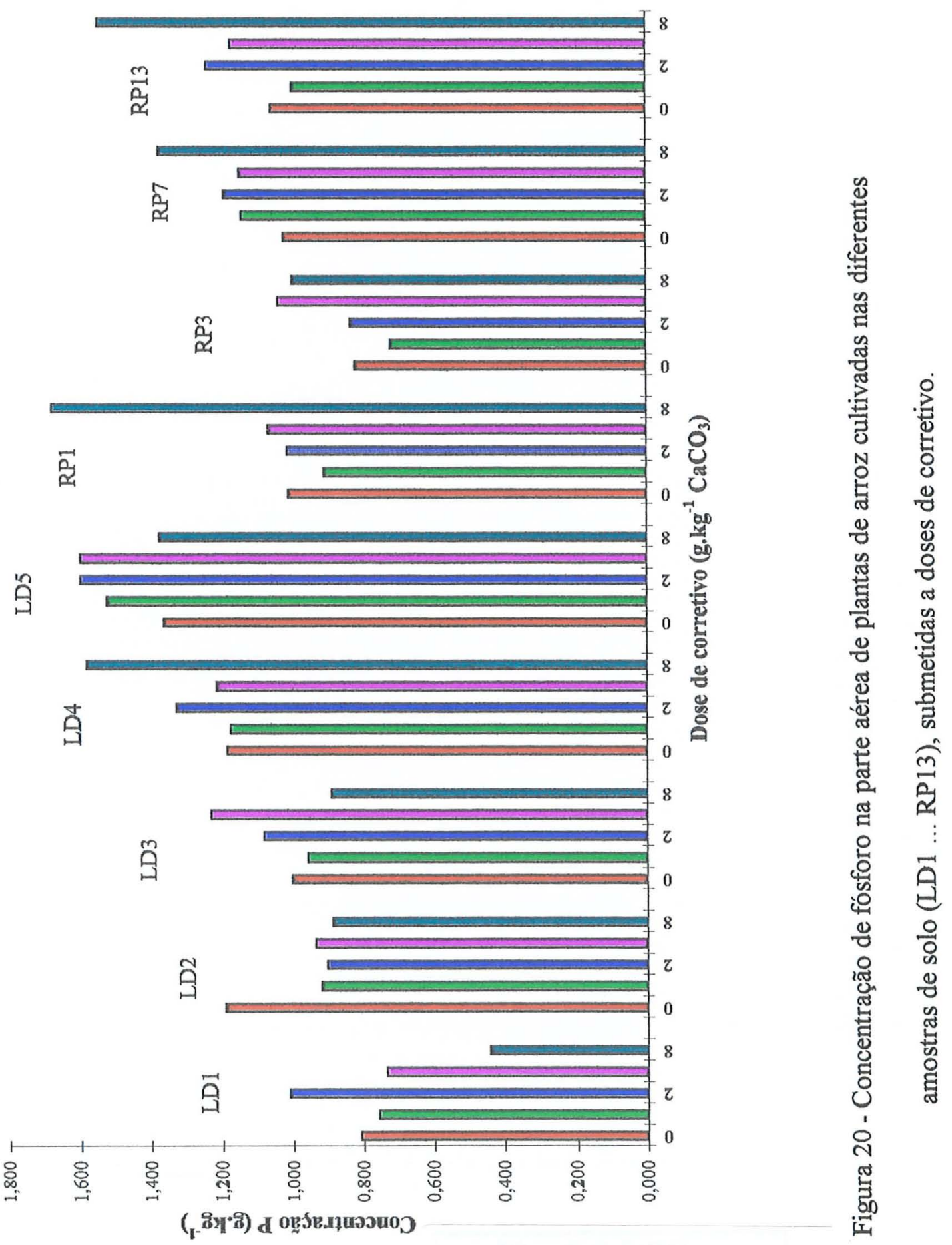


Tabela 18 - Dose de corretivo, em $\mathrm{g} \mathrm{kg}^{-1} \mathrm{Ca} \mathrm{CO}_{3}$, estimada para se obter o teor máximo de $\mathrm{P}$, em g. $\mathrm{kg}^{-1}$, na parte aérea de plantas de milho e valores de $\mathrm{pH} \mathrm{CaCl}_{2}$ 0,01 mol. $\mathrm{L}^{-1}$ e teor de $\mathrm{P}$ na dose 0 e dose para máxima concentração de $\mathrm{P}$ nas plantas.

\begin{tabular}{cccccc}
\hline Amostra-solo & $\begin{array}{l}\text { Dose de corretivo } \\
\text { para máxima } \\
\text { concentração de } \mathrm{P}\end{array}$ & $\mathrm{pH} \mathrm{CaCl} 2$ & 0,01 mol. $\mathrm{L}^{-1}$ & \multicolumn{2}{c}{ Concentração de P } \\
\cline { 5 - 7 } & Dose 0 & $\begin{array}{l}\text { Dose máxima } \\
\text { concentração }\end{array}$ & Dose 0 & Máxima \\
\hline LD2 & 3,55 & 4,2 & 5,4 & 0,822 & 1,223 \\
LD3 & 2,65 & 4,7 & 5,5 & 1,402 & 1,563 \\
LD4 & 3,90 & 4,8 & 5,7 & 1,045 & 1,758 \\
LD5 & $*$ & 4,3 & $*$ & 1,158 & $*$ \\
RP1 & 2,00 & 4,6 & 5,3 & 1,433 & 1,554 \\
RP7 & 3,20 & 4,6 & 5,3 & 1,433 & 1,640 \\
RP13 & 3,00 & 4,5 & 5,5 & 1,525 & 1,723 \\
\hline
\end{tabular}

*Não houve ajuste a modelo de regressão entre dose e teor de $\mathrm{P}$ na planta.

dose de corretivo que resultou no máximo teor de $\mathrm{P}$ nas plantas de milho, igualando-se $\mathrm{dy} / \mathrm{d} x=0$. Substituiu-se $o$ valor da dose máxima na equação que relacionou doses e $\mathrm{pH}$ (Tabela 4) e estimou-se os valores de pH para esse máximo teor (Tabela 18). Constata-se que as doses correspondentes aos teores máximos de fósforo na planta foram próximas daquelas para a máxima produção de matéria seca nos solos LD2, LD3, e um pouco menores nos solos RP1, RP7 e RP13 (Figura 21). Os maiores teores de P na planta 


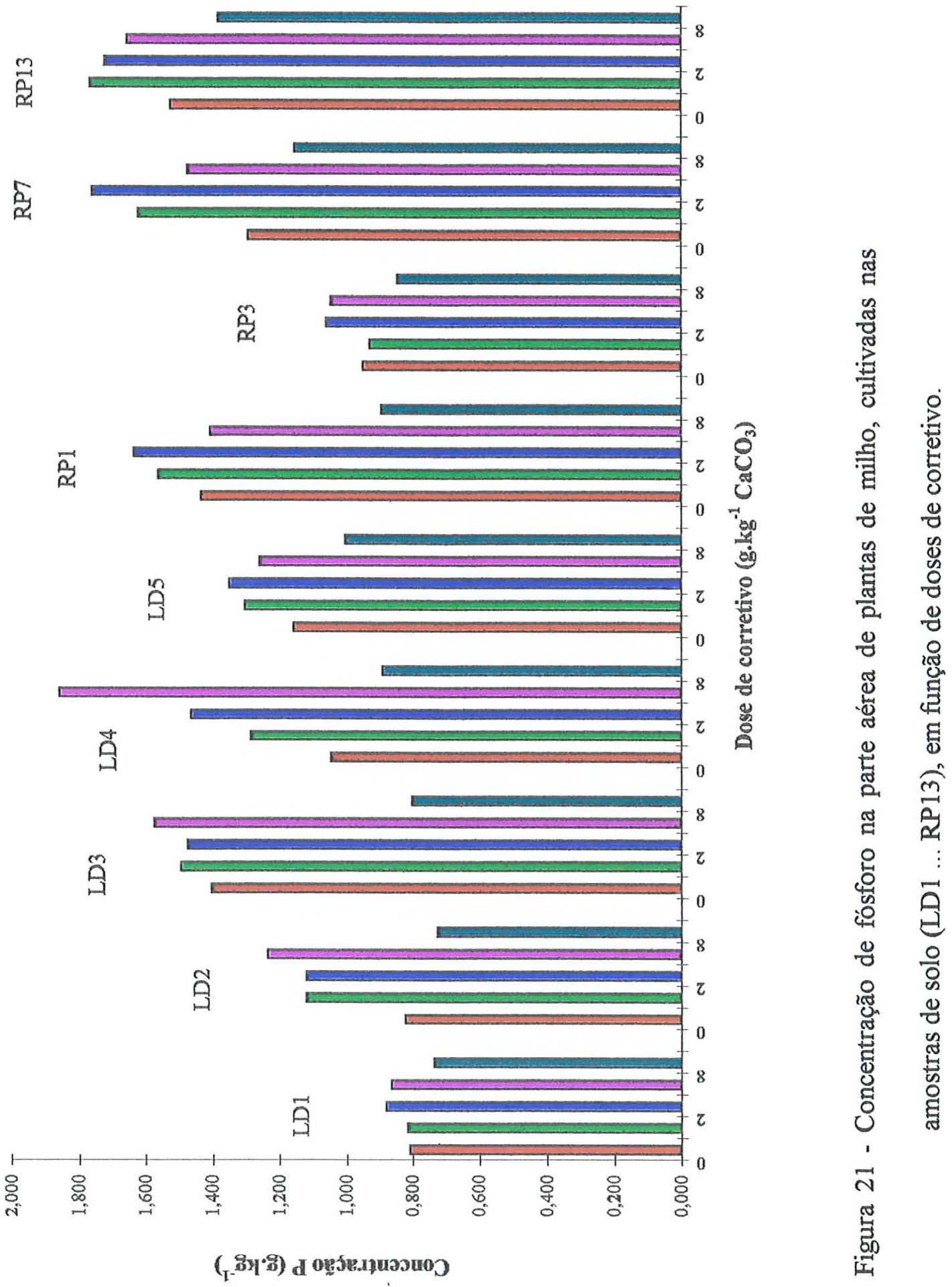


observados em valores absolutos (Tabela17), ocorreram nas mesmas doses que permitiram as maiores produções de matéria seca (Figura 17) nos solos LDI, LD5, RP1, RP13, ou em doses maiores nos solos LD2, LD3, LD4. A absorção de fósforo refletiu na produção de matéria seca: maior absorção propiciou maior produção de matéria seca e vice-versa.

\subsection{3. - Quantidade de fósforo na parte aérea.}

As quantidades de fósforo acumuladas na parte aérea de arroz e milho diferiram entre solos, doses e nas suas interações (Tabela 2).

As diferenças entre solos foram condicionadas pelos diferentes "status" de fósforo (Tabela 19). As plantas de arrozz apresentaram maior acúmulo de $\mathrm{P}$ nos solos com maior teor de fósforo, mantendo este tendência até a dose $4 \mathrm{~g} \cdot \mathrm{kg}^{-1} \mathrm{CaCO}_{3}$ (Figura 22). Na dose $8 \mathrm{~g} \cdot \mathrm{kg}^{-1} \mathrm{CaCO}_{3}$, os efeitos dos teores de fósforo no solo nas quantidades de $\mathrm{P}$ nas plantas diminuíram, com apenas a amostra do solo LD5 diferindo estatisticamente das demais, as quais foram semelhantes entre si, pelo teste Tukey ao nível de $5 \%$ de significância (Tabela 19).

As plantas de milho também apresentaram diferenças nas quantidades acumuladas em função dos solos e dentro das doses, com diminuição dos efeitos de solo

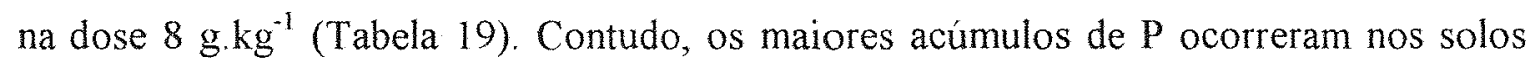
provenientes de Ribeirão Preto-SP, RP1, RP7, RP13, (Figura 23) diferentemente do que foi observado para o arroz (Figura 22). 
Tabela 19 - Fósforo acumulado na parte aérea de arroz e milho, em mg/vaso, cultivados nas diferentes amostras de solo submetidas a doses de corretivo, em g. $\mathrm{kg}^{-1} \mathrm{CaCO}_{3}$. Média de três repetições ${ }^{1}$.

\begin{tabular}{|c|c|c|c|c|c|}
\hline \multirow[t]{2}{*}{ Amostra-solo } & \multicolumn{5}{|c|}{ Dose de corretivo $\left(\mathrm{g}^{\mathrm{kg}} \mathrm{kg}^{-1} \mathrm{CaCO}_{3}\right)$} \\
\hline & 0 & 1 & 2 & 4 & 8 \\
\hline & \multicolumn{5}{|c|}{$1^{0}$ Cultivo (Arroz) } \\
\hline LD1 & $4,2 \mathrm{~d}$ & $3,4 \mathrm{f}$ & $3,6 \mathrm{f}$ & $1,4 \mathrm{e}$ & $0,25 \mathrm{~b}$ \\
\hline LD2 & $16,6 \mathrm{c}$ & $13,0 \mathrm{e}$ & $14,0 \mathrm{e}$ & $11,4 \mathrm{~d}$ & $0,63 \mathrm{~b}$ \\
\hline LD3 & $24,6 b$ & $23,1 \mathrm{c}$ & $23,6 \mathrm{~cd}$ & $22,8 b c$ & $0,91 \mathrm{~b}$ \\
\hline LD4 & $36,0 \mathrm{a}$ & $34,7 \mathrm{~b}$ & $37,1 \mathrm{~b}$ & $28,9 \mathrm{~b}$ & $4,17 b$ \\
\hline LD5 & $40,9 \mathrm{a}$ & $46,5 \mathrm{a}$ & $45,6 \mathrm{a}$ & $35,2 \mathrm{a}$ & $15,8 \mathrm{a}$ \\
\hline RPI & $19,1 b c$ & $16,8 \mathrm{de}$ & $18,3 \mathrm{de}$ & $18,2 \mathrm{c}$ & $5,1 b$ \\
\hline RP3 & $4,8 \mathrm{~d}$ & $3,5 \mathrm{f}$ & $2,9 \mathrm{f}$ & $2,9 \mathrm{e}$ & $1,3 \mathrm{~b}$ \\
\hline RP7 & $23,4 \mathrm{~b}$ & $23,4 \mathrm{c}$ & $24,7 \mathrm{c}$ & $20,7 \mathrm{c}$ & $2,8 \mathrm{~b}$ \\
\hline \multirow[t]{2}{*}{ RP13 } & $21,10 \mathrm{bc}$ & $21,1 \mathrm{~d}$ & $25,3 \mathrm{c}$ & $23,2 \mathrm{bc}$ & $5,4 b$ \\
\hline & \multicolumn{5}{|c|}{$2^{\circ}$ Cultivo (Milho) } \\
\hline LD1 & $2,0 \mathrm{c}$ & $2,1 \mathrm{~d}$ & $2,7 \mathrm{~d}$ & $2,0 \mathrm{~d}$ & $1,76 \mathrm{~b}$ \\
\hline LD2 & $2,3 \mathrm{c}$ & $4,0 \mathrm{~cd}$ & $4,6 \mathrm{~cd}$ & $4,0 \mathrm{~cd}$ & $1,8 \mathrm{~b}$ \\
\hline LD3 & $5,0 \mathrm{abc}$ & $6,6 b c$ & $7,2 \mathrm{bc}$ & $6,3 b c$ & $2,0 \mathrm{~b}$ \\
\hline LD4 & $4,7 b c$ & $6,4 \mathrm{bc}$ & $8,7 b$ & $8,8 \mathrm{ab}$ & $2,9 \mathrm{ab}$ \\
\hline LD5 & $6,2 a b$ & $7,6 \mathrm{abc}$ & $9,3 a b$ & $6,5 b c$ & $3,5 \mathrm{ab}$ \\
\hline RP1 & $7,3 a b$ & $8,7 \mathrm{ab}$ & $9,7 a b$ & $8,3 \mathrm{ab}$ & $2,6 \mathrm{~b}$ \\
\hline RP3 & $2,3 \mathrm{c}$ & $2,6 \mathrm{~d}$ & $3,2 \mathrm{~d}$ & $3,9 \mathrm{~cd}$ & $2,6 b$ \\
\hline RP7 & $6,9 \mathrm{ab}$ & $9,2 \mathrm{ab}$ & $12,8 \mathrm{a}$ & $11,8 \mathrm{a}$ & $3,7 \mathrm{ab}$ \\
\hline RP13 & $8,5 \mathrm{a}$ & $11,2 \mathrm{a}$ & $12,6 \mathrm{a}$ & 12,0 & $6,6 \mathrm{a}$ \\
\hline
\end{tabular}

1 - Médias seguidas pela mesma letra na coluna, dentro de cada cultivo, não diferem entre si, ao nivel de $5 \%$ pelo teste Tukey. $\mathrm{CV}$ arroz $=13,65 \%$ e CV milho $=24,58 \%$. 


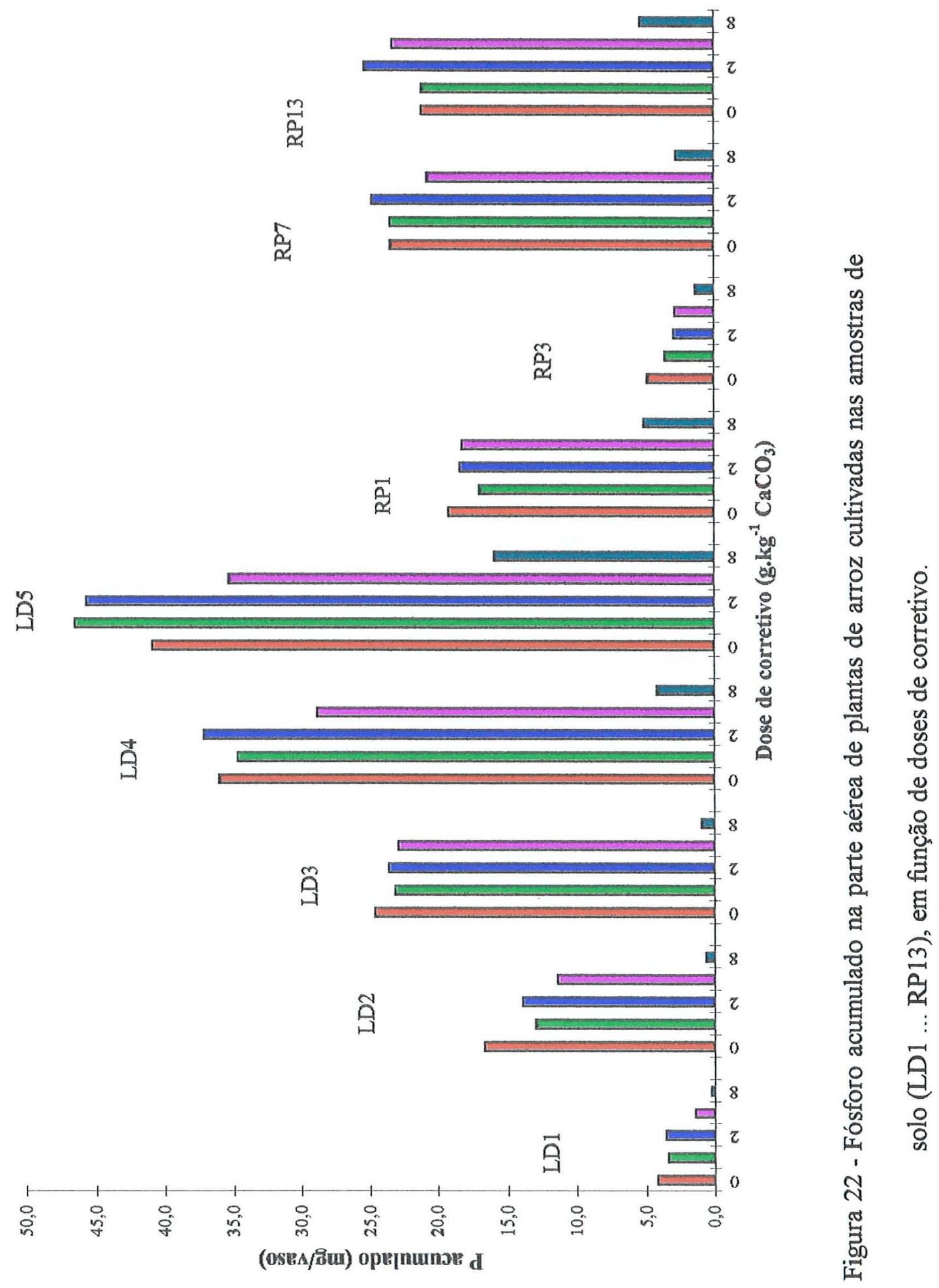




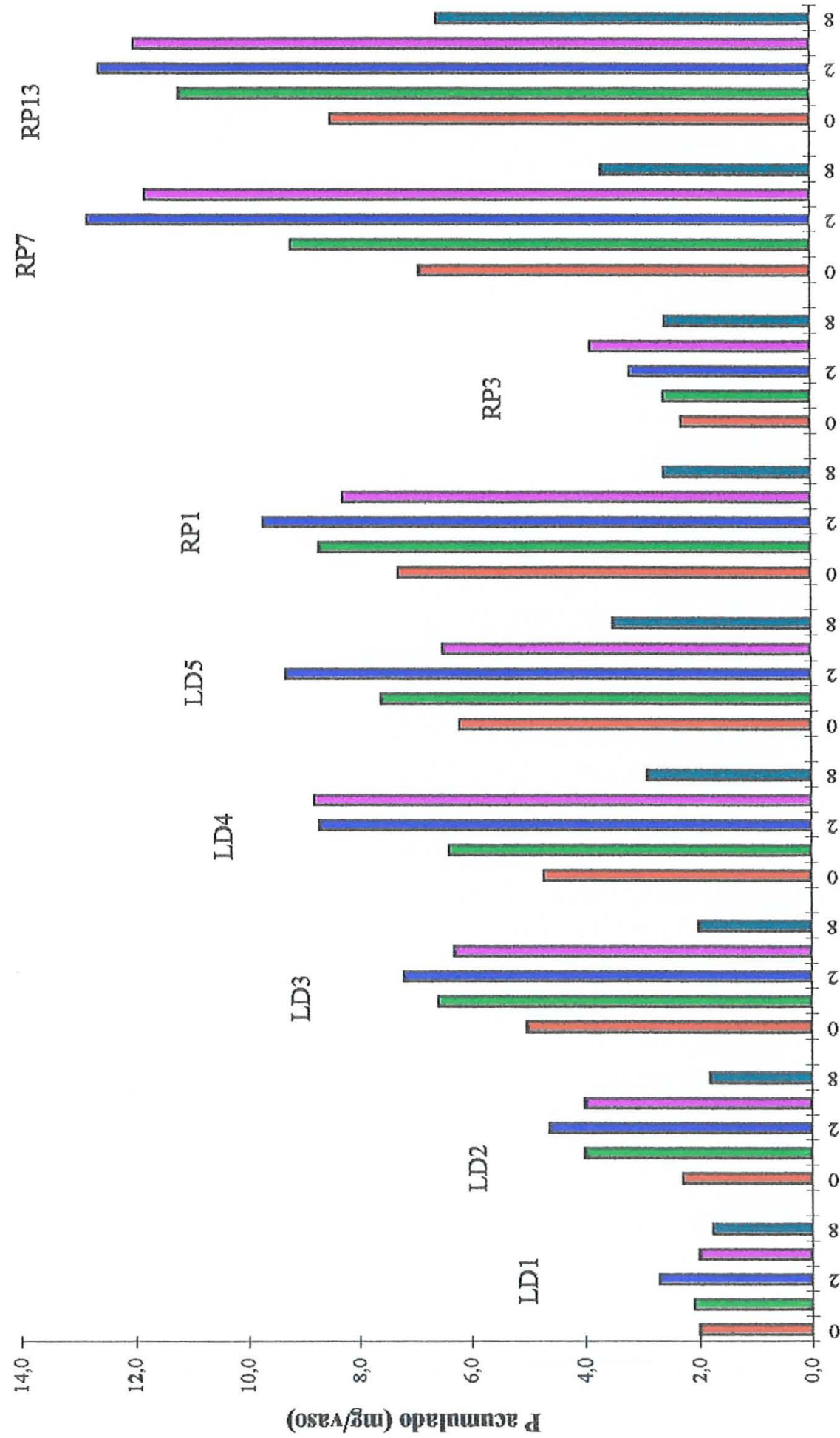


A quantidade de fósforo acumulada na parte aérea diminuiu com a dose de corretivo. Nas plantas de arroz os decréscimos foram aproximadamente proporcionais entre as doses 0 e $4 \mathrm{~g} \mathrm{~kg}^{-1} \mathrm{CaCO}_{3}$, e uma redução drástica nas quantidades acumuladas na dose $8 \mathrm{~g} \cdot \mathrm{kg}^{-1} \mathrm{CaCO}_{3}$. Como observado com a matéria seca do arroz, na maioria dos solos houve ajuste ao modelo quadrático (Figura 24) em decorrência do ajuste dos dados à seção decrescente da parábola, condicionado pela drástica redução de $\mathrm{P}$ acumulado na dose $8 \mathrm{~g}^{\mathrm{kg}}{ }^{-1}$ de carbonatos.

Nas plantas de milho, tal como na matéria seca acumulada, as quantidades de fósforo na parte aérea são maiores nas doses intermediárias e mínimas na dose $8 \mathrm{~g} \mathrm{~kg}^{-1}$ $\mathrm{CaCO}_{3}$, ajustando-se os dados a uma equação de segundo grau (Figura 24). As doses exerceram um efeito similar sobre todos os parâmetros medidos das plantas de milho, com maior crescimento, maior absorção de $\mathrm{P}$ entre as doses 2 e $4 \mathrm{~g}_{\mathrm{kg}}{ }^{-1}$ de corretivo e drástica redução na dose $8 \mathrm{~g} \cdot \mathrm{kg}^{-1} \mathrm{CaCO}_{3}$. A dose e o $\mathrm{pH}$ em $\mathrm{CaCl}_{2}$ 0,01 mol.L $\mathrm{L}^{-1}$ que proporcionou o máximo acúmulo de $\mathrm{P}$ na parte aérea, e o máximo $\mathrm{P}$ acumulado, em g/vaso, são indicados na Tabela 20. Verifica-se que houve maior acúmulo de $\mathrm{P}$ com o aumento do pH e com aumento do teor de $\mathrm{P}$ dentro de cada procedência de solos. 

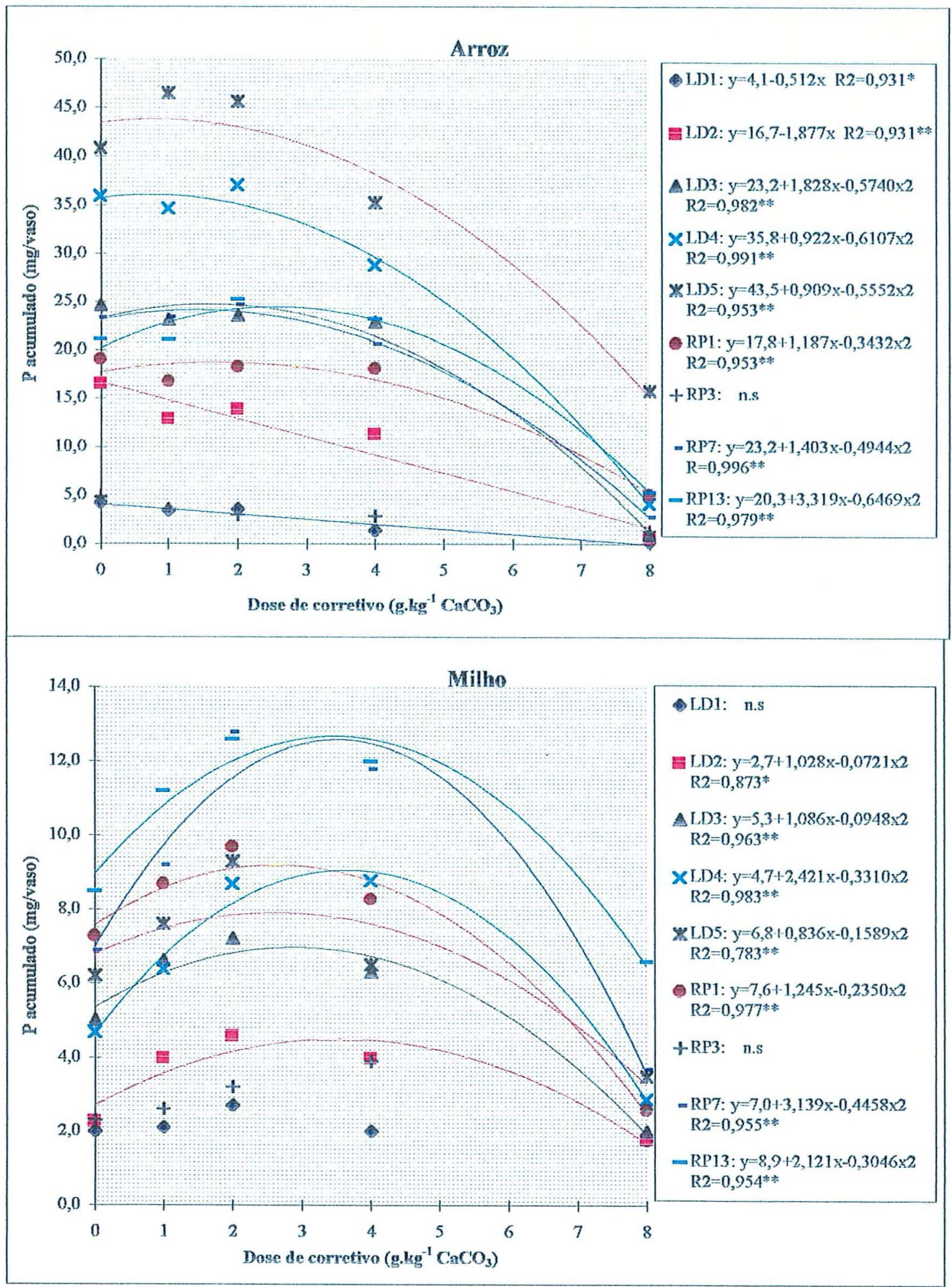

Figura 24 - Fósforo acumulado na parte aérea de plantas de arroz e milho, cultivadas nas amostras de solo (LD1...RP13), em função de doses de corretivo. 
Tabela 20 - Dose de corretivo, em g. $\mathrm{Kg}^{-1} \mathrm{Ca} \mathrm{CO}_{3}$, estimada para se obter o máximo $\mathrm{P}$ acumulado, em mg/vaso, na parte aérea de plantas de milho e valores de $\mathrm{pH}$ $\mathrm{CaCl}_{2}$ 0,01 mol. $\mathrm{L}^{-1}$ e quantidade de $\mathrm{P}$ acumulado, na dose 0 e dose para máximo acúmulo.

\begin{tabular}{|c|c|c|c|c|c|}
\hline \multirow[t]{2}{*}{ Amostra-solo } & Dose de corretivo & \multicolumn{2}{|c|}{$\mathrm{pHCaCl} 20,01 \mathrm{~mol} \cdot \mathrm{L}^{-1}$} & \multicolumn{2}{|c|}{ P acumulado. } \\
\hline & $\begin{array}{l}\text { para máximo } \\
\text { acúmulo de } \mathrm{P} \text {. }\end{array}$ & Dose 0 & $\begin{array}{l}\text { Dose } \\
\text { máximo } \\
\text { acúmulo. }\end{array}$ & Dose 0 & máximo \\
\hline \multicolumn{4}{|c|}{$-\mathrm{g} \cdot \mathrm{kg}^{\mathrm{T}} \mathrm{CaCO}_{3}$} & \multicolumn{2}{|c|}{$-m$} \\
\hline LD2 & 3,55 & 4,2 & 5,4 & 2,3 & 4,5 \\
\hline LD3 & 2,85 & 4,7 & 5,6 & 5,0 & 6,9 \\
\hline LD4 & 3,65 & 4,8 & 5,7 & 4,7 & 9,1 \\
\hline LD5 & 2,65 & 4,3 & 5,1 & 6,2 & 7,9 \\
\hline RP1 & 2,65 & 4,6 & 5,4 & 7,3 & 9,3 \\
\hline RP7 & 3,50 & 4,6 & 5,5 & 6,9 & 12,6 \\
\hline RP13 & 3,50 & 4,5 & 5,6 & 8,5 & 12,7 \\
\hline
\end{tabular}

\subsection{4. - A disponibilidade de fósforo e as respostas das plantas}

$\mathrm{O}$ arroz e o milho apresentaram comportamentos distintos em relação aos efeitos das doses de corretivo ina absorção de fósforo e produção de matéria seca. Observou-se no arroz que a produção de matéria seca e a quantidade de fósforo acumulada decresceram com o aumento das doses (Figura 16,22), enquanto o teor de $\mathrm{P}$ aumentou, na maioria dos solos (Figura 20). No milho, esses parâmetros atingiram valores máximos 


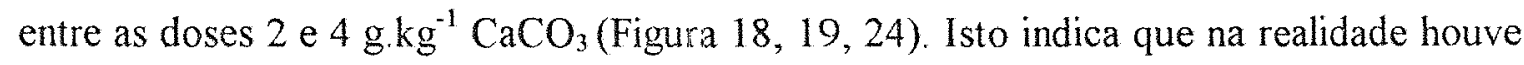
aumento da disponibilidade de fósforo e, tal como ocorreu com os extratores, as plantas apresentaram sensibilidades diferentes para detectar essa variação. Essa sensibilidade da planta será determinada, em última análise, pelo seu comportamento frente às variações nos outros componentes da nutrição das plantas, provocadas pela alteração do $\mathrm{pH}$. Provavelmente essas diferenças de sensibilidade podem estar relacionadas às respostas diferentes das plantas às alterações na disponibilidade de micronutrientes provocadas pela elevação do pH do solo.

JARRELL \& BEVERLY (1981) registram que o pH pode aparentemente afetar tanto as concentrações do nutriente em solução como a absorção do nutriente da solução. Consideram que os efeitos do $\mathrm{pH}$ sobre o crescimento das plantas são numerosos, tornando-se dificil separar aqueles relacionados ao aumento de disponibilidade de um nutriente. Entretanto, em alguns casos, aumentos de crescimento podem ser devidos primariamente a aumentos de disponibilidade de um nutriente específico.

HAYNES \& LUDECKE (1981) consideraram que o efeito estimulatório da calagem em aumentar a produção de matéria seca é indireto, não se devendo ao aumento da disponibilidade do fósforo, mas à redução dos níveis de $\mathrm{Al}$ e $\mathrm{Mn}$ disponíveis no solo. Tal hipótese não foi observada na presente pesquisa, considerando-se as respostas opostas das plantas utilizadas

No caso do arroz, outros efeitos foram principais e preponderantes em relação aos efeitos advindos do aumento na disponibilidade de fósforo, ou redução nos níveis de alumínio e manganês. $\mathrm{O}$ milho apresentou maior sensibilidade provavelmente por sua 
maior tolerância a esses outros efeitos indiretos da calagem, considerando-se que a saturação de alumínio, nas amostras aqui estudadas, não seria fator limitante Possivelmente outra planta, com padrão de exigência maior que o milho em relação ao $\mathrm{pH}$, apresentasse respostas maiores às variações de fósforo disponivel, ocasionadas pela elevação do $\mathrm{pH}$.

No presente trabalho buscaram-se variedades consideradas responsivas ao fósforo e, ao mesmo tempo, tolerantes à acidez. Não obstante, arroz mostrou-se bastante responsiva ao fósforo, contudo bastante sensivel às mudanças químicas provocadas pelo aumento de $\mathrm{pH}$.

$\mathrm{Na}$ realidade, as divergências encontradas quanto aos efeitos da calagem na disponibilidade de fósforo, e nas correlações com plantas devem estar associadas também, em grande parte, às características das plantas testes.

Em face das respostas aqui obtidas com as plantas de milho podemos verificar que com a calagem houve aumento na disponibilidade de fósforo.

\section{4. - Relação entre parâmetros da planta e fósforo extraído pelos diferentes extratores.}

Arroz e milho apresentaram respostas diferenciadas em termos de crescimento, entre solos. Essas respostas, dentro de uma mesma dose deveram-se em parte à variação dos teores de fósforo nesses solos e à influência do pH no crescimento das plantas. 


\subsection{1. - Arroz}

O efeito do solo está associado aos teores de fósforo. Especialmente para o arroz, houve aumento de produção de matéria seca com o aumento do teor de fósforo do solo dentro de doses de corretivos. As maiores produções foram observadas nos solos LD5 e LD4 que apresentam os maiores teores de P extraídos por todos os extratores (Figura $7,8,9,10$ ). Com a elevação do pH houve decréscimo de produção, mas esta continuou sendo maior nesses solos que nos demais, quando se considera a mesma dose (Figura 16)

$\mathrm{O}$ arroz respondeu ao fósforo até nos valores mais altos desse elemento. $\mathrm{Na}$ Tabela 21 são mostrados os coeficientes de correlação entre $\mathrm{P}$ extraído e parâmetros de crescimento da planta. Os altos coeficientes de correlação positivo entre estes parâmetros especificamente matéria seca e $\mathrm{P}$ acumulado mostram que houve resposta crescente do arroz aos teores de fósforo do solo. As mais altas correlações, na maioria dos casos, foram observadas para $P$ resina.

A não resposta do arroz às variações dos teores de fósforo em função da calagem ocorreu porque outro fator de produção passou a ser mais limitativo que o fósforo, possivelmente micronutrientes como sugerido por BARBOSA FILHO (1986)

Considerando cada solo, na Tabela 22 , os parâmetros da planta que mais se correlacionaram com $\mathrm{P}$ extraído pelos extratores foram matéria seca (g/vaso) e 
Tabela 21 - Coeficientes de correlação linear simples (r) entre os teores de fósforo extraidos pelos diferentes extratores e parâmetros das plantas de arroz, considerando-se os solos em conjunto.

\begin{tabular}{|c|c|c|c|c|c|c|}
\hline \multicolumn{2}{|c|}{ Parâmetros } & \multicolumn{5}{|c|}{ Dose de corretivo $\left(\mathrm{g} \cdot \mathrm{kg}^{-1} \mathrm{CaCO}_{3}\right)$} \\
\hline Solo & Planta & 0 & 1 & 2 & 4 & 8 \\
\hline \multirow{3}{*}{ P Bray-1 } & M. seca & $0,741 * *$ & $0,746 * *$ & $0,718 * *$ & $0,730 * *$ & $0,898 * *$ \\
\hline & $P(g / K g)$ & $0,746 * *$ & $0,894 * *$ & $0,854 * *$ & $0,658 * *$ & $0,213^{n . s}$ \\
\hline & $\mathrm{P}$ (mg/vaso) & $0,855 * *$ & $0,899 * *$ & $0,870 * *$ & $0,810 * *$ & $0,893 * *$ \\
\hline \multirow{4}{*}{ P Mehlich-1 } & M. seca & $0,709 * *$ & $0,727 * *$ & $0,696 * *$ & $0,678 * *$ & $0,904 * *$ \\
\hline & $\mathrm{P}(\mathrm{g} / \mathrm{Kg})$ & $0,749 * *$ & $0,871 * *$ & $0,819 * *$ & $0,621 * *$ & $0,025^{\text {घ.s }}$ \\
\hline & $\mathrm{P}$ (mg/vaso) & $0,838 * *$ & $0,886 * *$ & $0,850 * *$ & $0,766 * *$ & $0,860 * *$ \\
\hline & M. seca & $0,753 * *$ & $0,771 * *$ & $0,749 * *$ & $0,752 * *$ & $0,841 * *$ \\
\hline \multirow[t]{3}{*}{ P Mehlich-3 } & $\mathrm{P}(\mathrm{g} / \mathrm{Kg})$ & $0,738 * *$ & $0,900 * *$ & $0,863 * *$ & $0,689 * *$ & $0,251^{\mathrm{n.s}}$ \\
\hline & $\mathrm{P}$ (mg/vaso) & $0,865 * *$ & $0,918 * *$ & $0,896 * *$ & $0,831 * *$ & $0,853 * *$ \\
\hline & M. seca & $0,781 * *$ & $0,825 * *$ & $0,771 * *$ & $0,776 * *$ & $0,881 * *$ \\
\hline \multirow[t]{3}{*}{ P Olsen } & $\mathrm{P}(\mathrm{g} / \mathrm{Kg})$ & $0,768 * *$ & $0,912 * *$ & $0,863 * *$ & $0,681 * *$ & $0,239^{n . s}$ \\
\hline & $\mathrm{P}$ (mg/vaso) & $0,887 * *$ & $0,944 * *$ & $0,908 * *$ & $0,846 * *$ & $0,884 * *$ \\
\hline & M. seca & $0,800 * *$ & $0,849 * *$ & $0,815 * *$ & $0,856 * *$ & $0,752 * *$ \\
\hline \multirow[t]{2}{*}{ Presina } & $P(g / K g)$ & $0,747 * *$ & $0,909 * *$ & $0,885 * *$ & $0,742 * *$ & $0,430^{\text {n.s }}$ \\
\hline & $\mathrm{P}$ (mg/vaso) & $0,893 * *$ & $0,954 * *$ & $0,937 * *$ & $0,916 * *$ & $0,804 * *$ \\
\hline \multirow[t]{2}{*}{ M. Seca } & $P(g / K g)$ & $0,676 * *$ & $0,810 * *$ & $0,705 * *$ & $0,717 * *$ & $0,028^{\text {n.s }}$ \\
\hline & $\mathrm{P}$ (mg/vaso) & $0,966 * *$ & $0,945 * *$ & $0,942 * *$ & $0,976 * *$ & $0,970 * *$ \\
\hline$P(g / K g)$ & $P(\mathrm{mg} /$ vaso $)$ & $0,813 * *$ & $0,940 * *$ & $0,887 * *$ & $0,803 * *$ & $0,232^{n . s}$ \\
\hline
\end{tabular}

n.s. - não significativo.

* - significativo ao nivel de $5 \%$ de probabilidade.

** - significativo ao nivel de $1 \%$ de probabilidade. 


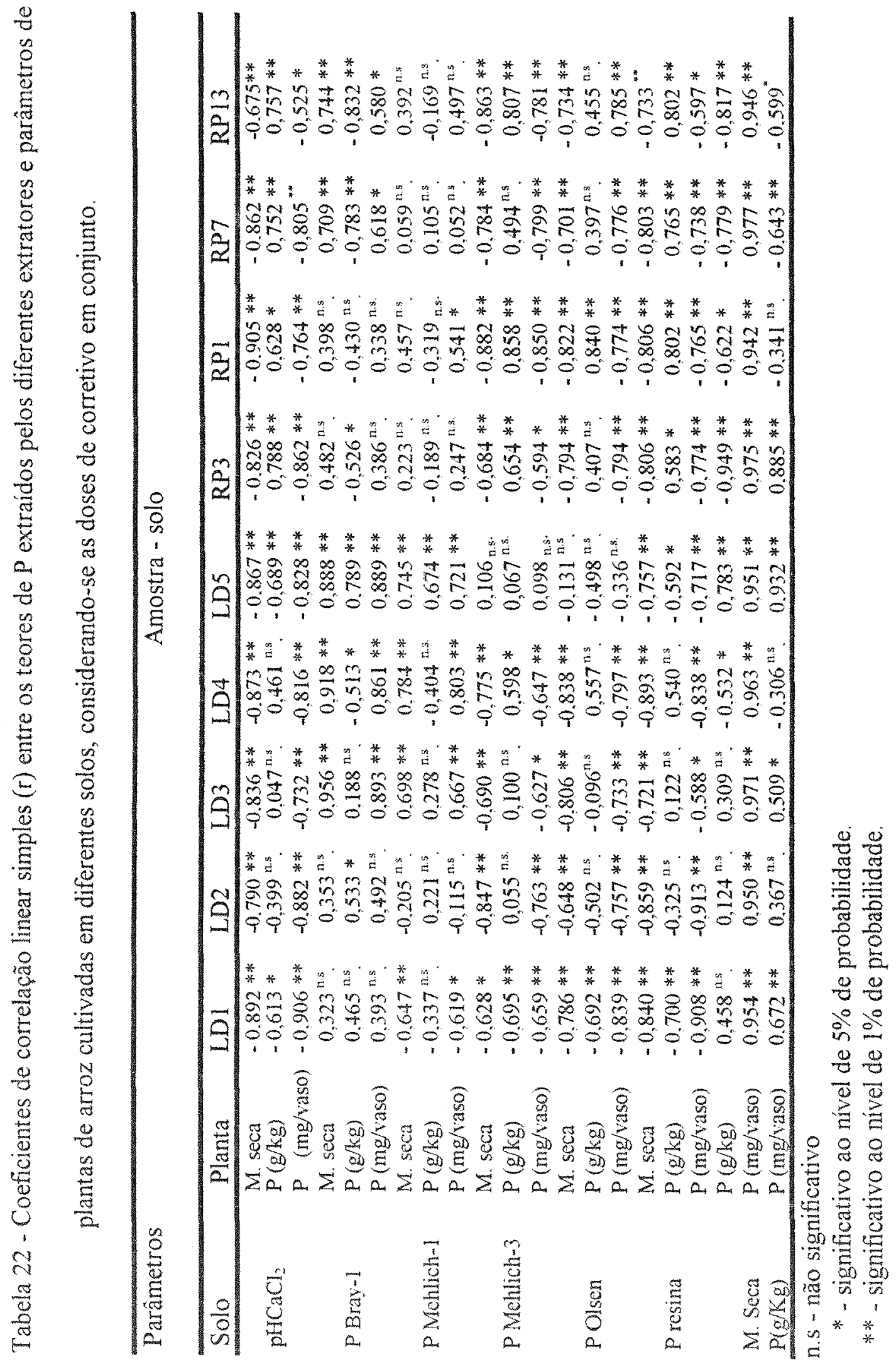


quantidade de fósforo acumulada na parte aérea (mg/vaso). Houve forte correlação inversa para os extratores Resina, Olsøn, Mehlich-3 e correlação direta para Bray-1. O extrator Mehlich-1 apresentou correlações mais fracas que os demais extratores, quando se considera cada solo em separado.

\subsection{2. - Milho.}

A equação quadrática que expressa a relação entre teor de fósforo na parte aérea de milho e dose de corretivo indica que houve inicialmente estímulo à absorção até o intervalo das doses 2 e $4 \mathrm{~g} \cdot \mathrm{kg}^{-1} \mathrm{CaCO}_{3}$ (Figura 21). Dois aspectos podem ser considerados para explicar esse fenômeno: menor absorção por causa da deficiência de um outro nutriente ou redução da disponibilidade de fósforo na dose $8 \mathrm{~g} \cdot \mathrm{kg}^{-1} \mathrm{CaCO}_{3}$, devido a elevados valores de $\mathrm{pH}$.

Separando os solos, por origem (RP ou LD) tem-se que a produção de matéria seca (Figura 17, 18) e a quantidade de $\mathrm{P}$ absorvido (Figura 23, 24)) aumentaram naquele intervalo de doses, assim como os teores de $\mathrm{P}$ extraidos pela resina, Mehlich-3 (Figural1 13). Nos solos LD5 e RP13 o milho apresentou maior teor de P na parte aérea, bem

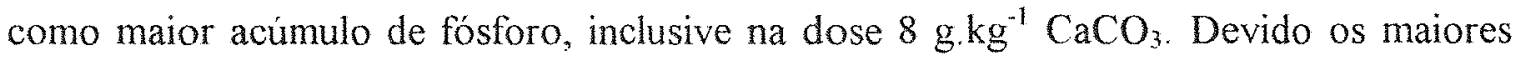
teores de fósforo no solo teve-se maior absorção desse nutriente e maior produção de matéria seca até o nivel de $\mathrm{pH}$ em que outro fator passou a ser preponderante. Este fato pode também ser visto na Tabela 23 , quando a partir da dose $4 \mathrm{~g} \cdot \mathrm{kg}^{-1} \mathrm{CaCO}_{3}$, as 
Tabela 23 - Coeficiente de correlação linear simples (r) entre os teores de fósforo extraídos pelos diferentes extratores e parâmetros das plantas de milho, considerando-se os solos em conjunto.

\begin{tabular}{|c|c|c|c|c|c|c|}
\hline \multicolumn{2}{|c|}{ Parâmetros } & \multicolumn{5}{|c|}{ Dose de corretivo $\left(\mathrm{g} \cdot \mathrm{kg}^{-1} \mathrm{CaCO}_{3}\right)$} \\
\hline Solo & Planta & 0 & 1 & 2 & 4 & 8 \\
\hline \multirow{3}{*}{ P Bray-1 x } & M. seca & $0,604 * *$ & $0,536 * *$ & $0,564 * *$ & $0,272^{\text {n.s }}$ & $0,365^{\mathrm{ns}}$ \\
\hline & $\mathrm{P}(\mathrm{g} / \mathrm{kg})$ & $0,205^{\text {n.s }}$ & $0,264^{\mathrm{nss}}$ & $0,237^{n . s}$ & $0,274^{\text {n.s. }}$ & $0,322^{\text {n.s }}$ \\
\hline & $\mathrm{P}(\mathrm{mg} / \mathrm{vaso})$ & $0,433 *$ & $0,403 *$ & $0,412 *$ & $0,259^{\mathrm{ns}}$ & $0,300^{\mathrm{ns}}$ \\
\hline \multirow{3}{*}{ P Mehlich-1 } & M. seca & $0,411 *$ & $0,383 *$ & $0,394 *$ & $0,060^{\mathrm{ns}}$ & $0,212^{n . s}$ \\
\hline & $\mathrm{P}(\mathrm{g} / \mathrm{kg})$ & $0,051^{\mathrm{ns}}$ & $0,073^{\text {n.s }}$ & $0,070^{\mathrm{n} . \mathrm{s}}$ & $0,212^{\mathrm{n} . \mathrm{s}}$ & $0,116_{\mathrm{n} . \mathrm{s}}$ \\
\hline & $\mathrm{P}$ (mg/vaso) & $0,226^{n . s}$ & $0,204^{\text {n.s }}$ & $0,224^{\text {n.s }}$ & $0,092^{\mathrm{n.s}}$ & $0,118^{\text {n.s }}$ \\
\hline \multirow{3}{*}{ P Mehlich-3 } & M. seca & $0,497 * *$ & $0,448 *$ & $0,482 *$ & $0,208^{\text {n.s }}$ & $0,329^{\mathrm{ns}}$ \\
\hline & $P(g / k g)$ & $0,112^{n . s}$ & $0,160^{n . s}$ & $0,134^{\text {n.s }}$ & $0,173^{\mathrm{n} . \mathrm{s}}$ & $0,298^{\mathrm{n} . \mathrm{s}}$ \\
\hline & $\mathrm{P}(\mathrm{mg} / \mathrm{vaso})$ & $0,314^{\mathrm{ns}}$ & $0,288_{n . s}$ & $0,311^{\mathrm{n.s}}$ & $0,170^{\text {n.s }}$ & $0,262^{\mathrm{n.s}}$ \\
\hline \multirow{3}{*}{ P Olsen } & M. seca & $0,554 * *$ & $0,554 * *$ & $0,549 * *$ & $0,258^{\mathrm{ns}}$ & $0,283^{\text {n.s. }}$ \\
\hline & $P(\mathrm{~g} / \mathrm{kg})$ & $0,195^{\text {n.s }}$ & $0,249^{\mathrm{ns}}$ & $0,232^{\mathrm{n} . \mathrm{s}}$ & $0,3.46^{n . s}$ & $0,220^{\mathrm{n} . \mathrm{s}}$ \\
\hline & $\mathrm{P}$ (mg/vaso) & $0,395 *$ & $0,399 *$ & $0,397 *$ & $0,287^{\text {n.s }}$ & $0,207^{\mathrm{n.s}}$ \\
\hline \multirow{3}{*}{ Presina } & M. seca & $0,575 * *$ & $0,564 * *$ & $0,620 * *$ & $0,375^{\mathrm{n} \cdot \mathrm{s}}$ & $0,460 *$ \\
\hline & $P(g / k g)$ & $0,201^{\text {n.s }}$ & $0,311^{\text {n.s }}$ & $0,306^{\mathrm{n} . \mathrm{s}}$ & $0,381 *$ & $0,445 *$ \\
\hline & $\mathrm{P}$ (mg/vaso) & $0,403 *$ & $0,429 *$ & $0,474 *$ & $0,380 *$ & $0,417 *$ \\
\hline \multirow[t]{2}{*}{ M. Seca } & $\mathbf{P}(\mathrm{g} / \mathrm{kg})$ & $0,586 * *$ & $0,702 * *$ & $0,801 * *$ & $0,566 * *$ & $0,818 * *$ \\
\hline & $\mathrm{P}$ (mg/vaso) & $0,924 * *$ & $0,936 * *$ & $0,963 * *$ & $0,914 * *$ & $0,942 * *$ \\
\hline $\mathrm{P}(\mathrm{g} / \mathrm{kg})$ & $\mathrm{P}$ (mg/vaso) & $0,832 * *$ & $0,888 * *$ & $0,914 * *$ & $0,831 * *$ & $0,934 * *$ \\
\hline
\end{tabular}

n.s - não significativo.

* significativo ao nivel de $5 \%$ de probabilidade.

** significativo ao nível de $1 \%$ de probabilidade 
diferenças entre amostras solos deixaram de influenciar nas relações entre os parâmetros correlacionados.

Os coeficientes de correlação linear entre $\mathrm{P}$ extraído e parâmetros de crescimento do milho foram mais baixos que os observados para arroz (Tabela 23, 24). A relação quadrática observada entre doses e os parâmetros de crescimento de milho explicam as baixas correlações lineares entre esses parâmetros com o fósforo extraído.

\subsection{3 - Sensibilidade dos extratores}

Na Tabela 25 são mostrados os teores de fósforo extraídos pelo extrator Bray-1, Mehlich-3, Olsen e resina na dose 0 de corretivo e os teores estimados na dose para a produção máxima de materia seca de milho, naqueles solos onde essa estimativa foi possivel. Esses teores foram estimados, substituindo-se o valor da dose para máxima produção nas equações que relacionou teores extraídos e doses (Figuras 2, 4, 5 e 6). Verifica-se que o intervalo entre esses níveis são bastante pequenos e, em alguns casos para o extrator Bray-1 e Olsen, o teor estimado, na dose para máxima produção de matéria seca foi menor. O extrator resina indicou teores sempre maiores para a produção máxima de matéria seca, sendo em alguns casos o dobro, como pode ser observado no solo LD2, RP1 e RP13. No solo LD2, na dose zero do corretivo, o solo apresentava 7,0 $\mathrm{mg} \cdot \mathrm{dm}^{-3}$ de $\mathrm{P}$ resina e produziu $2,79 \mathrm{~g} / \mathrm{vaso}$ de matéria seca.. Com a calagem, o teor estimado na dose para a máxima produção de materia seca, extraido pela resina, aumentou para $15,7 \mathrm{mg} \cdot \mathrm{dm}^{-3}$, possibilitando a produção de $3,72 \mathrm{~g} / \mathrm{vaso}$, maior do que 


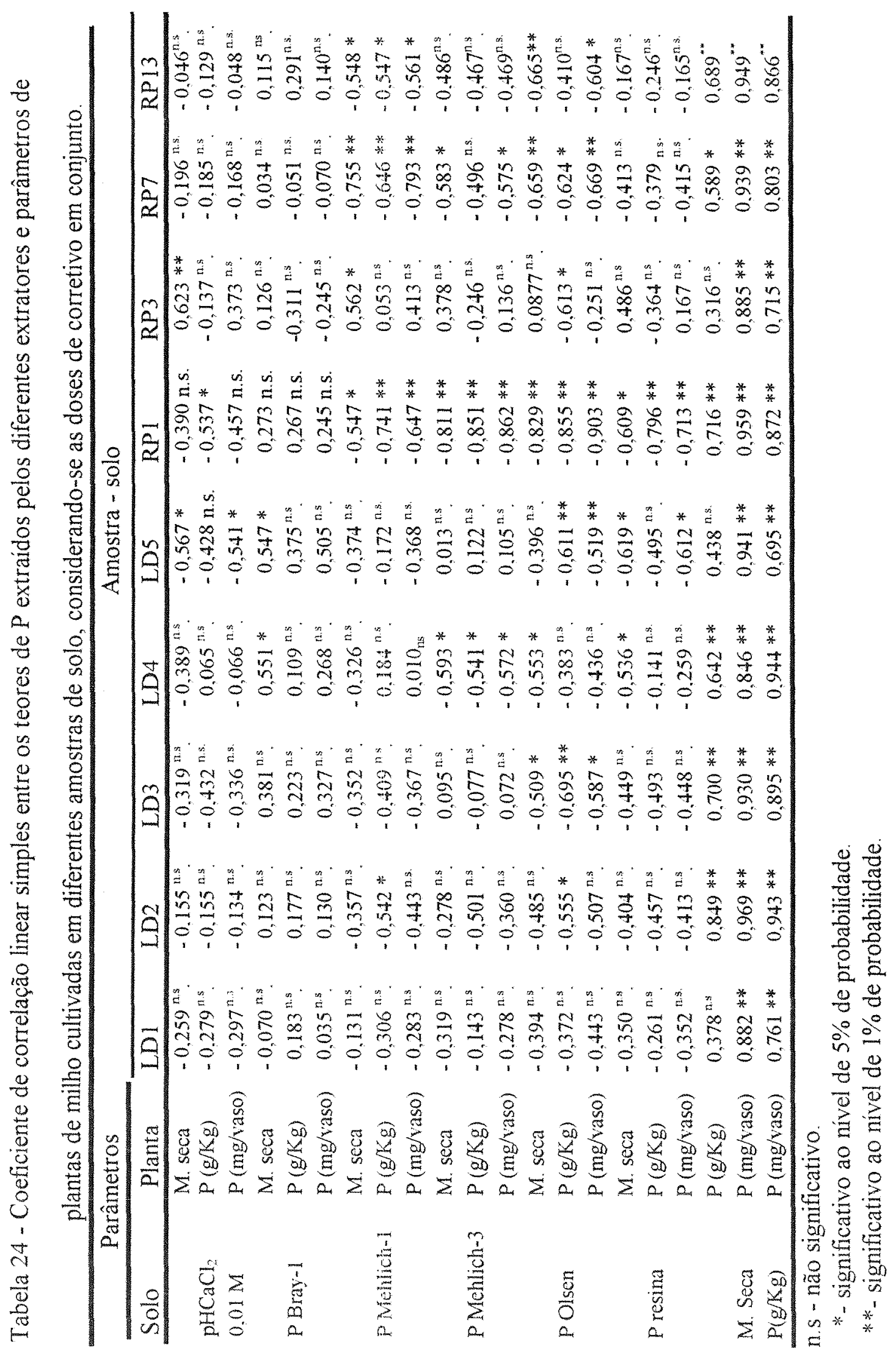




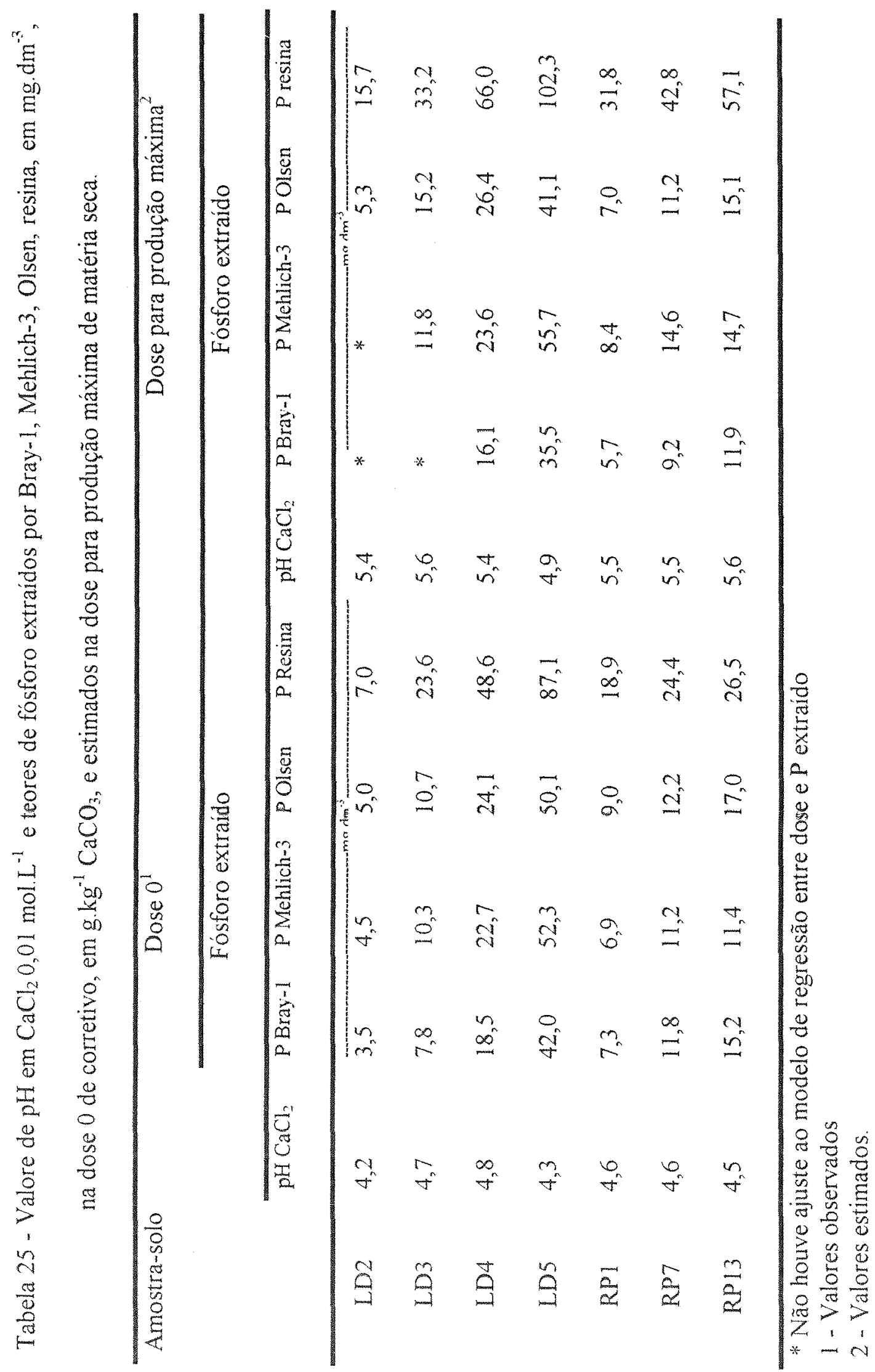


aquela observada $(3,56 \mathrm{~g} /$ vaso $)$ no teor de $23,6 \mathrm{mg} \mathrm{dm}^{-3}$ na dose zero do solo LD3. Portanto, além do aumento do $\mathrm{P}$ disponivel, houve efeito de interação. Outro aspecto relevante é que houve aumento na absorção de fósforo pela planta, tanto quando se considerou o teor na parte aérea, como quando se considerou a quantidade acumulada por vaso (Tabelas 16, 18, 20 e Figuras 19,24).

Os extratores resina e Mehlich-3 indicaram aumentos de $\mathrm{P}$ disponível com o $\mathrm{pH}$ e decréscimo entre cultivos. $\mathrm{O}$ extrator Bray-1 indicou decréscimo do $\mathrm{P}$ disponível com aumentos de $\mathrm{pH}$ e decréscimo entre cultivos. O extrator Mehlich-1 comportou-se de modo diferente, entre os dois cultivos: apresentou baixa sensibilidade para detectar as variações de $\mathrm{P}$ disponivel com menor extração, em função de doses no primeiro cultivo $\mathrm{e}$ maior extração no segundo cultivo, de forma oposta à previsão da redução de disponibilidade de fósforo com o tempo (BARROW, 1980). O extrator Olsen apresentou comportamento singular com decréscimo de P extraído até determinada dose de corretivo e posterior aumento, indicando porém redução da disponibilidade do fósforo no tempo.

Um extrator é considerado adequado para avaliar a disponibilidade de um nutriente quando as variações nos teores extraídos pelo extrator correspondem a variações no crescimento das plantas (BRAY, 1947). Neste contexto, vários extratores foram propostos para estimar a quantidade disponível de um elemento, da mesma forma que com um extrator pode se medir a fração disponivel de vários elementos (THOMAS \& PEASLE 1973). A busca é pelo extrator que seja o mais abrangente e, se possivel, universal. São propostos entre os diversos extratores, no atual estágio de conhecimento, o extrator Mehlich-3 (MEHLICH, 1984) e o extrator resina de troca mista (RAIJ, 1994). 
Apresentar boa correlação de quantidades extraídas com parâmetros de crescimento da planta e sofrer pouca influência das características do solo como $\mathrm{pH}$ e propriedades mineralógicas são propriedades desejáveis de um extrator (KAMPRATH \& WATSON, 1980). A sensibilidade correta incluiria as classes de nutrientes desde o nível de deficiência até o nivel de excesso, conforme a planta e a possibilidade de prever fatores essenciais e ou associados que são determinantes ao crescimento do vegetal. A planta utilizada influenciaria neste sentido.

A resina apresentou maior sensibilidade às variações na disponibilidade de fósforo em função de calagem, e o extrator Mehlich-1 a menor.

\subsection{Calagem e efeito residual do fósforo}

O efeito da calagem na disponibilidade do fósforo residual dos solos ocorreu tanto nas amostras contendo niveis baixos de fósforo quanto naquelas com niveis altos, mesmo nos solos que haviam sido adubados com fonte solúvel, a pelo menos dois anos antes, como foi o caso das amostras provenientes de Londrina-PR.

É amplamente registrado na literatura que a disponibilidade de uma fonte solúvel de fósforo aplicada ao solo reduz-se com o tempo (FASSBENDER,1968; BARROW,1980). Em pesquisas realizadas em latossolos do Brasil foi registrado por GONÇALVES (1988) e MOREIRA (1988) que esse fenômeno é bastante rápido bem como, tem-se constatado que a reversibilidade P-não lábil $\rightarrow$ P-lábil também é muito baixa (CAMPELLO, 1993) 
GONÇALVES et al (1989) registrou que a partir de 15 dias de contato com o solo houve redução na disponibilidade do $\mathrm{P}$ aplicado na forma solúvel, permanecendo praticamente inalterados os teores de $\mathrm{P}$ resina a partir deste tempo. Cabe registrar que as amostras desse experimento foram incubadas em condições artificiais.

Na presente pesquisa observou-se que a estabilização em condições de campo foi muito mais lenta que a relatada por GONÇALVES et al (1989) e MOREIRA (1988) A sazonalidade de umidade e temperatura nas condições de campo, deve ter contribuido para que o processo de redução da disponibilidade de fósforo do solo com o tempo ocorra em velocidade menor. Assim, as diferenças nas condições ambientais de estudos na relação fósforo-solo, devem merecer maior atenção.

CAMPELLO (1993) trabalhando em condições de laboratório, registrou que a calagem não alterou o teor total de P-lábil recuperado com extrações sucessivas pela resina Não se pode avaliar nesta pesquisa a relação P-lábil total e calagem, porém podese verificar que inicialmente a calagem teve efeito positivo no aumento do P-lábil do solo e que esse efeito permaneceu no solo durante o período de 19 meses em que durou o experimento. 


\section{CONCLUSÕES}

Os resultados obtidos nesta pesquisa permitem as seguintes conclusões:

1. A aplicação de corretivo influenciou na disponibilidade do fósforo residual do solo avaliada pelos extratores Bray-1, Mehlich-1, Mehlich-3, Olsen, e resina e plantas de arroz e milho.

2. Os extratores apresentaram sensibilidades diferentes na avaliação das mudanças na disponibilidade de fósforo provocada pela calagem. A resina seguida do Mehlich-3 mostraram-se os extratores mais sensifveis na avaliação das variaçóes do $\mathrm{P}$ disponível em função de calagem. Quanto à sensibilidade para detectar variações na disponibilidade do fósforo no solo, os extratores classificaram-se na seguinte ordem: resina $>$ Mehlich- $3>$ Olsen $>$ Bray $-1>$ Mehlich -1 .

3. Os teores de P extraídos por resina e Mehlich-3 aumentaram com as doses de corretivo, sendo que o aumento de extração pela resina foi muito mais expressivo e de forma linear. Os teores extraídos pelo extrator Bray-1 reduziram linearmente com o aumento de $\mathrm{pH}$, enquanto os teores de $\mathrm{P}$ Olsen diminuíram entre $\mathrm{pH}$ em $\mathrm{CaCl} 2$ 0,01 mol. $\mathrm{L}^{-1}$ 4,2 e 5,5. A extração por Mehlich-1 foi influenciada pelo tempo transcorrido na incubação. 
4. As plantas de arroz responderam de modo diferente das de milho às mudanças químicas no solo provocadas pela calagem. A produção de matéria seca pela parte aérea e a quantidade de fósforo acumulado na parte aérea das plantas de arroz decresceram com o aumento das doses do corretivo. O teor de fósforo na parte aérea das plantas de arroz aumentou com as doses do corretivo devido ao efeito de concentração.

5. O milho mostrou-se sensivel às variações dos teores de $\mathrm{P}$ do solo função da calagem, respondendo melhor que as de arroz às variações do teor de fósforo dos latossolos estudados. Os parâmetros de crescimento avaliados seguiram a mesma tendência de crescimento até pH 6,0 . 


\section{REFERÊNCIAS BIBLIOGRÁFICAS}

ADAMS, J.F. \& ODOM, J.W. Effects of $\mathrm{pH}$ and phosphorus rates on soil-solution phosphorus and phosphorus availability. Soil Science, Baltimore, v.40, n.3, p. 202$205,1985$.

AMARASIRI, S.L. \& OLSEN, S.R. Liming as related to solubility of P and plant growth in an acid tropical soil. Soil Science Society of America Proceedings, Madison, v.37, n.5, p. 716-721, 1973.

AMER, F.; BOULDINI, D.R; BLACK, C.A.; DUKE, F.R. Characterization of soil phosphorus by anion exchange resin adsorption and ${ }^{32} \mathrm{P}$-equilibration. Plant and Soil, The Hague, v. 6, p. 391-408, 1955.

ANJOS, J.T. \& ROWELL,D.L. The effect of lime on phosphorus adsorption and barley growth in three acid soils. Plant and Soil, The Hague, v.103, n.1, p. 75-82, 1987.

BACHE, B.W. Aluminum and iron phosphates studies relating to soils. Il. Reactions between phosphate and hydrous oxides. Journal Soil Science, Oxford, v. 15, p. 110$116,1964$.

BAHIA FILHO, A.F.C. Índices de disponibilidade de fósforo em Latossolos do Planalto Central com diferentes características texturais e mineralógicas. Viçosa, 1982. p. 178 Tese (Doutorado) - Universidade Federal de Viçosa. 
BAHIA FILHO, A.F.C. \& BRAGA, J.M. Fósforo em latossolos do estado de Minas Gerais. I. Intensidade e capacidade tampão de fósforo. Experientiae, Viçosa, v.19, n.2, p. 17-32, 1975a.

BAHIA FILHO, A.F.C \& BRAGA, J.M. Fósforo em latossolo do estado de Minas Gerais. II. Quantidade de fósforo e fósforo "disponível". Revista Ceres, Viçosa, v. 22, n. 119, p. 50-61, 1975 b.

BARBER, S.A. Soil-plant interactions in the phosphorus nutrition of plants. In: KHASAWNEH, E.C.; SAMPLE, E.C.; KAMPRATH, E.J. (ed.). The role of phosphorus in agriculture. Madison, ASA, CSSA, SSSA, 1980. p.591-615.

BARBOSA FILHO, M.P. Transformações do fósforo em solos ácidos e sua disponibilidade para a cultura de arroz de sequeiro (Oryza sativa L.). Piracicaba, 1986. 104p. Tese (Doutorado) - Escola Superior de Agricultura "Luiz de Queiróz", Universidade de São Paulo

BARROW, N.J. Evaluation and utilization of residual phosphorus in soil. In: KHASAWNEL, F.F.; SAMPLE, E.C.; KAMPRATH, E.J., ed. The role of phosphorus in agriculture. Madison, ASA, CSSA, SSSA, 1980, p 333-59.

BARROW, N.J. Modelling the effects of $\mathrm{pH}$ on phosphate sorption by soils. Journal Soil Science, Oxford, v. 35, n.2 p. 283-297, 1984

BINGHAM, F.T. Chemical soil tests for available phosphorus. Soil Science, Baltimore, v. 94 n. 1, p. $87-95,1962$.

BITTENCOURT, V.C. \& ZAMBELLO Jr, E. Comportamento do fósforo em solos tropicais II. Cinética de retenção. IX Reunião Anual de Fertilidade do solo. Belo Horizonte, 1974.

BOHN, V.E; BRIAN, L. M; O'CONNOR, G.A. Soil Chemistry. New York, John Wiley \& SONS. 1978. 341 p. 
BOWDEN. J.W; NAGARAJAH, S.; BARROW, N.J; QUIRK, J.P. Describing the adsorption of phosphate, citrate and selenite on a variable-charge mineral surface. Australian Journal of Soil Research, Melbourne, v. 18, n. 1, p. 49-60, 1980.

BRAGA, J.M. \& DEFELIPO, B.V. Relações entre formas de fósforo inorgânico, fósforo disponível e material vegetal em solos sob vegetação de cerrado: I. Trabalho de laboratório. Revista Ceres, Viçosa, v.19, n. 102, p. 124-36, 1972a.

BRAGA, J.M. \& DEFELIPO, B.V. Relação entre formas de fósforo inorgânico, fósforo disponivel e material em solos sob a vegetação de cerrado: II. Trabalhos em estufa. Revista Ceres, Viçosa, v. 19, n. 104, p. 248-60, 1972 b.

BRAGA, N.R.; MASCARENHAS, H.A.A.; FEITOSA, C.T.; HIROCE, R.; RAI, B. van. Efeitos de fosfatos sobre o crescimento e produção de soja. Revista Brasileira de Ciência do Solo, Campinas, v.4, n. 1, p. 36-9, 1980

BRASIL, E.C. Disponibilidade de fósforo em solos da Amazônia tratados com fertilizantes fosfatados. Piracicaba, 1994.160p. Dissertação ( Mestrado) - Escola Superior de Agricultura "Luiz de Queiróz", Universidade de São Paulo.

BRAY, R.H. Correlation of soil test with crop response to added fertilizers and with fertilizer requirements. In: KITCHEN, H.B. Diagnostic techniques for soils and crop. Washington, The American Potash Institute, 1947, p.53-85.

BRAY, R.H \& KURTZ, L.T. Determination of total organic and available forms of phosphorus. Soil Science, Baltimore, v.59, n. I, p. 39-45, 1945

BROWN, V.E. and LEHR, J.R. Aplication of phase rule to the chemical behavior of monocalcium phosphate monohydrate in soils. Soil Science Society of America Proceedings, Madison, v.23, n.1, p. 7-12, 1959.

CAJUSTE, L.J.; LAIRD, R.J.; CRUZ, D. and CAJUSTE, JR, L. Phosphate availability in tropical soils as related to phosphorus fractions and chemical tests. 
Communications in Soil Science and Plant Analyses, New York, v.25, n.9e10, p. $1881-1889.1949$.

CAMARGO, M. N.; KLANT, E.; KAUFFMAN, J. H. Classificação de solos usada em levantamentos pedológicos no Brasil. Boletim Informativo da Sociedade Brasileira Ciência do Solo, Campinas, v. 12, n.1, p. 11-33, 1987.

CAMPELLO, M. R. Avaliação da reversibilidade de fósforo não-lábil para lábil em solos com diferentes características químicas, físicas e mineralógicas. Viçosa. 1993. 66p. Tese (mestrado)- Universidade Federal de Viçosa.

CARMELLO, Q.A. de C. Fatores que afetam a determinação do "valor L" e sua comparação com a capacidade de adsorção de fósforo e o "valor E" em dois solos do Estado de São Paulo. Piracicaba, 1980. 72p. Dissertação (Mestrado) - Escola Superior de Agricultura "Luiz de Queiroz", Universidade de São Paulo.

CHANG, S.C. \& JACKSON, M.L. Fractionation of soil phosphorus. Soil Science, Baltimore, v.84, n.2, p. 133-144, 1957.

CHEN, Y.S.R.; BUTLER, J.N.; STUMM, W. Adsorption of phosphate on alumina and kaolinite from dilute aqueous solutions. Journal Colloid Interface Science, New York, v. 43, n. 421-436, 1973.

COMISSÃO DE FERTILIDADE DO SOLO DO ESTADO DE MINAS GERAIS. Recomendações para o uso de corretivos e fertilizantes em Minas Gerais. $4^{\mathrm{a}}$. Lavras, CFSEMG, 1989. 159p.

COOKE, J.J. \& HISLOP, $J$. Use of anion-exchange resin for the assessment of available soil phosphate. Soil Science, Baltimore, v.95, n.5, p. 308-312, 1963

COSTA, M.P. Efeito da matéria orgânica em alguns atributos do solo. Piracicaba, 1983. 137p. Dissertação (Mestrado) - Escola Superior de Agricultura "Luiz de Queiroz", Universidade de São Paulo. 
CURI, N. \& FRANZMEIER, D.P. Toposequence of oxisols from the Central Plateau of Brazil. Soil Science Society of America Journal, Madison, v.48, p. 341-346, 1984.

CURTIN, D \& SMILLIE, G.W. Influence of liming an soluble and labile P in fertilized soil. Communications in Soil Science and Plant Analysis, New York, v. 15, n.2, p. $177-188,1984$.

DAVEY, B.G. anda SHAYAN, A. Reactions between monocalcium phosphate monohydrate and chromic luvisol: I The morphology of reaction products. Soil Science Society of America Journal, Madison, v.44, p. 477, 1980.

EMBRAPA - EMPRESA BRASILEIRA DE PESQUISA AGROPECUÁRIA. Métodos de Análise de Solo. Rio de Janeiro, EMBRAPA, 1979. s.n.p.

FASSBENDER, H.W. La adsorcion de fosfatos em suelos fuertemente àcidos y su evaluacion usando la isoterma de Langmuir. Fitotecnia latinoamericana v.3, p. 203$216,1966$.

FASSBENDER, H.W. Química de suelos: con enfasis en suelos de América Latina. Turrialba, IICA, 1975. p. 397.

FASSBENDER, H.W; MÜLLER, L.; BALERDI, F. Estúdio del fósforo en suelos de América Central. II. Formas y su relación con las plantas. Turrialba, San Jose, v.18, n. 4 , p. 333-347, 1968.

FEITOSA, C.T. \& RAIJ, B. van. Influência da natureza de adubos fosfatados aplicados a dois solos no fósforo solúvel em extratores químicos e disponível para trigo e milho In: CONGRESSO BRASILEIRO DE CIÊNCIA DO SOlo, 15, Campinas, 1976 Anais. Campinas, Sociedade Brasileira de Ciência do Solo, 1976. p. 215-220

FIGUEROA, O.O.L. Influencia da aplicação parcelada do $\mathrm{Ca}(\mathrm{OH}) 2$ e do fósforo na produção de matéria seca do sorgo (Sorghum bicolor, $L$. Moench) e nas principais formas de fósforo do solo. Piracicaba, 1984. 79p. Tese (Doutorado) - Escola Superior de Agricultura "Luiz de Queiróz", Universidade de São Paulo. 
FITTS, J.W. \& NELSON, W.L. The determination of lime and fertilizer requirements of soils through chemical tests. Advances in Agronomy, New York, v.8, p. 241-283, 1956.

FIXEN, P.E. \& GROVE, J.H. Testing soils for phosphorus. In: ESTERMAN, R.L, ed. Soil testing and plant analysis, 3. ed. Madison, S.S.S.A., 1990, p. 141-80.

FREIRE, F.M.; NOVAIS, R.F.; BRAGA, J.M; FRANÇA, G.E.; SANTOS, H.L; SANTOS, P.R.R.S. Adubação fosfalada para a cultura da soja (Glycine max (L.) Merrill) baseado no fósforo disponivel e no fator "capacidade". Revista Brasileira de Ciência do Solo, Campinas, v.3, n.2 p. 105-111, 1979.

FREITAS, L.M.M.; MIKKELSEN, D.S.; McCLUNG, A.C.; LOTT, W.L. Agricultura no cerrado: efeitos da calagem e adubação na produção de algodão, milho e soja em três solos de campo cerrado. In FERRI, M.G. (ed) SIMPÓSIO SOBRE CERRADO. São Paulo, USP, 1963.p. 325-377.

FRIESSEN, D.K.; JUO, A.S.R.; MILLER, M.H. Liming and lime phosphorus-zinc interactions in two nigerian ultisols. I. Interactions in the soil. Soil Science Society of America Journal, Madison, v.44, p. 1221-1226, 1980.

GOEDERT, W.J. \& SOUZA, D.M.G. Uso eficiente de fertilizantes fosfatados. In: SIMPÓSIO SOBRE FERTILIZANTES NA AGRICULTURA BRASILEIRA, Brasília, 1984. Brasilia, EMBRAPA; ANDA; POTAFOS, 1984 p.255-289.

GONÇALVES, J.L.M. Cinética de transformação de fósforo lábil em não lábil em amostras de solo de cerrado. Viçosa, 1988. p. 62. Tese Mestrado - Universidade Federal de Viçosa.

GONCALVES, J.L.M; NOVAIS, R.F.; BARROS, N.F.; NEVES, J.C.L.; RIBEIRO, A.C. Cinética de transformação de fósforo-lábil em não lábil, em solos de cerrado. Revista Brasileira de Ciência do Solo, Campinas, v.13, n.1, p. 13-24, 1989. 
GRIFFIN, R A \& JURINAK, J.J. Kinetics of the phosphate interaction with calcite. Soil Science Society of América Proceedings, Madison, v.38, n. 1, p. 75-79, 1974.

HAYNES, R.J. \& LUDECKE, T.E. Effect of lime and phosphorus aplications on concentrations of available nutrients two pasture legumes in acid soils. Plant and soil, The Hague, v.62, p. 17-28, 1981.

HAYNES, R.J. Effects of liming on phosphate availability in acid soils. Plant and Soil, The Hague, v. 68, n.3, p. 289-308, 1982.

HAYNES, R.J Lime and phosphate in the soil-plant system. Advances in Agronomy, New York, v.378, p. 249-315, 1984.

HINGSTON, F.J.; POSNER, A.M.; QUIRK, J.P. Anion adsorption by goethite and gibsite. I. The role of the proton in determining adsorption envelopes. Journal of Soil Science, Oxford, v.23, p. 175-192, 1972.

HOLFORD, I.C.R. Effects of phosphate buffer capacity of soil on the phosphate requirements of plants. Plant and Soil, The Hague, v. 45, n. 4, p. 433-444, 1976.

HOLFORD, I.C.R. Effects of phosphate buffer capacity on critical levels and relationships between soils tests and labile phosphate in wheat-growing soils. Australian Journal of Soil Research, Melbourne, v.18, n.4, p. 405-414, 1980 a.

HOLFORD, I.C.R. Greenhouse evaluation of four phosphorus soil tests in relation to phosphate buffering and labile phosphate in soils. Soil Science Society of America Journal, Madison, v.44, n.4, p. 555-559, 1980 b.

HORNECK, D.A.; HART, J.M.; PEEK, D.C. The influence of sampling intensity, liming, $\mathrm{P}$ rate, and method of $\mathrm{P}$ application on $\mathrm{P}$ soil test values. Communication in Soil Science and Plant Analysis, New York, v.21, n. 13-16, p. 1079-1090, 1990.

HSU, P.H. Adsorption of phosphate by aluminium and iron in soils. Soil Science Society of America Proceedings, Madison, v.28, p. 474-478, 1964. 
HSU, P.H. Fixation of phosphate by aluminum and iron in acidic soils. Soil Science, Baltimore, v.99, p. 398-402, 1965.

JARREL, W.M. e BEVERLY, R. B. The dilution effect in plant nutrition studies. Agronomy Journal, Madison, v.34, p. 197-224. 1981.

KAMPRATH, E.J. \& WATSON, M.E. Conventional soil and tissue tests for assessing the phosphorus status of soils. In: KHASAWNEH, F.E; SAMPLE, E.C. \& KAMPRATH, E.J., ed. The role of phosphorus in agriculture. Madison, ASA, CSSA, SSSA, 1980, p.433-469.

KHASAWNEH, F.E. Solution ion activity and plant growth. Soil Science Society of America Proceedings, Madison, v.35, n.3, p. 426-436, 1971.

KILE, J.H.; PUSNER, A.M. \& QUIRK, J.P.Kinetics of isotopic exchange adsorbed P on gibbsite. Journal of Soil Science, Oxford, v.26, n.1, p. 32-43. 1975

KUNISHI, H.M. Combined effects of lime, phosphate fertilizers, and aluminum on plant yield from an acid soil of the Southerstern United States. Soil Science, Baltimore, v. 134, n. 4, p. 233-238, 1982.

LARACH, J. O ; CARDOSO, A ; CARVALHO, A P ; HOCMULER, D. P.; FASOLO, P. J. ; RAUEN, M. J. Levantamento e reconhecimento dos solos do estado do Paraná. Curitiba, EMBRAPA - SNLCS/SUDESUL/IAPAR, 1984. 413p. (Tomo I)

LARSEN, S. Soil phosphorus. Advances in Agronomy, New York, v.19, p. 151-211, 1967.

LEAL, J.R. \& VELLOSO, A.C.X. Dessorção do fosfato adsorvido em latossolos sob vegetação de cerrado. I Reversibilidade da isoterma de adsorção em relação à concentração de fosfato, Pesquisa agropecuária brasileira, série agronomia. Brasilia, v.7, n.5, p. 193-197. 1972. 
LEAL, J.R. \& VELOSO, A.C. Dessorção do fosfato adsorvido em Latossolos sob vegetação de cerrado II. Reversibilidade da isoterma de adsorção de fosfato em relação ao pH da solução em equilíbrio. Pesquisa agropecuária brasileira, série agronomia, Brasilia, v.8, n.7, p. 89-92. 1973

LEHR, J.R., BROWN, V.E., BROWN, E.H. Chemical behavior of monocalcium phosphate monohidrated in soils. Soil Science Society of America Proceedings, Madison, v. 23, p. 3-7, 1959.

LINDSAY, W.L. Chemical equilibria in soils. New York, John Wiley, 1979. 449p.

LINDSAY, W.L. MORENO, E.C. Phosphate phase in soils. Soil Science Society of America Proceedings, Madison, v.24, p. 177-182, 1960

LINDSAY, W.L. and STEPHENSON, H.F. Nature of the reactions of monocalcium phosphate monohydrate in soils: 1; The solution that reacts with the soil. Soil Science Society Proceedings, v.23, n. 1, p. 12-18, 1959 a.

LINDSAY, W.L. and STEPHENSON, H.F. Nature of the reactions of monocalcium phosphate monohydrate in soils. II: Dissolution and precipitation reactions involving iron, aluminum, manganase, and calcium. Soil Science Society Proceedings, v.23, p. $18-22,1959, \mathrm{~b}$.

LINDSAY, W.L.; PEECH, M., CLARK, I.S. Solubility criteria for the existence of variscite in soils. Soil Science Society of America Proceedings, Madison, v.23, p. $357-360,1959$

LOPEZ-HERNANDES, D. \& BURNHAM, C.P. The effect of pH on phosphate adsorption in soils. Jourmal of Soil Science, Oxford, v.25, n.2, p. 207-216, 1974

MALAVOLTA, E; CROCOMO, OJ; ANDRADE, RG; ALZURTI, C; VENCOVSKY, E.; FREITAS, L.M.M. Estudos sobre a fertilidade dos solos de cerrado. 1. Efeito da calagem na disponibilidde do fósforo. Anais da Escola Superior de Agricultura "Luiz de Queiroz", Piracicaba, v.22, p. 131-138, 1965 
MALAVoltA, E.; VITTI, G.C.; OLIVEIRA, S.A. de. Avaliação do estado nutricional das plantas: princípios e aplicações. Piracicaba, Associação Brasileira para Pesquisa da Potassa e Fosfato, 1989. 201p.

MARTIN, R.R., SMART, R. St. C, and TAZAKI, K. Direct observation of phosphate precipitation in the goethite/phosphate system. Soil Science Society of America Journal, Madison, v.52, p. 1492-1500. 1988

MEHLICH, A. Mehlich 3 soil test extractant: a modification of mehlich 2 extractant Comunication in Soil Science and Plant Analysis, New York, v.15, n.12, p. 1409$1416,1984$.

McAULIFFE, C.D; HALL, N.S.; DEAS, L.A.; HENRICKS, S.B. Exchange reactions between phosphates and soil minerals. Soil Science Society of America Proceedings, Madison, v. 12, n.1, p. 119-123, 1948.

McLEAN, A.J \& COOK, R.L. The effect of soil reaction on the availability of phosphorus for alfafa in some Eastern Ontario Soils. Soil Science Society of America Proceedings, Madison, v. 19, p. 311-314, 1955.

McLUNG, A.C; FREITAS, L.M.M de; MIKKELSEN,D. S. e LOTT. W.L Adubação do algodoeiro en solos de campo cerrado no Estado de São Paulo. São Paulo, IBEC, Research Institute, 1961. (Boletim Técnico 27)

MENDEZ B.,J.R. Efeito das épocas de calagem na disponilidade de fósforo aplicado 180 dias antes do plantio do arroz (Oryza sativa, L.) em latossolos sob cerrado. Piracicaba, 1986. Dissertação (Mestrado) - Escola Superior de Agricultura "Luiz de Queiroz", Universidade de São Paulo

MOREIRA, JF. Cinética de transformação de P-lábil em não lábil no solo avaliada por análise química e crescimento de mudas de eucalipto. Viçosa UFV, 1988. 52p. Tese (Mestrado) - Universidade Federal de Viçosa. 
MOURA FILHO, G. Disponibilidde de fósforo em amostras de solos de várzeas. Viçosa, 1990. 92p. Tese (Mestrado) - Universidade Federal de Viçosa.

MULJADI, D.; POSNER, A.M; QUIRK, J.P. The mechanism of phosphate adsorption by kaolinite, gibbisite and pseudohematite. 1. The isotherms and the effect of $\mathrm{pH}$ on absorption. Journal of Soil Science, Oxford, v. 17, n.2, p. 212-229, 1966a.

MULJADI, D; POSNER, A.M.; QUIRK, J.P. The mechanism of phosphate adsorption by kaolinite, gibbisite and pseudohematite. 2. The location of adsorption sites. Journal of Soil Science, Oxford, v. 17, n.2, p. 230-237, 1966 .

MULJADI, D ; POSNER, A.M; QUIRK, J.P. The mechanism of phosphate adsorption by kaolinite, gibbisite and pseudohematite. 3. The effect of temperature on absorption. Journal of Soil Science, Oxford, v.17, n.2, p. 238-247, 1966c.

MUNIZ, A.S. Disponibilidde de fósforo avaliada por extratores químicos e pelo crescimento de soja (Glyxine max (L.) Merrill) em amostras de solos com diferentes valores do fator capacidade. Viçosa, 1983. 79p. Tese (Mestrado) - Universidade Federal de Viçosa.

MUNIZ, A , S.; NOVAIS, R.F.; FREIRE, F.M.; NEVES, J. L.C.; BARROS, N.F. Disponibilidade de fósforo e recomendação de adubação avaliadas por meio de extratores químicos e do crescimento de soja em amostras de solo com diferentes valores do fator capacidade. Revista Ceres, Viçosa, v. 34, n. 192, p. 125-151, 1987

MURAOKA, T; MALAVOLTA, E; BOARETO, A.E. Valor "E" (P isotopicamente trocável). Piracicaba, CENA/USP, 1991.6p. (Apostila)

MURRMANN \& PEECH. Effect of pH on labile and soluble phosphate in soils. Soil Science Society of America Journal, Madison, v.33, p. 205-210, 1969.

NAIDU, R; TILLMAN, R.W.; SYERS,J.K. \& KIRKMAN. Effect of liming on phosphate extracted by two soil-testing procedures. Fertilizer Research, Dordrecht, v.14, n.2, p. 143-152, 1987. 
NELLER, J.R. Effect of lime on availability of labeled phosphorus of phosphates in rutlege fine sand and Morboro and Carnegie fine sand loams. Soil Science, Baltimore, v.75, p. 103-108, 1953.

NEVES, J.C.L. Aspectos nutricionais em mudas de Eucalyptus spp. - tolerância ao alumínio e níveis críticos de fósforo no solo. Viçosa, 1983. 87p. Tese (Mestrado) Universidade Federal de Viçosa.

NOVAIS, R.F. Phosphorus supplying capacity of previously heavily fertilized soils. Raleigh, 1977. 153p. Thesis (Ph.D.) - North Carolina State University.

NOVAIS, R.F. \& KAMPRATH, E.J. Parâmetros das isotermas de adsorção de fósforo como critério de recomendação de adubação fosfatada. Revista Brasileira de Ciência do Solo, Campinas, v. 3, n. 1, p. 37-41, 1979a.

NOVAIS, R.F. \& KAMPRATH, E.J. Fósforo recuperado em três extratores químicos como função do fósforo aplicado no solo e do "fator capacidade". Revista Brasileira de Ciência do Solo, Campinas, v.3, n. 1, p. 41-46, 1979 b.

NOVAIS, R.F.; NEVES, J.C.L.; MUNIZ, A.S; BARROS, N.F. Interação entre o fósforo pela resina e o fator capacidade deste nutriente no solo. In: REUNIÃO BRASILEIRA DE FERTILIDADE DO SOLO, 18., Guarapari, 1988. Resumos. Guarapari, SBCS, 1988. p.109-10.

NOVOA, F.V.Y.; NUNES, E.R. Comportamento de cinco fertilizantes fosfatados en três suelos de México con diferente capacidad de fijacion de fósforo. Agrociencia, México, v. 19, n.1, p. 69-82, 1975

OLAYA, H.R.E. Efeitos de diferentes intervalos de aplicação de calcário e fosfato na disponibilidade de fósforo em dois solos sob cerrado. Lavras, 1988. $101 \mathrm{p}$. Dissertação (Mestrado) - Escola Superior de Agricultura de Lavras. 
OLIVEIRA, J.B.; MONIZ, A.C. Levantamento pedológico detalhado da Estação Experimental de Ribeirão Preto, SP. Bragantia, Campinas, v.34, n.2, p. 59-113, 1975.

OLSEN, S.R \& KHASAWNEH, F.E. Use and limitations of physical-chemical criteria for assessing the status of phosphorus in soils. In: KHASAWNEH, F.E.; SAMPLE, E.C.; KAMPRATH, E.J., ed. The role of phosphorus in agriculture. Madison, ASA, CSSA, SSSA, 1980. p.361-410.

OLSEN, S.R.; COLE, C.V.; WATANABE, F.S. and DEAN, L.A. Estimation of available phosphorus in soils by extraction with sodium bicarbonate. United States Departament of Agriculture. Circular 939. 1954.

PAYTON, F.V., RHUE, R.D.; HENSEL, D.R. Mitscherlich-Bray equation used to correlated soil phosphorus and potato yields. Agronomy Journal, Madison, v. 81, p. $571-579,1989$.

PARFITT, R.L. Anion adsorption by soils and soil materials. Advances in Agronomy, New York, v.30, p. 1-50, 1978

PARFITT, R.L.; ATKINSON, R.J. \& SMART, R. St. C. The mechanism of phosphate fixation by iron oxides. Soil Science Society of America Proceedings, Madison, V. 39, p. $837-841,1975$.

PARFITT, RL.; FRASER, A.R; RUSSEL, J.D.; FARMER, V.C. Adsorption on hydrous oxides. II. Oxalate, benzoate and phosphate on gibbsite. Journal of Soil Science, Oxford, Madison, v.28, n.1, p. 40-47, 1977.

PIERZYNSKI, G.M; LOGAN, T.J; TRAINA, S.J. \& BIGHAM, J.M. Phosphorus chemistry and mineralogy in excessively fertilized soils. Descriptions of phosphorus rich particles. Soil Science Society of America Journal, Madison, v.54, p. 1583$1589,1990$. 
PRATT, P.F. \& GARBER, MJ. Correlations of phosphorus availability by chemical tests with inorganic phosphorus fractions. Soil Science Society of America Proceedings, Madison, v.28, n.1, p. 23-26, 1964

QUAGGIO, J.A; MASCARENHAS, H.A.A.; BATAGLIA, O.C. Resposta da soja à aplicação de doses crescentes de calcário em latossolo roxo distrófico de cerrado. II. Efeito residual. Revista Brasileira de Ciência do Solo, Campinas, v.6, p. 113-118, 1982.

RAIJ, B. van. Seleção de métodos de laboratório para avaliar a disponibilidade de fósforo em solos. Revista Brasileira de Ciência do Solo, Campinas, v.2, n. 1, p. 1-9, 1978.

RAI, B. van. Avaliação da fertilidade do solo. Piracicaba, Instituto da Potassa e Fosfato, Instituto Internacional da Potassa, 1981. 142p.

RAIJ, B. van. Fertilidade do solo e adubação. São Paulo, Piracicaba, Ceres/POTAFÓS, 1991, 343p.

RAJJ, B. van. New diagnostic technique, universal soil extractants, Communications in Soil Science and Plant Analysis, New York, v.25, n.7-8, p. 809-816, 1994.

RAIJ, B.van \& QUAGGiO, J.A. Métodos de Análise de solo para fins de fertilidade. Campinas, Instituto Agronômico, 1983.31 p. (Boletim Técnico $n^{\circ} 81$ )

RAIJ, B. van \& QUAGGIO, J.A. Extractable phosphorus availability index as affected by liming. Communication in Soil Science and Plant Analysis, New York, v.21, n. 13-16, p. 1267-1276, 1990.

RAIJ, B. van; CABALA ROSAND, P.; LOBATO, E. Adubação fosfatada no Brasil: apreciação geral, conclusões e recomendações. In: OLIVEIRA, A.J., ed. Adubação fosfatada no Brasil. Brasilia, EMBRAPADID, 1982. p.9-28 
RAIJ, B. van; FEITOSA, C.T; SILVA, N.M. da. Comparação de quatro extratores de fósforo de solos. Bragantia, Campinals, v.43, n.1, p. 17-29, 1984.

RAI, B. van; QUAGGIO, J.A.; SILVA., N.M. Extraction of phosphorus, potassium, calcium and magnesium from soils by an ion-exchange resin procedure. Communications in Soil Science and Plant Analysis, New York, v.17, n.5, p. 547 $566,1986$.

REIS, C. Modelo cinético de sorção de fosfato em algumas amostras de solos de Minas Gerais. Viçosa, 1992. 72p. Tese ( mestrado) - Universidade Federal de Viçosa.

RESENDE, J.O. Capacidade de fixação de fósforo por solos dos estados da Bahia e Sergipe. Influencia do pH e tempo de reação. Piracicaba, 1974. 81p. Dissertação (Mestrado)- Escola Superior de Agricultura "Luiz de Queiróz", Universidade de São Paulo.

RESENDE, M. Pedologia. Viçosa, U.F. V., 100p. 1981.(Apostila).

RYDEN, J.C, McLAUNGHLIN, J.R. \& SYERS, J.K. Mechanisms of phosphate sorption by soils and hydrous ferric oxide gel. Journal of Soil Science, Oxford, v.28, p. $72-92,1977$ a

RYDEN, J.C; MCLAUGHLIN, J.R \& SYERS, J.K. Time dependent sorption of phosphate by soils and hydrous ferric oxides. Journal of Soil Science, Oxford, v. 28, p. $585-595,1977 b$.

RODRIGUES, D. \& MENDOZA, R. Readsorption of phosphate by soil during acid and alcaline extrations Communications in Soil Science and Plant Analysis, New York, v.24, n.1-2, p. 133-147, 1993.

RUSSEL, R.S; ERICKSON, J.B.; ADAMS, S.N. Isotopes equilibria between phosphates in soil and their significance in the assessment of fertility by tracer methods. Journal of Soil Science, Oxford, v . 5, n. 2, p. 88-105, 1954. 
SAMPLE, E.C., SOPER, R.J., RACZ, G.J. Reactions of phosphate fertilizers in soils. In: The role of phosphorus in agriculture. F.E. Khasawnwh: E.C. SAMPLE, EJ. KAMPRATH (ed). Madison, ASA, CSSA, SSSA, 1980, p.263-310.

SANCHES, R.A. \& UEHARA, G. Management considerations for acid soil with high phosphorus fixation capacity. In: KHASAWNEH, P.E; SAMPLE, E.C. \& KAMPRATH, E.J. (ed.). The role of phosphorus in agriculture. Madison, ASA, CSSA, SSSA, 1980, p.471-514.

SFREDO, G.J.; BORKERT, C.M.; CORDEIRO, D.S.; PALHANO, J.B.; DITTRICH, R.C. Comparação de cinco extratores de fósforo do solo considerando-se o tempo de incorporação de três adubos fosfatados. Revista Brasileira de Ciência do Solo, Campinas, v.3, n.2, p. 111-115, 1979.

SHANG, C.; STEWART, J.W.B.; HUANG, P.M. pH effect on kinetics of adsorption of organic and inorganic phosphates by short - range ordered aluminum and iron precipitates. Geoderma, Amsterdã, v.53, n.1, p. 1-14, 1992.

SILVA, F.C. Avaliação da disponibilidade de fósforo em solos cultivados com cana de açúcar (Saccharum spp). Piracicaba, 1991. 164p. Dissertação (Mestrado) - Escola Superior de Agricultura "Luiz de Queiróz”, Universidade de São Paulo.

SILVA, J.T.A. Relações entre características do solo que refletem a capacidade-tampão de fósforo e o nível crítico para sorgo, em dez latossolos de Minas Gerais, em casa de vegetação. Viçosa, 1990. 87p. Tese (Mestrado) - Universidade Federal de Viçosa.

SILVA, N.M; CARVALHO, L.H.; HIROCE, R.; QUAGGIO, J.A. A calagem na reação do algodoeiro à adubação com superfosfato simples. Bragantia, Campinas, v.46, n.2, p. $381-396,1987$.

SIMARD, R.R \& LAPIERRE, C. Effects of tillage, lime, and phosphorus on soil pH and Mehlich-3 extractable nutrients. Communications Soil Science Plant Analysis, New York, v.25, n.9-10, p. 1081-1085. 1994. 
SIMS, J.T. \& ELLIS, B.G. Adsorption and availability of phosphorus following the application of limestone to an acid, aluminous soils. Soil Science Society of America Journal, Madison, v.47, p. 888-893, $1983 \mathrm{a}$.

SIMS, J.T. \& ELIS, B.G. Changes in phosphorus adsorption associated with aging of aluminum hydroxide suspensions. Soil Science Society of America Journal, Madison, v.47, p. 912-916, 1983 b.

SLOAN, J.J.; BASTA, N.T. \& WESTERMAN, R.L. Aluminium transformations and solution equilibria induced by banded phosphorus fertilizer in acid soil. Soil Science Society of America Journal, Madison, v. 59, n.2, p. 357-364. 1995.

SIQUEIRA, O.F.J. Recomendações de adubação e calagem para os estados do Rio Grande do Sul e Santa Catarina. Passo Fundo, EMBRAPA/CNPT, 1987. 100p.

SMITH, T.J. \& SANCHEZ, P.A. Effects of lime, silicate and phosphorus applications to an Oxisol on phosphorus sorption and ion retention. Soil Science Society of America Journal, Madison, v.44, n.3, p. 500-505, 1980.

SMITH, T.J. \& SANCHEZ, P.A. Phosphate rock and super-phosphate combinations for soybean in a Cerrado Oxisol. Agronomy Journal, Madison, v.74, p. 739-745, 1982.

SOUZA, J.A; CURI, N.; GUEDES, G.A.A. Relação entre mineralogia e adsorçãodessorção de fósforo em alguns latossolos sob cerrado do Planalto Central. Ciência e Prática, Lavras, v.15, n.1, p. 103-111, 1991.

SWENSON, R.M.; COLE, C.V.; SIELING, D.H. Fixation of phosphate by Fe and Al and replacement by organic and inorganic ions. Soil Science, Baltimore, v.67, n.1, p. $3-22,1949$.

TAYLOR, A.W. and GURNEY, E. L. Precipitation of phosphate by iron oxide and aluminum hydroxide from solutions containing calcium and potassium. Soil Science Society of America Proceedings, Madison, v.29, p. 18-22, 1965a. 
TAYLOR, A.W. \& GURNEY, E.L. The effect of lime on the phosphate potential and resin extractable phosphate in five acid soils. Soil Science Society of America Proceedings, Madison, v.29, p. 482-483, 1965 b.

THE COUNCIL ON SOIL TESTING AND PLANT ANALYSIS. Handbook on reference methods for soil testing. Athens, University of Georgia, 1980.

THOMAS, G.W. Chemical reactions controlling soils solution electrolyte concentration. In: CARSON, E.W., ed. The plant root and its environment. Charlottesville, The University Press of Virginia, 1974. p.483-506.

THOMAS, G.W. \& PEASLE, D.E. Testing soil for phosphorus. In: WALSH, L.M. \& BEATON, J.D. Soil testing and plant analysis. Madison, ASA, 1973. p.115-32.

VAN der ZEE, S.E.A.T.M; Transport of reactive contaminants in heterogeneous soil sistems. 1988. $283 \mathrm{p}$.

VAN der ZEE, S.E.A.T.M.; FOKKING, L. G. J. and van RIEMSDIJK, W.H. A new technique for assessment of reversibly adsorbed phosphate. Soil Science Society of America Journal, Madison, v. 51, p.599-604, 1987.

VAN RIEMSDIJK, W.H.; BOUMANS, L. J.M. \& HAAN, F.A.M. Phosphate sorption by soils: I A model for phosphate reaction with metal-oxides in soil. Soil Science Society American Journal, Madison, v.48, n.3, p. 537-541, 1984

VASCONCELOS, C.A.; BRAGA, J.M; NOVAIS, R.F. \& PINTO, O.C. Fósforo em dois latossolos do estado de Mato Grosso. Experimenteae, Viçosa, v. 18, p. 267-285, 1974.

VASCONCELOS, C.A.; SANTOS, HL. dos; FRANÇA, G.E. de; PITTA, G.V.E; BAHIA FILHO, A.F.C. Eficiência agronômica de fosfatos naturais para a cultura do sorgo granífero. II. Produção de grãos, eficiência relativa e fósforo disponivel. Revista Brasileira de Ciência do Solo, Campinas, v.10. n.2, p.123-128, 1986. 
VEITH, J.A \& SPOSITO, G. On the use of the Langmuir equation in the interpretation of "adsorption" phenomena. Soil Science Society of America Journal, Madison, v. 41, p. $697-702,1977$

VIDOR, C. \& FREIRE, J.R.J. Calibração de análises do solo para a cultura da soja (Glycine max (L.) Merrill). Agronomia Sulriograndense, Porto Alegre, v.7, n. 1, p. $63-72,1971$.

VIEGAS, R.A. Dinâmica de fontes de fósforo aplicadas a solos com diferentes níveis de acidez. Viçosa, 1990. 67p. Tese (Mestrado) - Universidade Federal de Viçosa.

WHITE, R.E. The enigma of pH-P solubility relationship in soil. In: INTERNATIONAL CONGRESS ON PHOSPHORUS COMPOUNDS, 3., Brussels. Proceedings. Brussells, IMPHOS, 1983. p.53-63. 
APENDICE 


\section{Apêndice 1}

Valores de $\mathrm{pH} \mathrm{H}_{2} \mathrm{O}$ e $\mathrm{pH} \mathrm{CaCl} \mathrm{Cl}_{2} 0,01 \mathrm{~mol}^{-1} \mathrm{~L}^{-1}$ de amostras de solo LRd, provenientes de Londrina-PR, incubadas com doses de corretivo durante 14 dias. Média de duas repetições.

\begin{tabular}{|c|c|c|c|c|c|}
\hline \multirow[b]{2}{*}{ Amostra } & \multicolumn{5}{|c|}{ Dose corretivo $\left(\mathrm{g}^{\mathrm{kg}}{ }^{-1} \mathrm{CaCO}_{3}\right)$} \\
\hline & 0 & 2,5 & 5 & 7,5 & 10 \\
\hline & \multicolumn{5}{|c|}{$\mathrm{pH} \mathrm{H} \mathrm{H}_{2} \mathrm{O}$} \\
\hline LDI & 4,6 & 6,2 & 7,4 & 7,9 & 7,9 \\
\hline LD2 & 4,5 & 5,9 & 7,1 & 7,7 & 7,9 \\
\hline LD3 & 5,0 & 6,7 & 7,6 & 7,9 & 7.9 \\
\hline LD4 & 5.1 & 6,7 & 7,5 & 7.9 & 7,9 \\
\hline LD5 & 4,7 & 6,0 & $\stackrel{7,1}{\mathrm{pH} C a C}$ & 7,8 & 7,8 \\
\hline LDI & 4,1 & 5.8 & 6.9 & 7.5 & 7,5 \\
\hline LD2 & 4,1 & 5,8 & 6,9 & 7,4 & 7,5 \\
\hline LD3 & 4.4 & 6.1 & 7,1 & 7,4 & 7,4 \\
\hline LD4 & 4,4 & 6.2 & 7,1 & 7,3 & 7,5 \\
\hline LD5 & 4.1 & 5.7 & 6.8 & 7.3 & 7,4 \\
\hline
\end{tabular}

\section{A pêndice 2}

Doses e fontes de macro e micronutrientes empregadas na adubação de pré-semeadura de arroz e milho (1).

\begin{tabular}{|c|c|c|c|}
\hline \multirow[t]{2}{*}{ Nutriente } & \multicolumn{2}{|c|}{$\mathrm{mg} \cdot \mathrm{kg}^{-1}$ terra } & \multirow[t]{2}{*}{ Fonte (2) } \\
\hline & Arroz & Milho & \\
\hline $\mathrm{N}$ & 66,0 & 66,0 & $\mathrm{KN} 03-\mathrm{NH} 4 \mathrm{NO} 3$ \\
\hline $\mathrm{K}$ & 200,0 & 200,0 & $\mathrm{KN} 03-\mathrm{K} 2 \mathrm{SO} 4$ \\
\hline $\mathrm{Mg}$ & 24,3 & 24,0 & $\mathrm{MgSO} 47 \mathrm{H} 2 \mathrm{O}$ \\
\hline$S$ & 52,0 & 52,0 & $\mathrm{MgSO} 47 \mathrm{H} 2 \mathrm{O}$ \\
\hline B & 0,5 & 0,5 & $\mathrm{Na} 2 \mathrm{~B} 407.1 \mathrm{OH} 2 \mathrm{O}$ \\
\hline $\mathrm{Cu}$ & 1,0 & 2,0 & $\mathrm{CuSO} 4.5 \mathrm{H} 2 \mathrm{O}$ \\
\hline $\mathrm{Fe}^{(3)}$ & 10,0 & 10,0 & $\mathrm{FeSO} 4.7 \mathrm{H} 2 \mathrm{O}$ \\
\hline $\mathrm{Mn}$ & 5,0 & 5,0 & $\mathrm{MnSO} 44.5 \mathrm{H} 2 \mathrm{O}$ \\
\hline Mo & 0,10 & 0,10 & (NH4)6Mo7 O24.H2O \\
\hline $\mathrm{Zn}$ & 5,0 & 10,0 & $\mathrm{ZnSO} 4.7 \mathrm{H} 2 \mathrm{O}$ \\
\hline
\end{tabular}

(1) Todos os nutrientes foram aplicados no solo, via solução.

(2) Todos os reagentes com grau de pureza p.a.

(3) Aplicado sob a forma de Fe-EDTA. 


\section{Apêndice 3}

Valores das diferenças mínimas significativas para solos dentro de doses ao nível de $5 \%$ pelo teste Tukey para as variáveis avaliadas no experimento de arroz e milho.

\begin{tabular}{|c|c|c|}
\hline \multirow[t]{2}{*}{ Variável } & \multicolumn{2}{|c|}{ D.M.S. } \\
\hline & Arroz & Milho \\
\hline $\mathrm{pHCaCl}_{2} 0,01 \mathrm{~mol} . \mathrm{L}^{-1}$ & 0,32 & 0,38 \\
\hline P Bray-1 (mg $/ \mathrm{kg})$ & 3,06 & 3,14 \\
\hline P Mehlich-1 (mg/kg) & 2,38 & - \\
\hline P Mehlich-3 (mg/kg) & 2,32 & 3,43 \\
\hline P Olsen $(\mathrm{mg} / \mathrm{kg})$ & 3,33 & 2,98 \\
\hline P resina $(\mathrm{mg} / \mathrm{kg})$ & 14,87 & 10,00 \\
\hline Matéria seca ( $g / v a s o)$ & 4,348 & 1,771 \\
\hline P concentração $(\mathrm{g} / \mathrm{kg})$ & 0,3397 & 0,4457 \\
\hline $\mathrm{P}$ acumulado (mg/vaso) & 6,08 & 3,76 \\
\hline
\end{tabular}

